ISSN 1391 - 3174

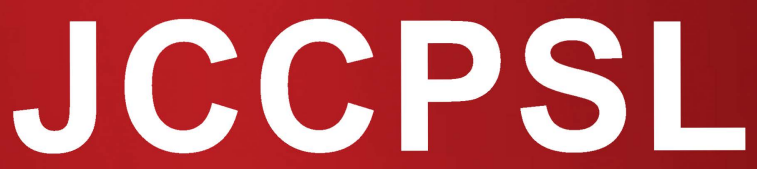

Journal of the College of Community Physicians of Sri Lanka

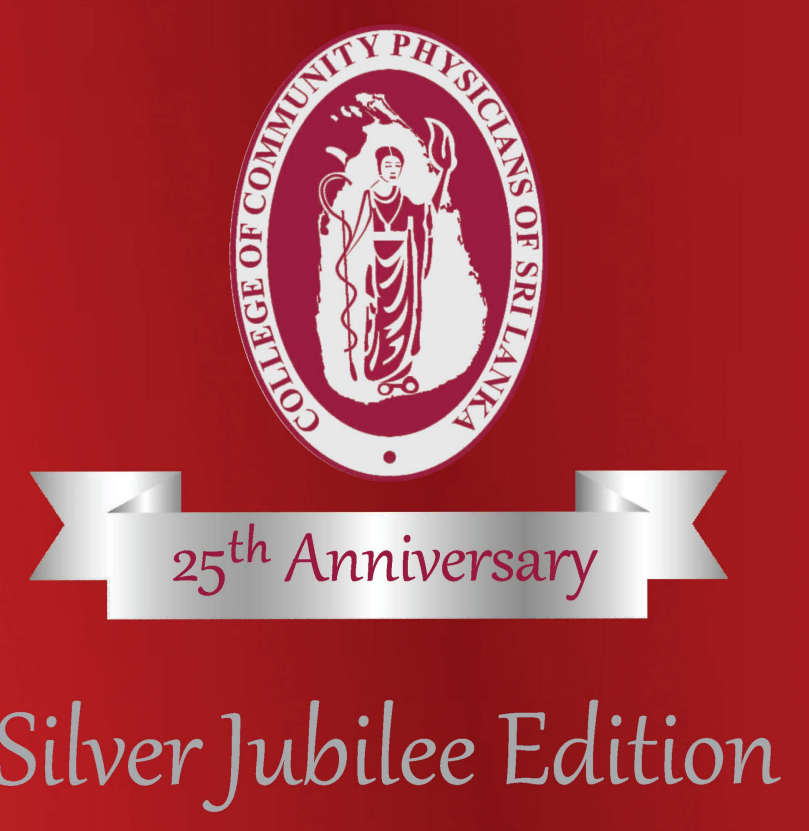

$25^{\text {th }}$ Annual Academic Sessions of the College of Community Physicians of Sri Lanka

\title{
Abstracts of Oral and Poster Presentations
}

$$
\begin{aligned}
& 16^{\text {th }}-18^{\text {th }} \text { of September } 2020 \\
& \text { Shangri-La Hotel, Colombo }
\end{aligned}
$$


ISSN 1391 - 3174

\section{JCCPSL}

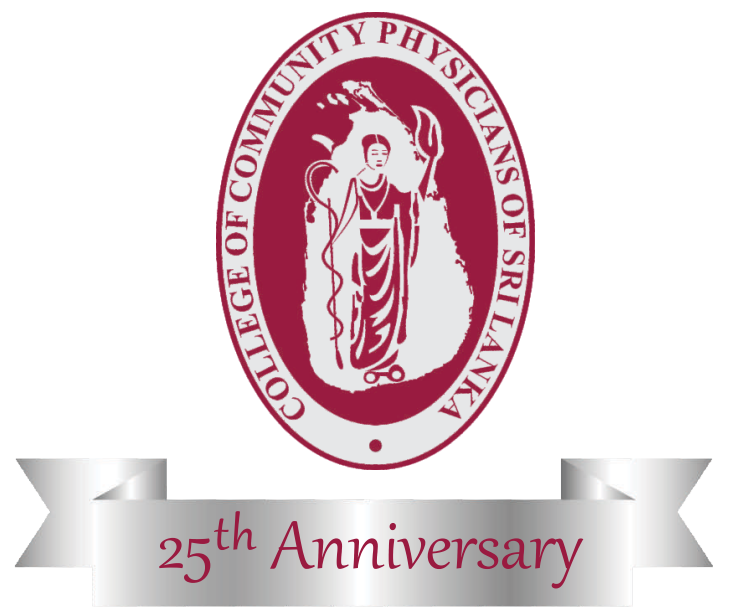

\section{$25^{\text {th }}$ Annual Academic Sessions of the College of Community Physicians of Sri Lanka}
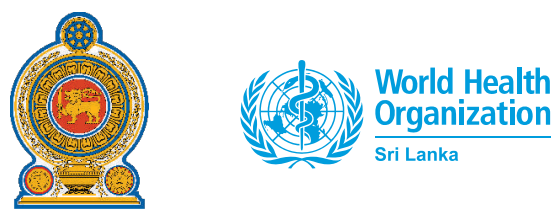

unicef

(4) THE WORLD BANK
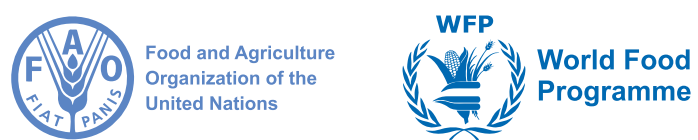



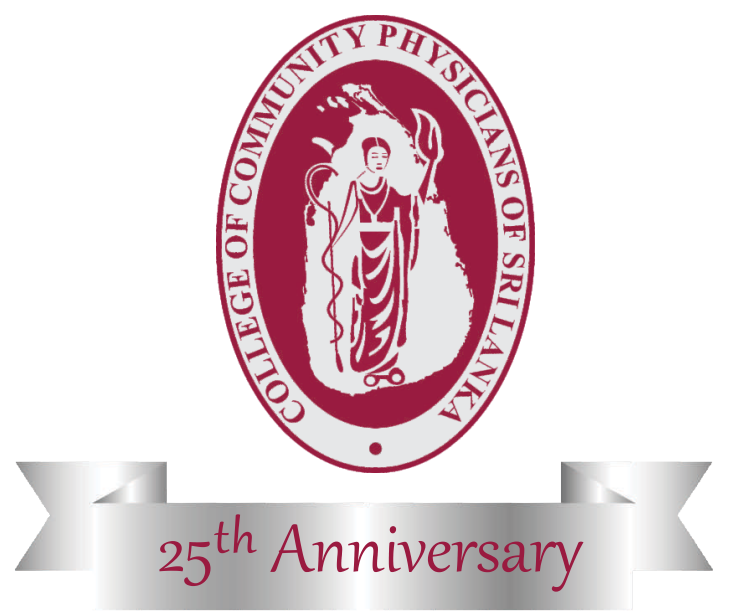

\author{
$25^{\text {th }}$ Annual Academic Sessions of the \\ College of Community Physicians of Sri Lanka
}

\title{
Abstracts of Oral and Poster Presentations
}

The College of Community Physicians of Sri Lanka is the oldest and the first medical professional body which has been established under an Act of Parliament for public health professionals in Sri Lanka.

It is the largest gathering of public health physicians in the country.

This year the College proudly celebrates 25 years as a pioneer in the field of Public Health and Community Medicine. 
Copyright - Copyright of articles in the Journal of the College of Community Physicians of Sri Lanka is retained by the author(s). The authors grant the College of Community Physicians of Sri Lanka a licence to publish the article and to identify itself as the original publisher. The Journal of the College of Community Physicians of Sri Lanka is published under the Creative Commons Attribution License 4.0. This licence permits use, distribution and reproduction in any medium, provided the original work is properly cited. Authors are free to deposit their articles in an institutional repository.

Disclaimer - The information, opinions and views presented in the Journal of the College of Community Physicians of Sri Lanka reflect the views of the authors and contributors of the articles and not of the Journal of the College of Community Physicians of Sri Lanka or the Editorial Board or its publishers. Journal of the College of Community Physicians of Sri Lanka and/or its publisher cannot be held responsible for any errors or for any consequences arising from the use of the information contained in this Journal. Although every effort is made by the editorial board and the publishers to see that no inaccurate or misleading data, opinion or statement appear in this Journal, the data and opinions appearing in the articles including editorials and advertisements herein are the responsibility of the contributors concerned. The publishers and the editorial board accept no liability whatsoever for the consequences of any such inaccurate or misleading data, information, opinion or statement.

\section{Editorial office:}

Journal of the College of Community Physicians of Sri Lanka

No. 6, Wijerama House Phone: 0094 (0)114487139

Wijerama Mawatha Fax: 0094 (0)114487139

Colombo 7, Sri Lanka E-mail: editorjccps।@gmail.com

\section{Printer:}

\section{Techno Graphics}

No: 77, De Soysa Road, Moratuwa

Phone: 0094 (0) 776000600

E-mail:technographics678@gmail.com 


\section{Contents}

01. The Scientific and Ethics Review Process 06

02. List of Abstract Reviewers $\quad 07$

03. Conference Scientific Committee 12

04. Summary of Abstracts for Oral Presentations $\quad 14$

05. Abstracts for Oral Presentations

Free Paper Session 1: Maternal Health $\quad 22$

$\begin{array}{lr}\text { Free Paper Session 2: Communicable Diseases } & 27\end{array}$

Free Paper Session 3: Health Systems 31

Free Paper Session 4: Health Promotion 36

Free Paper Session 5: COVID-19 41

Free Paper Session 6: Child Health 46

Free Paper Session 7: Health of Youth \& Newly Married 51

Free Paper Session 8: Mental Wellbeing 56

Free Paper Session 9: Sexual \& Reproductive Health 61

Free Paper Session 10: Elderly Health \& Wellbeing 66

Free Paper Session 11: Environment \& Occupational Health 71

Free Paper Session 12: Adolescent Health $\quad 76$

06. Summary of Abstracts for Poster Presentations 81

07. Abstracts for Poster Presentations 86

$\begin{array}{ll}\text { Poster Session 1: Health Promotion } & 87\end{array}$

$\begin{array}{ll}\text { Poster Session 2: COVID-19 } & 91\end{array}$

Poster Session 3: Health of Women \& Children $\quad 95$

$\begin{array}{ll}\text { Poster Session 4: Communicable Diseases } & 100\end{array}$

$\begin{array}{ll}\text { Poster Session 5: Healthy Life Style } & 104\end{array}$

$\begin{array}{ll}\text { Poster Session 6: Non-Communicable Diseases } & 108\end{array}$

$\begin{array}{ll}\text { Poster Session 7: Health Systems } & 113\end{array}$

$\begin{array}{ll}\text { Poster Session 8: Nutrition } & 117\end{array}$ 


\section{The Scientific and Ethics Review Process}

A total of 116 abstracts were received for the Annual Academic Sessions this year covering a wide range of disciplines from diverse health professionals throughout the country. The abstract review was a complex process and was accomplished through a very dedicated and impartial panel of reviewers consisting of 46 specialists in Community Medicine representing diverse fields.

Each abstract was reviewed by two reviewers, a content specialist and a research specialist whilst maintaining anonymity of both the authors and the reviewers. The Abstract Review Form contained a clear marking scheme to ensure uniform assessment of the abstracts and the reviewers were requested to give the decisions on the abstract as 'accepted without modification', 'accepted with minor modifications', 'accepted with major modifications' and 'rejected'. In addition, they were also requested to recommend the mode of presentation (oral or poster) and to edit and to give comments on the abstracts as well.

The provisional selection of the abstracts was done based on the decisions of the reviewers. The abstracts that had discrepancies between the decisions given by the reviewers were re-sent to a senior, well-experienced academic for independent review as the third reviewer. All the reviewed abstracts were reassessed for ethical issues. This was ensured by tracking the ethical clearance certificates and through a discussion of the abstracts which had methodological or ethical issues by a committee consisting of representatives from the Ethics Review Committees and from the College of Community Physicians of Sri Lanka. In deciding what is to be classified as research and also in delineating research from clinical audit, surveillance, usual practice in public health and service evaluation, the tools developed by the National Health Services UK available at http://www.hradecisiontools. org.uk/ethics/ , at https://www.nsft.nhs.uk/Get-involved/Documents/Is\%20my\%20Project\% 20Research\% 20Evaluation\%20or\%20Audit.pdf and at http://www.salisbury.nhs.uk/InformationForPatients/ Departments/Research/ResearchDocs/Documents/defining-research.pdf were adopted. The intellectual contribution and the cooperation rendered by the panel of reviewers and by the participants in the respective meetings amidst their busy schedules are gratefully acknowledged by the Abstract Review Committee.

The final decision regarding the selection and the mode of presentation was based upon the reviewers' decisions and decisions made at the ethics scrutiny meeting. When the abstract reviewers or editorial committee members were the authors for any of the abstracts, they did not take part in reviewing or in decision making in the selection of the said abstracts. An intensive protocol was maintained to ensure that all accepted abstracts are presented at the Sessions by tracking the authors and encouraging them to abide by the tight time schedule.

The details of the abstracts are as follows;

Total number of abstracts received

$-116$

- Total number of abstracts withdrawn / rejected at the scientific review and at the ethics scrutiny

- Reviewer recommended amalgamation

$-11$

- Corrected and formatted abstract not submitted by the author after scientific and ethics scrutiny

$-1$

- Total number of abstracts not selected

$-23(11+1+11)$

- Total number selected

- Selected for oral presentation

$-59$

- Selected for poster presentation

Finally, 59 oral presentations, categorized into 12 thematic free paper sessions and 34 poster presentations under 8 thematic areas will be presented at the Annual Academic Sessions of the College of Community Physicians of Sri 


\section{List of Abstract Reviewers}

We express our deepest appreciation to the panel of reviewers who contributed to the anonymous abstract review process amidst their very busy schedules with generous commitment and dedication.

1. Prof. Rohini Seneviratne MBBS (Hons.), MD, DipMedEd (UK), MMEd (UK), FCCP (SL)

Senior Professor in Community Medicine, Para-Clinical Department, Faculty of Medicine, General Sir John Kotelawala Defence University

2. Former Professor Pushpa Lalani Jayawardana MBBS, MSc, MD (Community Medicine) Former Professor (Retired) in Community Medicine, Department of Public Health, Faculty of Medicine, University of Kelaniya

3. Professor A. Pathmeswaran MBBS, MSc, MD (Community Medicine) Professor in Public Health, Department of Public Health, Faculty of Medicine, University of Kelaniya

4. Prof. Sampatha Goonewardena MBBS, MSc, MD (Community Medicine)

Professor in Community Medicine, Faculty of Medical Sciences, University of Sri Jayewardenepura

5. Prof. Shamini Prathapan MBBS, MSc, MD (Community Medicine) Professor in Community Medicine, Department of Community Medicine, Faculty of Medical Sciences, University of Sri Jayewardenepura

6. Prof. Suneth Agampodi MBBS, MSc, MD (Community Medicine), MPH, FRSPH Founder Professor and Chair, Department of Community Medicine, Faculty of Medicine and Allied Sciences, University of Rajarata

7. Dr. Aindralal Balasuriya MBBS, MSc, MD (Community Medicine) Consultant Community Physician, Senior Lecturer, Para-Clinical Department, Faculty of Medicine, General Sir John Kotelawala Defence University

8. Dr. Rahuman Booso MBBS, Dip (Def. Mgt.), MSc, MD (Community Medicine) Consultant Community Physician, Sri Lanka Air Force

9. Dr. Mizaya Cader MBBS, MSc, MD (Community Medicine) Consultant Community Physician, National Programme for Tuberculosis Control and Chest Diseases, Ministry of Health

10. Dr. Pubudu Chulasiri MBBS, MSc, MD (Community Medicine) Consultant Community Physician, Anti-Malaria Campaign, Ministry of Health 
11. Dr. Dinesh Coonghe MBBS, DCH (Colombo), MSc, MD in Community Medicine Board Certified Specialist in Community Medicine \& Senior Lecturer, Head, Department of Community and Family Medicine, Faculty of Medicine, University of Jaffna

12. Dr. Manjula Danansuriya MBBS, MSc, MD (Community Medicine)

Consultant Community Physician, National Professional Officer, World Health Organization, Country Office, Sri Lanka

13. Dr. Anuji Upekshika Gamage MBBS, MSc, MD (Community Medicine), Grad. Certificate in Economics, MSc (Health Economics and Policy) (Australia)

Senior Lecturer, Para-Clinical Department, Faculty of Medicine, General Sir John Kotelawala Defencse University

14. Dr. Indrani Godakanda MBBS, MSc, MD (Community Medicine) Consultant Community Physician, Medical Superintendent, Base Hospital - Panadura

15. Dr. Sanjeeva S. P. Godakandage MBBS (Ruhuna), MSc, MD (Community Medicine), PGC Nutri.Med. (Surrey) Consultant Community Physician, Family Health Bureau, Ministry of Health

16. Dr. Nadeeja Herath MBBS, MSc, MD (Community Medicine)

Consultant Community Physician, Estate and Urban Health Unit, Ministry of Health

17. Dr. Sathya Herath MBBS, MSc, MD (Community Medicine with special training in Sexual Health/HIV) Consultant Community Physician, National STD/AIDS Control Programme, Ministry of Health

18. Dr Janitha Hettiarachchi MBBS, Diploma in Diplomacy \& World Affairs (BIDTI), MSc, $\mathrm{MD}$ (Community Medicine) Consultant Community Physician, Medical Superintendent, Base Hospital - Homagama

19. Dr. Renuka Jayatissa, MBBS, MSc, MD (Community Medicine), FPGIM, FCCP Head-Department of Nutrition, Medical Research Institute, Ministry of Health

20. Dr. Hamsananthy Jeewatharan MBBS, MSc, MD Community Medicine Actg. Consultant Community Physician, Laboratory Services, Ministry of Health 
21. Dr. Ratnasabapathipillai Kesavan MBBS, MSc, MD (Community Medicine), FRSPH (UK)

Consultant Community Physician,

Provincial Department of Health Services - Northern Province,

Ministry of Health

22. Dr. Vindya Kumarapeli MBBS, MSc, MD (Community Medicine)

Consultant Community Physician,

Director - Directorate of Non-Communicable Diseases,

Ministry of Health

23. Dr. Udani Lokuketagoda MBBS, MSc, MD (Community Medicine)

Consultant Community Physician,

Chronic Kidney Disease Unit,

Ministry of Health

24. Dr. Nirupa Pallewatte MD (Minsk), MSc, MD (Community Medicine)

Consultant Community Physician and Deputy Director,

National Programme for Tuberculosis Control and Chest Diseases,

Ministry of Health

25. Dr. Manuja Perera MBBS, MSc, MD (Community Medicine)

Specialist in Public Health, Senior Lecturer in Community Medicine, Faculty of Medicine,

University of Kelaniya

26. Dr. Samantha Ramachandra MBBS, MSc, MD (Community Medicine)

Consultant Community Physician,

Acting Director

District General Hospital-Embilipitiya

27. Dr. Sriyani Ranasinghe MBBS, MSc, MD (Community Medicine)

Consultant Community Physician,

Deputy Director,

Teaching Hospital - Ratnapura

28. Dr. Thilanga Ruwanpathirana MBBS, MSc, MD (Community Medicine)

Consultant Epidemiologist,

Epidemiology Unit,

Ministry of Health

29. Dr. Priyadarshani Samarasinghe MBBS, MSc, MD (Community Medicine)

Consultant Community Physician

Director (Actg.) - Anti Filariasis Campaign,

Ministry of Health

30. Dr. Sameera Senanayake MBBS, MSc, MD (Community Medicine)

Ph.D. Candidate (Health Economics),

Australian Centre for Health Services Innovation,

Queensland University of Technology, Australia

31. Dr. Maheeka Seneviwickrama MBBS, MSc, MD (Community Medicine)

Consultant Community Physician and Senior Lecturer in Community Medicine,

Department of Community Medicine, Faculty of Medical Sciences,

University of Sri Jayewardenepura 
32. Dr. Rajendra Surenthirakumaran MBBS, MSc, MD (Community Medicine)

Consultant Community Physician and Senior Lecturer,

Department of Community and Family Medicine, Faculty of Medicine,

University of Jaffna

33. Dr. Ishanka Talagala MBBS, MSc, MD (Community Medicine)

Consultant Community Physician,

Directorate of Non Communicable Diseases,

Ministry of Health

34. Dr. Chiranthika Vithana MBBS, MSc, MD (Community Medicine)

Consultant Community Physician,

National Programme Manager - Adolescent and Youth Health,

Family Health Bureau,

Ministry of Health

35. Dr. Shreenika De Silva Weliange MBBS, MSc, MD (Community Medicine)

Senior Lecturer,

Department of Community Medicine, Faculty of Medicine,

University of Colombo

36. Dr. Nuwan Wickramasinghe MBBS, Dip (OH\&S), MSc (App. Epid.), MSc, MD (Community Medicine), FRSPH

Head/Senior Lecturer,

Department of Community Medicine, Faculty of Medicine and Allied Sciences,

Rajarata University of Sri Lanka

37. Dr. Supun Wijesinghe MBBS, MSc, MD (Community Medicine), MPH, MRSPH

PGCert Clinical and Public Health Research (Harvard), Certificate in Clinical Occupational Medicine (Monash)

Head / Family Health and Nutrition Communication Unit,

Health Promotion Bureau,

Ministry of Health

38. Dr. Nishani Fonseka MBBS, MSc, MD (Community Medicine)

Senior Registrar in Community Medicine,

Family Health Bureau,

Ministry of Health

39. Dr. Sumudu Awanthi Hewage MBBS, MSc, MD (Community Medicine)

Senior Registrar in Community Medicine,

National Programme for Tuberculosis Control and Chest Diseases,

Ministry of Health

40. Dr. Surangi Jayakody MBBS, MSc, MD (Community Medicine)

Lecturer,

Department of Community Medicine, Faculty of Medical Sciences,

University of Sri Jayewardenepura

41. Dr. Iresha Jayawickrama MBBS, MSc, MD (Community Medicine)

Senior Registrar in Community Medicine,

Community and Health Research Unit,

University of Lincoln, United Kingdom

42. Dr. Dimuth Peiris MBBS, MSc, MD in Community Medicine

Senior Registrar in Community Medicine,

Family Health Bureau, Ministry of Health 
Silver Jubilee Special Issue

43. Dr. Chithranganie Perera MD, MSc, MD (Community Medicine)

Senior Registrar in Community Medicine,

Non-Communicable Diseases Unit,

Ministry of Health

44. Dr. Nadeeka Perera MBBS, MSc, MD (Community Medicine)

Senior Registrar in Community Medicine,

Family Health Bureau,

Ministry of Health

45. Dr. Thirumagal Sivashankar MBBS, MSc, MD (Community Medicine)

Senior Registrar in Community Medicine,

Gender and Women's Health Unit,

Family Health Bureau, Ministry of Health

46. Dr. Yasaswi Walpita MBBS, MSc, MD (Community Medicine)

Lecturer,

Department of Community Medicine, Faculty of Medicine,

University of Colombo 


\section{Conference Scientific Committee}

\section{Conference Scientific Committee}

- Dr. Ruwan Ferdinando - Editor CCPSL

- Dr. Sapumal Dhanapala - President CCPSL

- Dr. Athula Liyanapthirana

- Dr. Ruwanika Seneviratne - Deputy Editor CCPSL

- Dr. Anoma Marasinghe

- Dr. Niludi Yasaratna

- Dr. Rimaza Niyas

- Dr. Chithramali Rodrigo

- Dr. Vidura Jayasinghe

\section{Editorial Assistance:}

- Dr. Irshad Mashood 
SUMMARY OF ABSTRACTS FOR ORAL PRESENTATIONS 


\section{Summary of Abstracts for Oral Presentations}

\section{FREE PAPER SESSON 01: MATERNAL HEALTH}

OP 1

ANTENATAL CARE AND GLYCEMIC CONTROL AMONG MOTHERS WITH GESTATIONAL DIABETES MELLITUS, DELIVERING AT TWO MATERNITY HOSPITALS IN COLOMBO

Wickramarachchi T., Samaranayake D.

OP 2

PHYSICAL AND PSYCHOLOGICAL MORBIDITIES IN THE LATE POSTPARTUM PERIOD AND ITS ASSOCIATED FACTORS AMONG MOTHERS ATTENDING POLYCLINICS AT HORANA AND PANADURA MEDICAL OFFICER OF HEALTH (MOH) AREAS

de Lanerolle N., Arambepola C.

OP 3

INCIDENCE OF HEADACHE FOLLOWING CAESAREAN SECTION UNDER SPINAL ANAESTHESIA AMONG MOTHERS IN GENERAL HOSPITAL MATARA, SRI LANKA

Dharmendra G.K.E., Peiris T. C. K.

OP 4

PREVALENCE OF SELECTED HEALTH OUTCOMES AMONG NEWBORNS OF TEENAGE MOTHERS ADMITTED TO GENERAL HOSPITAL, KALUTARA

Ramachandra R.B.B.S., Siriwardana H.T.K., Jayaratne H.A.T.N., Perera, M.P.C.S., Liyanage B.H.E., Nishshanka W.A., Rupasinghe K.R.A.U.K.

OP 5

MINOR AILMENTS DURING EARLY PREGNANCY: EVIDENCE FROM A PREGNANCY COHORT IN ANURADHAPURA DISTRICT

Gunarathne S., Wickramasinghe N., Agampodi T., Prasanna R., Agampodi S.

\section{FREE PAPER SESSON 02: COMMUNICABLE DISEASES}

OP 6

SERO-PREVALENCE AND PREDICTIVE VALUE OF VARICELLA IN THE COLOMBO DISTRICT, SRI LANKA

MunasinghaH., Amarasinghe A., Malavige N., Sathiakumar N.

OP 7

FACTORS ASSOCIATED WITH TREATMENT INTERRUPTION AMONG MALE AND FEMALE TUBERCULOSIS PATIENTS

Hemachandra C., Pathmeswaran A., Samaraweera S.

OP 8

PREVALENCE AND CORRELATES OF POST-INFECTIOUS FATIGUE AFTER DENGUE INFECTION AMONG ADULTS IN COLOMBO DISTRICT

Perera N.,Prathapan S., WassD., Wijewickrama A.

OP 9

ESTIMATION OF THE BASIC REPRODUCTION NUMBER (RO) FOR THE NOVEL CORONAVIRUS DISEASE IN SRI LANKA

Sudaraka S., Dharmaratne S., Abeyagunawardena I., Manchanayake K., Kothalawala M., Gunathunga W.

OP 10

This was removed from the presentations. 
OP 11

COST OF ILLNESS OF VARICELLA IN COLOMBO DISTRICT, SRI LANKA

Munasingha H., Amarasinghe A., Malavige N.

OP 12

DO PHARMACISTS ADHERE TO ANTIBIOTICS ISSUING GUIDELINES? A TEST PURCHASE STUDY IN RAGAMA MEDICAL OFFICER OF HEALTH AREA

Kularathne N., Karunarathne D., Karunathilake U., Kodithuwakku L., Kumari C., Perera M.

OP 13

HOUSEHOLD ECONOMIC STATUS AND OUT-OF-POCKET EXPENDITURE DURING EARLY PREGNANCY AMONG PREGNANT MOTHERS IN ANURADHAPURA DISTRICT

Gunarathne S., Wickramasinghe N., Agampodi T., Prasanna R., Agampodi S.

OP 14

BARRIERS AND OPPORTUNITIES FOR IMPLEMENTATION OF HEALTH IMPACT ASSESSMENT (HIA) IN SRI LANKA: A CASE STUDY

WalpitaY., Liyanage P., Kumarasinghe M.

OP 15

TRAINING NEEDS ASSESSMENT OF MIDDLE LEVEL MANAGERS (MLMS) FOR THE MLM TRAINING PROGRAMME

Rodrigo C.H., Gunarathna C., Suraweera N., Senarathna Y., Ferdinando R.

FREE PAPER SESSION 04:HEALTH PROMOTION

OP 16

DIFFERENT METHODS OF CERVICAL CANCER SCREENING AMONG EVER MARRIED WOMEN IN KALUTARA DISTRICT

Mapitigama N ${ }^{1}$, Beneragama BVSH ${ }^{2}$, Moonesinghe L. ${ }^{3}$, Punchihewa $\mathrm{R}^{4}$, Perera $\mathrm{KCM}^{5 *}$

OP 17

UTILIZATION OF HEALTHY LIFESTYLE CENTRES AND POSITIVE AND NEGATIVE INFLUENCERS FOR PARTICIPATION

Herath T., Perera M., Kasturiratne A.

OP 18

PERCEPTION AND EXPECTATIONS OF ELDERS ON COMMUNITY HEALTHCARE SERVICES FOR THE ELDERS IN COLOMBO DISTRICT

Fonseka N., Balasuriya A.

OP 19

KNOWLEDGE OF GUARDIANS ON IMMUNIZATION OF THEIR CHILDREN AGED FIVE YEARS AND BELOW IN MEDICAL OFFICER OF HEALTH AREA KOLONNAWA, COLOMBO, SRI LANKA

Jayasumana S., Wasala K., Senavirathna N., Dassanayake R., Sakalasooriya A.

OP 20

EFFECTS OF SPINACH ON CHANGE IN BLOOD PRESSURE AMONG ADULTS: A SYSTEMATIC REVIEW AND METAANALYSIS

Weerathunge T., Obeyesekara N., Mahesh B., Arnold M., Ferdinando R., Gunathunga W. 
OP 21

GRASS ROOT LEVEL EXPERIENCES IN COVID-19 MANAGEMENT IN THE FIELD PRACTICE AREA OF NATIONAL INSTITUTE OF HEALTH SCIENCES, KALUTARA

Jayasinghe V., Karunatilake M., Jayasundera R., Suraweera N., Kalubowila T., Ferdinando R.

OP 22

EFFECT OF COVID-19 OUTBREAK ON MATERNAL AND CHILD HEALTH SERVICES: EXPERIENCE OF PREGNANT MOTHERS IN ANURADHAPURA DISTRICT.

Jayasinghe I., Hettiarachchi A., Wickramasinghe Y., Kurera D., Samarakoon N., Rupasingha I., Ponmalay P., Wickramasinghe $\mathrm{N}$.

OP 23

CLINICAL AND EPIDEMIOLOGICAL CHARACTERISTICS OF THE COVID-19 PATIENTS IN THE INITIAL CASE SERIES: IS SRI LANKA AN OUTLIER?

Wickramasinghe N., Arambepola C., Hewage S., Jayakody S., Wijewickrama A., Gunawardena N., Prathapan S.

OP 24

EFFECT OF COVID-19 OUTBREAK ON HOUSEHOLD ECONOMIC STATUS OF PREGNANT MOTHERS IN ANURADHAPURA DISTRICT

Gunarathne S., Wickramasinghe N., Agampodi T., Jayasinghel., Hettiarachchi A., Jeevethan J., Banduwardana H., AgampodiS.

OP 25

CLINICAL COURSE OF ASYMPTOMATIC, PRE-SYMPTOMATIC, AND SYMPTOMATIC COVID-19 PATIENTS IN SRI LANKA

Hewage S., Prathapan S., Wickramasinghe N., Jayakody S., Wijewickrama A., Gunawardena., Arambepola C.

FREE PAPER SESSION 06: CHILD HEALTH

OP 26

ADMINISTERING SINHALA PEDI-EAT TO DETECT FEEDING DIFFICULTIES IN CHILDREN WITH DISABILITIES: EVIDENCE FROM A UNIVERSITY CLINIC IN SRI LANKA

Priyadarshana S., Dharmarathna I.

OP 27

NUTRITION LITERACY, ITS ASSOCIATED FACTORS AND NUTRITION-RELATED PRACTICES AMONG GRADE 12 STUDENTS IN WALAPANE EDUCATION ZONE

ObeyesekeraN., Samaranayake D.

OP 28

NEONATAL HYPOTHERMIA AND ITS AFTERMATH IN BABIES LESS THAN 34 WEEKS GESTATION

Nawarathne D., De Silva S., Kumuduni K., Lucas N., Kumara S.

OP 29

MANAGEMENT AT FIRST CONTACT CARE LEVEL AND REFERRAL PRACTICES OF CHILDREN TREATED FOR DENGUE FEVER IN TEACHING HOSPITAL KARAPITIYA

Chandrasiri P.A.A., Vithanage R.Y., Saranga U.G.C., Kodithuwakku H.M.A.K., Kumarasiri D.N.P. 
OP 30

ASSOCIATION BETWEEN OBESITY OF FIVE YEARS OLD CHILDREN AND PARENTING STRESS OF THEIR PARENTS

Wickramanayake H.B.P.W., Wijesundara H.B.S.S.K., Paranagama T.D., Ranasinghe O.C., Walisinghe S.K.

\section{FREE PAPER SESSION 07: YOUTH AND NEWLY MARRIED}

OP 31

PRE-CONCEPTIONAL KNOWLEDGE, ATTITUDES AND UTILIZATION OF PRE-CONCEPTIONAL CARE SERVICES AMONG NEWLY MARRIED FEMALES IN MAHARAGAMA MEDICAL OFFICER OF HEALTH AREA

WanniArachchi S., RanasingheS.

OP 32

WHEN THE REFLECTION LIES: BODY IMAGE PERCEPTION AND SATISFACTION AMONG ADOLESCENT SCHOOL CHILDREN IN AN URBAN SETTING IN SRI LANKA

Thevatheepan P., Jeyarajah L., Karunainathan T., Markandayar S., Thavendra M., Liyanage G., Seneviwickrama M.

OP 33

KNOWLEDGE, ATTITUDES AND PRACTICES ON HEALTHY LIFESTYLE RELATED BEHAVIOURS AMONG YOUTH TRAINEES ATTACHED TO YOUTH TRAINING CENTERS IN SRI LANKA

Mataraarachchi D., Vithana P.V.S.C., Lokubalasooriya A., Jayasundara C.J., Suranutha S.A., De Silva C.

OP 34

CORRELATES OF BULLYING VICTIMIZATION AMONG EARLY ADOLESCENTS IN GOVERNMENT SCHOOLS IN THE KEGALLE EDUCATIONALZONE

Rupananda D., Dissanayake D., Wickramasinghe N.

OP 35

MAGNITUDE OF DATING VIOLENCE AMONG STATE UNIVERSITY UNDERGRADUATES IN THE WESTERN PROVINCE

Fernando H., Balasuriya A., Jayawardena P.

FREE PAPER SESSION 08: MENTAL WELLBEING

OP 36

IS BEHAVIOUR RELATED STIGMA AMONG MEN WHO SEX WITH MEN ASSOCIATED WITH THEIR HIV TESTING UPTAKE?

Fernando M., Vidanapathirana J.

OP 37

PSYCHOLOGICAL DISTRESS AND PSYCHOSOCIAL NEEDS OF CAREGIVERS OF CHILDREN WITH CANCER, ATTENDING THE MAIN CANCER TREATMENT CENTRE IN SRI LANKA

Dilhani S., Sivayogan S., De Silva J.

OP 38

PREVALENCE OF DEPRESSION, ANXIETY AND STRESS FOLLOWING DENGUE INFECTION AMONG ADULTS IN COLOMBO DISTRICT

Perera N., Prathapan S., Dulshika Wass D., Wijewickrama A. 
OP 39

EFFECTIVENESS OF AN EDUCATIONAL INTERVENTION TO PROMOTE PSYCHOSOCIAL WELLBEING OF SCHOOLGOING ADOLESCENTS IN THE WESTERN PROVINCE, SRI LANKA

Lokubalasooriya A., Vithana C., Pragasan G., Mahagamage K., Nanayakkara K., Herath H., Karunarathna P., Jayawardane D., WickramasingheN.

OP 40

A SYSTEMATIC APPROACH IN MENTAL HEALTH ASSESSMENT IN EARLY PREGNANCY; AN EXPERIENCE FROM RAJARATA PREGNANCY COHORT

Jayasinghe I., Agampodi T., Amarasinghe G., Hettiarachchi A., Warnasekera J, Ilangasinghe R., Wickramasinghe N., Agampodis.

\section{FREE PAPER SESSION 09: SEXUAL AND REPRODUCTIVE HEALTH}

OP 41

FACTORS ASSOCIATED WITH BEHAVIOUR RELATED STIGMA AMONG FEMALE SEX WORKERS IN WESTERN PROVINCE

Fernando M., Vidanapathirana J.

OP 42

HPV/DNA SCREEN POSITIVE FOLLOW-UP AT THE COLPOSCOPY CLINIC FAMILY HEALTH BUREAU

Silva R., Punchihewa R., Perera K.C.M., Kanchana S.A.D.J.,

Pathirana LR.B.

OP 43

POSTPARTUM FAMILY PLANNING PRACTICES AND ASSOCIATED FACTORS AMONG MOTHERS OF INFANTS ATTENDING CHILD WELFARE CLINICS: A COMPARISON OF TWO URBAN AND RURAL SETTINGS IN POLONNARUWA DISTRICT

Fernando M., Godakandage S.

OP 44

KNOWLEDGE, ATTITUDES, PRACTICES REGARDING BREAST, CERVICAL AND THYROID GLAND CANCER SCREENING AND ASSOCIATED FACTORS OF UTILIZATION OF WELL WOMAN CLINIC SERVICES IN THE MORATUWA MEDICAL OFFICER OF HEALTH AREA.

Radhakrishnan V.K., Moonesinghe L.

OP 45

KNOWLEDGE ON FAMILY PLANNING AND USE OF CONTRACEPTIVES AMONG WOMEN WORKING IN AVISSAWELLA EXPORT PROCESSING ZONE

Pathirana S., Pathmeswaran A., Jayaratne K.

FREE PAPER SESSION 10: IMPROVING ELDERLY HEALTH AND WELLBEING

OP 46

PATTERNS, RELATED CONDITIONS OF UNINTENTIONAL HOME INJURIES AND SELECTED FACTORS ASSOCIATED WITH ITS SEVERITY AMONG ELDERLY IN THE MEDICAL OFFICER OF HEALTH AREA BATTARAMULLA

Ananda S., Kumarapeli V. 
OP 47

POLYPHARMACY, MEDICATION ADHERENCE, AND ASSOCIATED FACTORS AMONG ELDERLY PATIENTS IN NATIONAL HOSPITAL OF SRI LANKA

Weerathunge T., Ruwanpathirana T.

OP 48

STATUS OF UNDER-NUTRITION AND ASSOCIATED FACTORS AMONG THE ELDERLY IN COLOMBO DISTRICT

Vijewardane S., Balasuriya A.

OP 49

HEALTH RELATED PROBLEMS AND FACTORS ASSOCIATED WITH HEALTH-SEEKING BEHAVIOR AMONG THE ELDERS IN COLOMBO DISTRICT

Fonseka N., Balasuriya A.

OP 50

MENOPAUSE SPECIFIC QUALITY OF LIFE AND CORRELATED FACTORS AMONG POST-MENOPAUSAL WOMEN IN KALUTARA DISTRICT, SRI LANKA

Rodrigo C.H, Ferdinando R., de Alwis Seneviratne R.

FREE PAPER SESSION 11: ENVIRONMENTAL AND OCCUPATIONAL HEALTH

OP 51

SELF-REPORTED PRACTICES, AND AWARENESS WITH ITS ASSOCIATES ON OCCUPATIONAL HAZARDS AND SAFETY PRACTICES AMONG MEDICAL LABORATORY TECHNOLOGISTS IN COLOMBO DISTRICT

Karunarathna B., Weerasinghe M.

OP 52

KNOWLEDGE, ATTITUDES AND PRACTICES ON DENGUE AND DENGUE CONTROL AND THE FACTORS ASSOCIATED WITH THE UTILIZATION OF DENGUE SCHOOL CARD

Bandara T.D., Cader M., Dheerasinghe D.S.A.F.

OP 53

COMPASSION FATIGUE AND SELF-CARE AMONG NURSING OFFICERS WORKING AT THE NATIONAL CANCER INSTITUTE OF SRI LANKA

Herath C., Basnayake A.

OP 54

WORK RELATED FACTORS ASSOCIATED WITH THE LEVEL OF POSITIVE MENTAL HEALTH AMONG MEDICAL OFFICERS IN TEACHING HOSPITAL, KANDY

Prasanga P.T.S., Gunathunga W.

OP 55

This abstract was not presented in the conference, hence removed. 
OP 56

RISK FACTORS FOR UPPER LIMB FRACTURES AMONG ADOLESCENTS ATTENDING SELECTED GOVERNMENT HOSPITALS IN THE COLOMBO DISTRICT

Jayasekera H., Siritunga S., Senarath U.

OP 57

LEVELS OF AGGRESSION, ITS PATTERNS AND ASSOCIATED FACTORS AMONG SCHOOL GOING ADOLESCENTS OF GRADE 10, IN THE NEGOMBO EDUCATIONAL DIVISION.

Nathaniel D., Vithana C.

OP 58

PREVALENCE AND CORRELATES OF INTERPERSONAL VIOLENCE AMONG SRI LANKAN ADOLESCENTS: RESULTS FROM THE 2016 SRI LANKAN GLOBAL SCHOOL-BASED HEALTH SURVEY

Gallage A., Wickramasinghe S., Gunawardena S., Wickramasinghe C., Gunawardena N.S., Lokubalasooriya A., Peiris R., Senanayake S.J.

OP 59

PREVALENCE AND CORRELATES OF BEHAVIOUR PROBLEMS AMONG GRADE EIGHT (EARLY ADOLESCENTS) SCHOOL STUDENTS IN THE JAFFNA DISTRICT, SRI LANKA

Sivashankar J.T., Sathiakumar N., Surenthirakumaran R.

OP 60

BEHAVIOURAL AND EMOTIONAL PROBLEMS AND THEIR ASSOCIATED FACTORS AMONG GRADE 10 STUDENTS IN REGIONAL DIRECTOR OF HEALTH SERVICES AREA, AMPARA

Nadeeka N.H.S., Wijewardena K. 


\section{ABSTRACTS FOR ORAL PRESENTATIONS}


FREE PAPER SESSON 1- MATERNAL HEALTH

16.09.2020 /9.00 AM TO 10.00 AM / HALL - A

CHAIRPERSONS: PROF. SHAMINI PRATHAPAN, DR. NETHANJALIE MAPITIGAMA

OP-01

Antenatal care and glycaemic control among mothers with gestational diabetes mellitus, delivering at two maternity hospitals in Colombo

Thanuja Wickramarachchi ${ }^{{ }^{*}}$, Dulani Samaranayake ${ }^{2}$

${ }^{1}$ Postgraduate Institute of Medicine, University of Colombo; ${ }^{2}$ Department of Community Medicine, Faculty of Medicine, University of Colombo.

*tkwickram@gmail.com

Background: Prevalence of gestational diabetes mellitus in Sri Lanka is rapidly increasing and reached $13.9 \%$ in 2018.

Objective: This study aimed to describe the characteristics of antenatal care received and its association with glycaemic control among mothers with gestational diabetes mellitus, delivering at two selected, tertiary care maternity hospitals in Colombo.

Methods: A descriptive cross-sectional study was conducted among mothers diagnosed with gestational diabetes mellitus, who delivered at De Zoysa Hospital for Women, Colombo or Castle Street Hospital for Women, Colombo. Through consecutive sampling, 265 mothers were selected. An interviewer-administered questionnaire and a data extraction sheet were used to collect data. Satisfactory glycaemic control was defined as having more than $65 \%$ of blood sugar series values within the recommended range (fasting $<100 \mathrm{mg} / \mathrm{dl}$ and $2 \mathrm{hour}$ post prandial $<120 \mathrm{mg} / \mathrm{dl}$ ) Characteristics of antenatal care received by mothers and their glycaemic control were described using standard descriptive methods. Factors associated with glycaemic control were analyzed using Chi-square test and odds ratios.

Results: Out of 265 mothers, 88.7\% ( $n=235)$ had attended field clinics, 69.4\% $(n=184)$ received domiciliary care from Public Health Midwife, 98.1\% ( $n=260)$ utilized government hospitals and $50.2 \%(n=133)$ accessed specialists at private sector. Majority $(89.8 \%, n=211)$ were satisfied with field clinics. Majority $(82.6 \%, n=219) \mathrm{had}$ satisfactory knowledge on GDM but only 47.1\% $(n=125)$ had adequate glycaemic control. Monthly income less than Rs. 55,000 (OR=1.69, 95\%Cl: 1.03-2.77), poor compliance with dietary modifications (OR=1.98, 95\% $\mathrm{Cl}$ : 1.75 2.23), poor compliance with physical exercises (OR=2.11, 95\% Cl: 1.28-3.47), poor drug compliance (OR=4.21, 95\% Cl: 1.71-10.35), poor attendance to field clinics (OR=2.16, 95\% $\mathrm{Cl}: 1.29-3.61)$ and poor attendance to government hospital clinics (OR=3.59, 95\% Cl: 2.08-6.18), poor knowledge on GDM (OR=2.00, 95\% $\mathrm{Cl}: 1.02-3.93$ ) and excess weight gain in pregnancy $(\mathrm{OR}=4.00,95 \% \mathrm{Cl}: 2.27-7.07)$ were significantly associated with poor glycaemic control.

Conclusions \& recommendations: Glycaemic control was unsatisfactory in a majority, and poor glycaemic control was associated with poor utilization of health services and poor compliance with treatment modalities. Importance of shared care in pregnancy should be emphasized to achieve adequate glycaemic control. For ideal glycaemic control, life-style changes and compliance of pregnant mothers should be supported by service providers and family.

Key words: gestational diabetes mellitus, antenatal care, glycaemic control 


\title{
OP-02
}

Physical and psychological morbidities in the late postpartum period and its associated factors among mothers attending polyclinics at Horana and Panadura Medical Officer of Health (MOH) areas

\author{
Nimani de Lanerolle ${ }^{1 *}$, Carukshi Arambepola ${ }^{2}$ \\ ${ }^{1}$ Ministry of Health and Indigenous Medical Services; ${ }^{2}$ Faculty of Medicine, University of Colombo \\ *nimani.del.b@gmail.com
}

Background: Mother should be free of physical and psychological morbidities during postpartum to maintain wellbeing of family. Though routinely assessed at four weeks, morbidities don't receive attention during late postpartum. These have not been previously studied in Sri Lanka.

Objective: To describe physical \& psychological morbidities during and within three time points of late postpartum period, and their associated factors among mothers in Horana and Panadura, $\mathrm{MOH}$ areas.

Methods: A cross-sectional study conducted among postpartum mothers 6-12 months following low-risk pregnancy and not previously unhealthy or having an ill child. They were selected using systematic sampling while attending polyclinics. An interviewer-administered-questionnaire collected data on personal and pregnancy related characteristics; physical morbidities and postpartum depression (using Edinburgh Postnatal Depression Score) experienced after childbirth and prevalent in the last two weeks; and maternal social support (using Maternity Social Support Scale). Prevalence was assessed. Associations were assessed using Chi-squared test.

Results: The Sample size was 380. Response rate was 95.5\%. Majority were Sinhalese (79.7\%, n=303); aged 21-30 years (55\%, $n=209)$; and unemployed (77.6\%, $n=295)$. Among them, $77.6 \%(n=295)(95 \% \mathrm{Cl}: 73.1,83.7)$ had at least one physical morbidity. The most common morbidities were chronic lower back pain (49.7\%, $n=189)$; lack of sexual desire ( $n=171,45 \%)$; and $20 \%(n=76)$ painful intercourse. Of them $11.1 \%(n=42)(95 \% \mathrm{Cl}: 8.1,14.6)$ were screened positive for depression. Caesarean section as the mode of delivery was associated with chronic back pain, constipation and lack of sexual desire $(p<0.05)$. Being employed was associated with haemorrhoids and dysuria $(p<0.05)$. Postpartum depression was significantly associated with lack of social support received from friends, family and partner, in addition to other significant factors, such as poor income, ethnicity, number of dependents, number of work hours and duration of maternity leave. Differences in the prevalence at 6, 9 and 12 months of the late postpartum were significantly related to having at least one morbidity, chronic back pain, urinary incontinence, and lack of sexual desire $(p<0.05)$.

Conclusions \& recommendations: Prevalence of physical morbidities and psychological depression was substantial among mothers during late postpartum period, which were determined by caesarean delivery and lack of social support, respectively. An assessment of morbidities are recommended in late postpartum.

Key words: late postpartum, physical morbidities, psychological depression

\section{OP-03}

Incidence of headache following caesarean section under spinal anaesthesia among mothers in General Hospital Matara, Sri Lanka

\section{GKE Dharmendra ${ }^{1 *}$, TCK Peiris ${ }^{2}$}

${ }^{1}$ Family Health Bureau; ${ }^{2}$ District General Hospital Matara

*gkedharmendra@gmail.com

Background: Rate of caesarean section deliveries is increasing worldwide. Spinal anaesthesia is the most 
commonly used mode of regional anaesthesia for caesarean section, as it is more cost-effective, safe and postpartum mothers can be mobilized early after delivery. Headache is common after caesarean section. Post Dural Puncture Headache is one form of headache and a well-known complication of spinal anaesthesia Studies carried out to assess headache following section are few and far between in Sri Lanka.

Objective: To determine the incidence of and types of headache and its associated factors following caesarean section under spinal anaesthesia among mothers in General Hospital Matara.

Methods: Hospital based descriptive longitudinal study was conducted at district General Hospital (DGH) Matara. A total number of 376 postpartum mothers aged above 18 years were included in the study. Data were collected by the Principal Investigator using a questionnaire. It was structured to collect data from Anaesthetist record, from the bed head ticket and from interview with post-partum mothers. Excluded mothers with the history of pre-existing headaches. Mothers, who were given spinal anaesthesia were followed until the $3^{\text {rd }}$ day post operative to see, whether they developed a headache. Data entry was done by the Principal Investigator by using SPSS version 20. Incidences of the Post Dural Puncture Headache and the other types of headache were calculated and bivariate analysis was carried out to assess associated factors.

Results: There were no cases of Post Dural Puncture Headache reported while the incidence of other headache and associated symptoms was $44.95 \%(n=169)$. Among those who had headache, $61.5 \%(n=104)$ reported headache solely in the frontal region, $15.4 \%$ ( $n=58$ ) only in back of the head and $23 \%(n=39)$ in both regions. Prevalence of headache among postpartum mothers was significantly associated with repeated puncture attempts $(p<0.001)$, young age $(p<0.022)$ and not having gestational diabetes $(p<0.028)$.

Conclusions and Recommendations: The incidence of headache is common and there were no cases of Post Dural Puncture Headache in this sample. Incidence of the headache was associated with some environmental causes. Measures need to be taken to prevent headache following caesarean section

Key words: caesarean section, spinal anaesthesia, post dural puncture headache

\section{OP-04}

Prevalence of selected health outcomes among new-borns of teenage mothers admitted to General Hospital, Kalutara

RBBS Ramachandra..$^{1 *}$, HTK Siriwardana ${ }^{2}$, HATN Jayaratne,,${ }^{2}$, MPCS Perera,,${ }^{2}$, BHE Liyanage, ${ }^{3}$, WA Nishshanka. ${ }^{4}$, KRAUK. Rupasinghe ${ }^{5}$

${ }^{1}$ District General Hospital, Embilipitiya, ${ }^{2}$ District General Hospital, Kalutara, ${ }^{3}$ National Institute of Health Sciences, Kalutara, ${ }^{4}$ Base Hospital, Rikillagaskada, ${ }^{5}$ National Hospital Sri Lanka

*samantharamachandra19@gmail.com

Background: Teenage pregnancy is defined as the pregnancy of a teenage girl, usually within the ages of 13-19. Teenage pregnancy is a public health issue worldwide. It has many negative effects on the mother, child, family and society. Many studies describe a significant risk of having preterm, Low Birth Weight (LBW), Small for gestation age (SGA) and low APGAR score of newborns delivered by teenage mothers.

Objective: The study aimed to describe pregnancy related characteristics of teenage mothers and to describe health outcome of newborns.

Methodology: A descriptive cross-sectional study was conducted at District General Hospital Kalutara in 2016. Every teenaged mother admitted for delivery during the first 6 months of the year was included in the study; total 
was 219. Teenaged mothers transferred due to complications were excluded from the study. The primary data was collected on details of pregnancy status using a questionnaire and secondary data were extracted from BHT on the delivery and the baby. Ethical approval was obtained from the ethics review committee, NIHS.

Results: Age of the teenage mothers ranged from 14 to 20 years, mean age was 18.45 years and mode, median were 19 years. Eighty-five percent were primi mothers and 3.7\% had live babies in the previous pregnancy. Thirtytwo others were having risk factors other than the age; $17.8 \%$ were anaemic, $11 \%$ with low $\mathrm{BMI}$ and $16.9 \%$ had some other risk factors. When considering pregnancy outcomes, $83.1 \%$ had normal vaginal delivery, $7.5 \%$ were pre-mature and $98.6 \%$ were live births. Only $14.2 \%$ were with low birth weight and $22.6 \%$ of them ( $3.4 \%$ from the total) were extremely low in birth weight. Six percent newborn babies had APGAR score $<10$ at the time of delivery, $47.9 \%$ had higher body temperature at the end of $1^{\text {st }}$ day of life. Only $4.6 \%$ mother-baby dyads were found to have poor attachment and $14.6 \%$ had poor positioning for breast feeding. Nearly $9 \%$ of babies were admitted to special care baby unit.

Conclusions: Rate of complications were higher among both teenage mothers and their newborns compared to national averages, but the rate of caesarean sections was lower among teenage mothers.

Recommendations: As teenage pregnancy is a risk to both the mother and the baby, maximum preventive strategies should be adopted to prevent it.

Key words: teenage, pregnancy, birth outcomes

\section{OP-05}

\section{Minor ailments during early pregnancy: evidence from a pregnancy cohort in Anuradhapura district}

\section{Sajaan Gunarathne ${ }^{1 *}$, Nuwan Wickramasinghe ${ }^{1}$, Thilini Agampodi ${ }^{1}$, Ruwan Prasanna $^{2}$, Suneth Agampodi ${ }^{1}$}

${ }^{1}$ Department of Community Medicine, Faculty of Medicine and Allied Sciences, Rajarata University of Sri Lanka;

${ }^{2}$ Department of Economics, Faculty of Social Sciences and Humanities, Rajarata University of Sri Lanka

*sajaanpraveen7@gmail.com

Background: Sri Lanka has exceptional achievements in maternal and child health indicators with the lowest maternal mortality ratio in the South Asian region. However, to further improve the quality of maternal health services in Sri Lanka, it is imperative to early identify and promptly manage maternal morbidities.

Objective: The objective of this study to describe the maternal ill-health conditions during the first trimester among pregnant mothers in Anuradhapura district.

Methods: The study was carried out in 22 Medical Officer of Health areas in Anuradhapura district. Pregnant women in the first trimester registered in the field antenatal clinics were recruited to this study as a part of a large cohort, Rajarata Pregnancy Cohort (RaPCo). A self-administered questionnaire was used to collect details on selfreported episodes of ill-health during the first trimester.

Results: The sample consisted of 1206 mothers. The mean age was 28.2 years ( $S D=5.6)$ and $85.5 \%$ mothers $(n=1031)$ were unemployed. $83.9 \%$ mothers $(n=1012)$ had at least one episode of ill-health during the first trimester. Out of them, $55.7 \%$ ( $n=564)$ had nausea and vomiting, $10.3 \%(n=104)$ had respiratory symptoms, $9.5 \%$ $(n=96)$ had headache and faintishness. 829 mothers $(82.6 \%)$ reported that they think their ill-health episode is due to the pregnancy. 498 mothers $(49.2 \%)$ had claimed that the symptoms affected their routine daily activities. Only 340 mothers (33.6\%) had sought medical care and out of them, $182(53.5 \%)$ had used private medical services and $147(43.2 \%)$ had used government medical services. Only, 9.6\% ( $n=98)$ mothers needed 
hospitalization. The total number of days in the hospital for the sample was 247 days and the mean hospital stay was 2.5 days ( $S D=1.7)$.

Conclusion and Recommendations: The findings suggest that nausea and vomiting, respiratory symptoms, headache and faintishness are the common ill-health episodes during early pregnancy and in half of the pregnant mothers, ill-health episodes have affected their routine daily activities. One third of the mothers had to seek medical care and half of them have sought private medical care. Hence, evidence-based management guidelines need to be incorporated into the national maternal care package to improve the quality of maternal care.

Key words: maternal morbidity, early pregnancy, Rajarata pregnancy cohort 
FREE PAPER SESSON 2 - COMMUNICABLE DISEASES

16.09.2020 / 9.00 AM TO 10.00 AM / HALL B

CHAIRPERSONS: PROF. P.V.R. KUMARASIRI, DR. NIMALKA PANNILAHETTI

\section{OP-06}

\section{Sero-prevalence and predictive value of varicella in Colombo district, Sri Lanka}

\section{Hathshya Munasingha ${ }^{1}{ }^{*}$, Ananda Amarasinghe ${ }^{2}$, Neelika Malavige ${ }^{3}$, Nalini Sathiakumar ${ }^{4}$}

${ }^{1}$ Consultant Epidemiologist, Epidemiology Unit, Ministry of Health; ${ }^{2}$ Public Health Specialist / Medical Epidemiologist, OfficeWHO (Philippines); ${ }^{3}$ Professor of Microbiology, Department of Microbiology, University of Sri Jayawardenapura, Sri Lanka, ${ }^{4}$ Professor of Epidemiology, Department of Epidemiology, School of Public Health, University of Alabama at Birmingham, USA.

*munasinghahathshya@gmail.com

Background: Varicella is a highly communicable disease. It can cause complications in high risk groups including pregnant women, elderly and immune compromised patients. Demographic data forecasts more elderly population in the future with many co-morbidities which can lead to severe complications of Varicella.

Objective: To describe Sero-Prevalance and predictive value of varicella in the Colombo district, Sri Lanka.

Methods: A cross-sectional population-based study was conducted among 1,258 participants of all ages. Multistage cluster sampling technique with probability proportionate to size was used to select study subjects. Blood samples were collected and questionnaires administered. Serum samples were assayed for Varicella Zoster Virus (VZV) antibodies (IgG) using a commercial enzyme-linked immunosorbent assay kit. Data was analyzed by using a statistical software version 20. Reliability of recalling past history of Varicella was assessed by applying, Positive Predictive Value and Negative Predictive Value tests.

Results: Overall sero-prevalence was 54.21\% [95\% Cl: 51.46\% - 56.96\%]. Seropositivity was $0 \%$ for children below one year of age and increased with increasing age. From 40 years onwards, about $75 \%$ were seropositive for VZV. Statistically significant differences were noted for gender and educational level: males had a lower seropositivity compared to females ( $43.2 \%$ vs. $58.8, p<0.0001)$; and seropositivity was lower among the subgroup with only primary education compared to those with secondary school upwards to a college degree education ( $25.6 \%$ vs. $62 \%, p<0.0001)$. Differences by urban/rural residence or socioeconomic status were unremarkable. Among women of childbearing age, the overall seroprevalence was about $62.0 \%$ (95\% Cl:57.7\%-66.1\%), but was low $37 \%$ (95\% $\mathrm{Cl}=25.1 \%-50.3 \%)$, in the $15-19$ age group. Self-reported varicella infection by the overall study group was $92.3 \%(95 \% \mathrm{Cl}=89.8 \%-94.4 \%)$. Subgroups of adolescents $(90.6 \%)$, adults $(93.2 \%)$ and women of childbearing age (94.9\%) had a high positive predictive value.

Conclusions \& recommendations: About 50\% lacked natural immunity against varicella. About $40 \%$ of women of childbearing age lacked immunity. For persons who are not at high risk of varicella infection, a positive past history of varicella may be used to indicate positive immune status in lieu of serological testing.

Key words: Varicella, Sero prevalence, Predictive value 


\title{
OP-07
}

\section{Factors associated with treatment interruption among male and female tuberculosis patients}

Chandima Hemachandra ${ }^{1 *}$, Arunasalam Pathmeswaran ${ }^{2}$, Sudath Samaraweera ${ }^{1}$

${ }^{1}$ Epidemiology Unit, Ministry of Health; ${ }^{2}$ Department of Public Health, Faculty of Medicine, University of Kelaniya

*chandimadh@yahoo.com

Background: Treatment of uncomplicated pulmonary tuberculosis lasts six months. Interruption to treatment results in spreading the disease, developing complications, treatment failures and drug resistance. Risk factors for treatment interruption among males and females had not been adequately researched in Sri Lanka.

Objective: To determine the factors associated with treatment interruption in male and female Tuberculosis patients

Method: A mixed method study was conducted. The prospective cohort study consecutively sampled 296 male and 148 female pulmonary tuberculosis patients, from Chest Clinic Colombo and Sub-Chest Clinic Kalubowila and followed them up for six-months through clinic records. An interviewer-administered questionnaire gathered sociodemographic, behavioural and healthcare access data. Cox regression was applied incorporating variables with $<0.2$ statistical significance in bivariate analysis for entire sample and males and females separately to identify associated factors for interruption within a six-months treatment course. Key informant interviews were conducted with purposively selected treatment interrupted patients. Ethical clearance was obtained from Ethics Review Committee, Colombo Medical Faculty.

Results: The mean age (SD) was 47.8 (15.3) years of males and 44.5 (17.2) years of females. Majority among males $(87.8 \%, \mathrm{n}=260)$ and females $(88.5 \%, \mathrm{n}=131)$ belonged to urban sector. More males interrupted treatment $(32.1 \%$ vs $16.2 \%, \mathrm{p}<0.001)$. Being a male (AHR=1.99, $95 \% \mathrm{Cl}$ : $1.27-3.12)$, low education level ( $\mathrm{AHR}=1.82,95 \% \mathrm{Cl}$ : 1.17-2.84) and low/medium socioeconomic status ( $A H R=1.49,95 \% \mathrm{Cl}: 1.02-2.18$ ) were predictors of treatment interruption. Among males, low education level (AHR=1.89, 95\% Cl: 1.16-2.98) and not being consulted in important family matters (AHR=1.75, 95\% Cl: $1.10-2.79$ ) were predictors. Quantitative study failed to identify specific predictors for females. Narratives with male patients highlighted job related factors as barriers to treatment and some stopped treatment upon feeling better whereas females cited cost of travel and the need to be accompanied to clinics as barriers to treatment. Side effects of drugs and physical weakness affected both groups.

Conclusion \& Recommendation: More males interrupted treatment. Both male and female patients had unique as well as common barriers to regular treatment. It is recommended to take individualised decisions, especially regarding males, in selecting drug providers based on their socioeconomic background and working environment.

Key words: Tuberculosis, treatment interruption, gender

\section{OP-08}

Prevalence and correlates of post-infectious fatigue after dengue infection among adults in Colombo district

\author{
Nadeeka Perera $^{1 *}$ Shamini Prathapan ${ }^{2}$, Dulshika Wass $^{3}$, Ananda Wijewickrama $^{4}$ \\ ${ }^{1}$ School Health Unit, Family Health Bureau; ${ }^{2}$ Department of Community Medicine, Faculty of Medical Sciences, University of
}


Sri Jayawardenepura; ${ }^{3}$ Department of Psychiatry, Faculty of Medical Sciences, University of Sri Jayawardenepura; ${ }^{4}$ Institute for Infectious Diseases, Angoda

*dnadeekaperera@yahoo.com

Background: Fatigue is a common feature associated with the acute stage of Dengue infection. The convalescence period can be complicated with post-infectious or persistent fatigue resulting in various physical, psychological and economic constrains.

Objectives: To determine the prevalence and correlates of post-infectious fatigue at one month follow up among adults confirmed with Dengue infection admitted to selected healthcare institutions in Colombo district.

Methods: A longitudinal study was conducted with an analytical component from July 2018 to January 2019. Data was collected from adult patients diagnosed with Dengue infection on discharge from hospital adopting systematic sampling. They were reviewed at one month after day one of fever. The final sample size was 480 with added $20 \%$ loss to follow up. Prevalence of post-infectious fatigue was assessed by the validated Sinhala version of the Chalder Fatigue Questionnaire. Correlates were assessed by a pre-tested interviewer administered questionnaire. Prevalence was presented with $95 \% \mathrm{Cl}$. In assessing correlates, bivariate analysis and binomial multiple logistic regression analysis was carried out via SPSS-21 version.

Results: Response rate was 84.58 (406/480). Majority were between 18-35 years $(69.2 \%, n=281$,) and males $(60.15 \%, n=244$,). Prevalence of post-infectious fatigue at one month follow up was 35\% (95\% Cl:30.3-39.8). After controlling for confounders, age $\geq 35$ years ( $A O R=4.05,95 \% \mathrm{Cl}: 2.04-8.04$ ), not being married $(\mathrm{AOR}=2.7,95 \%$ $\mathrm{Cl}: 1.38-5.28)$, having experience of stressful life events ( $\mathrm{AOR}=1.98,95 \% \mathrm{Cl}: 1.16-3.36)$, not receiving an adequate quantity of sleep ( $A O R=2.51,95 \% \mathrm{Cl}: 1.00-6.31)$, poor quality of sleep ( $\mathrm{AOR}=15.34,95 \% \mathrm{Cl}: 3.25-72.49)$, headache post discharge $(A O R=2.69,95 \% \mathrm{Cl}: 1.6-4.53)$, presence of myalgia post discharge $(\mathrm{AOR}=3.63,95 \% \mathrm{Cl}: 2.16-6.11)$, haemoglobin $<11 \mathrm{~g} / \mathrm{dL}$ at acute stage (AOR=2.01, 95\% Cl:1.02-3.98) and having a platelet count $\leq 30,000 / \mathrm{mm}^{3}$ $(A O R=2.38,95 \% \mathrm{Cl}: 1.42-3.99)$ have significant associations with having post infectious fatigue.

Conclusions and Recommendations: Post-infectious fatigue was present among a notable proportion one month following Dengue infection. In the current context Dengue patients are not routinely followed up at institutional level, therefore, it is recommended to improve awareness regarding this condition and the importance of screening and the modifiable correlates among the clinicians and the general medical practitioners.

Key words: dengue fever, convalescence period, persistent fatigue,

\section{OP-09}

\section{Estimation of the basic reproduction number (RO) for the novel coronavirus disease in Sri Lanka}

\section{Supun Sudaraka ${ }^{1^{*}}$, Samath Dharmaratne ${ }^{2}$, Ishanya Abeyagunawardena ${ }^{3}$, Kasun Manchanayake ${ }^{4}$, Mahen $^{2}$ Kothalawala ${ }^{5}$, Wasantha Gunathunga ${ }^{6}$}

${ }^{1}$ Faculty of Medicine, University of Peradeniya, Sri Lanka; ${ }^{2}$ Department of Community Medicine, Faculty of Medicine, University of Peradeniya, Sri Lanka and Institute for Health Metrics and Evaluation, Department of Health Metrics Sciences, School of Medicine, University of Washington, United States of America; ${ }^{3}$ Faculty of Medicine, University of Peradeniya, Sri Lanka; ${ }^{4}$ Faculty of Engineering, University of Ruhuna, Sri Lanka; ${ }^{5}$ National Hospital, Kandy, Sri Lanka; ${ }^{6}$ Department of Community Medicine, Faculty of Medicine, University of Colombo, Sri Lanka

*ssm123ssm@gmail.com 
Background: The basic reproduction number (RO) is the number of cases directly caused by an infected individual throughout his infectious period, in a completely susceptible population. RO is used to determine the ability of a disease to spread within a given population and to determine the proportion of population required to be vaccinated to curb the spread of disease.

Objective: To calculate the R0 of novel coronavirus disease in Sri Lanka.

Methods: Data was obtained from the daily situation reports and the report on the exposure history of diagnosed patients, from the Epidemiology Unit, Ministry of Health, Sri Lanka, up to the 22nd of April, 2020. The patients detected in quarantine centers and the returnees from abroad were excluded. The RO was then calculated by two different models, using the exponential growth rate method and maximum likelihood estimation method to obtain a better estimate. The exponential growth rate method utilizes the classic epidemic model which consists of the Susceptible, Infected and Removed (SIR) compartments. This model implicitly specifies that the generation time interval $(\mathrm{w})$ follows an exponential distribution. $\mathrm{RO}$ is calculated using the moment generating function of the assumed generation time distribution (M), using the equation $\quad R 0=\frac{1}{M(-r)}$. The maximum likelihood estimation method estimates R0 by maximizing the log-likelihood for the observation of incident cases NO, N1..., NT in the following manner, assuming that the number of secondary cases caused by an index case is Poisson distributed. $R 0=\sum_{t=1}^{T} \log \left(\frac{e^{-\mu_{t} \mu_{t} t_{t}}}{N_{t} !}\right)$ where $\mu_{t}=R \sum_{i=1}^{t} N_{t-i} w_{i}$

All calculations were done using the 'RO, Estimation of RO and Real-Time Reproduction Number from Epidemics' package, for $\mathrm{R}$ language in statistical computing.

Results: The exponential growth rate model yielded an R0 of 1.28 (95\% Cl: 1.04 - 1.54), with a root mean squared error for the cumulative number of patients of 4.10. The R0 calculated using the maximum likelihood estimation model was $1.36(95 \% \mathrm{Cl}: 0.94-1.90)$ with a root mean squared error of 6.51 .

Conclusions and recommendations: The estimated RO for the novel coronavirus disease in Sri Lanka using two different methods are 1.28 and 1.36, which are lower than the global figures.

Key words: Basic reproduction number, RO, Coronavirus

\section{OP-10}

This was removed from presentation 
FREE PAPER SESSON 3 - HEALTH SYSTEMS

CHAIRPERSONS: PROF. CHRISHANTHA ABEYSENA

DR. PADMAL DE SILVA

16.09.2020 / 10.00 AM TO 11.00 AM / HALL A

\section{OP-11}

\section{Cost of illness of varicella in Colombo district, Sri Lanka}

\section{Hathshya Munasingha ${ }^{{ }^{*}}$, Ananda Amarasinghe ${ }^{2}$, Neelika Malavige}

${ }^{1}$ Consultant Epidemiologist, Epidemiology Unit, Ministry of Health; ${ }^{2}$ Public Health Specialist / Medical Epidemiologist, OfficeWHO (Philippines); ${ }^{3}$ Professor of Microbiology, Department of Microbiology, University of Sri Jayewardenepura, Sri Lanka

*munasinghahathshya@gmail.com

Background: Varicella is a vaccine preventable, communicable disease caused by Varicella virus. Information is not available on the economic burden of Varicella in Sri Lanka. Economic assessments are critical for evaluating vaccine recommendations.

Objective: To describe the cost of illness of Varicella in the Colombo district in Sri Lanka

Methods: Cost of illness was assessed on clinical Varicella cases and patients. Cost breakdown included household cost of illness among non-hospitalized Varicella cases and household and hospital costs among hospitalized Varicella patients. Direct and Indirect costs were assessed for household cost by using interviewer administered questionnaire. In the estimation of direct cost, cost of transport to take treatment and cost for treatment (consultation and medication) were considered. Indirect cost assessed the cost of lost earnings of patients and care givers. Health system cost was assessed on hospitalized patients for which the bed head ticket was the source document and per patient per day cost was calculated through "scenario building" method using a non-medical checklist. Data collected through the checklist combined with explicitly expressed assumptions were used to carry out cost estimation of non-medical components and per patient per day non-medical health system costs were calculated. Cost to household incurred due to hospitalization and medical costs were entered into an Excel sheet and per patient costs (mean, median, standard deviation and inter quartile range (IQR)) were calculated.

Results: Direct cost of non -hospitalized varicella cases was as follows: mean Rs. 1461.00, median Rs. 980.00, IQR Rs. 510.00-1650.00. Indirect cost: mean Rs. 13741.00, median Rs. 13650.00, IQR Rs. 7000.00 -20000.00. The median total average cost was Rs. 1,375.00 Direct cost of hospitalized varicella patients was as follows: mean Rs 1426.87, median Rs. 1188.00, IQR Rs. 584.00-1800.00. Indirect cost was mean Rs. 5061.36, median Rs. 5050.00, IQR Rs. 2250.00-6000.00. Total average median cost was Rs. 2,277.00. Health system cost per an uncomplicated Varicella patient for an average 4 day stay cost was Rs 5,142. 96.

Conclusions \& Recommendations: Cost of illness of hospitalized varicella patient is higher than non-hospitalized. Recommend revitalized Varicella prevention activities including vaccination.

Key words: varicella, cost of illness, vaccine 
Do pharmacists adhere to antibiotics issuing guidelines? A test purchase study in Ragama medical officer of health area

Nadeeshani Kularathne ${ }^{1 *}$, Dimuthu Karunarathne ${ }^{1}$, Udara Karunathilake ${ }^{1}$, Lakshitha Kodithuwakku ${ }^{1}$, Chathurika Kumari ${ }^{1}$, Manuja Perera ${ }^{2}$

${ }^{1}$ Faculty of Medicine, University of Kelaniya; ${ }^{2}$ Department of Public Health, Faculty of Medicine, University of Kelaniya

*nadeeshani.kularathne@gmail.com

Background: Misusing antibiotics leads to serious negative consequences including antibiotic resistance and complications related to antibiotics and pharmacists play a major role in its prevention. Ragama city hosts three large hospitals and daily attracts a considerable number of patients. In Sri Lanka, issuing of drugs is regulated by the National Medical Regulatory Act No 05 of 2015 and Cosmetic Device and Drugs Act No 27 of 1980.

Objective: To describe knowledge, attitudes and practices related to issuing antibiotics among pharmacists in Ragama Medical Officer of Health area and to determine the association of their actual practices with selfreported practices and knowledge

Methods: All pharmacies $(\mathrm{N}=20)$ in the area were assessed using three test-purchases each by: asking for an antibiotic without a prescription (Test purchasing 1, with an invalid prescription (Test purchasing 2 ) and by presenting a symptom without a prescription (Test purchasing 3 ). During the test purchasing, the practices in issuing antibiotics were observed and recorded later in a log sheet. Self-reported practices and knowledge regarding regulations, prescriptions and antibiotics were assessed by an interviewer administered questionnaire in a fourth visit to each pharmacy.

Results: Of the 20 pharmacists, 11 were males and 15 were qualified. Nine, 13 and six pharmacists issued antibiotics in test purchasing 1,2 and 3 respectively leading to $46.7 \%(28 / 60)$ positive test purchases. Selfreported practices $(7 / 60 ; 11.7 \%)$ differed significantly $\left(X^{2}=4.855 ; \mathrm{df}=1 ; \mathrm{p}=0.043\right)$ from the actual practice. Four issued in all three test purchases and three didn't in any $(N=60)$. When antibiotics were issued $(n=28)$, appropriate labelling was only seen in 15 (53.6\%) and verbal instructions were given only in 16 (57.1\%). Overall knowledge was satisfactory with a median score of 76 (Maximum=100), even though knowledge on antibiotics (Median=24; Maximum=36) and regulations (Median=18; Maximum=24) were comparatively low. Knowledge level was not associated with the overall test purchasing performance $(U=24 ; p=0.447)$.

Conclusion \& Recommendations: Antibiotics related knowledge and practices were unsatisfactory among the pharmacists participated in the study. Test purchasing can be useful in monitoring and improving issuing of antibiotics via private pharmacies.

Key words: Knowledge, Practices, Pharmacists, Prescription, Antibiotics, Guidelines

\title{
OP-13
}

Household economic status and out-of-pocket expenditure during early pregnancy among pregnant mothers in Anuradhapura District

\author{
Sajaan Gunarathne ${ }^{1 *}$, Nuwan Wickramasinghe ${ }^{1}$, Thilini Agampodi ${ }^{1}$, Ruwan Prasanna ${ }^{2}$, Suneth Agampodi $^{1}$ \\ ${ }^{1}$ Department of Community Medicine, Faculty of Medicine and Allied Sciences, Rajarata University of Sri Lanka; ${ }^{2}$ Department \\ of Economics, Faculty of Social Sciences and Humanities, Rajarata University of Sri Lanka \\ "sajaanpraveen7@gmail.com
}


Background: Evidence suggests that high out-of-pocket expenditure (OOPE) can be seen even in free health providing nations. The local evidence base on economic cost during pregnancy is limited and evidence on the economic burden of OOPE during pregnancy is scarce in Sri Lanka.

Objective: This study aimed at describing the household economic status and OOPE during early pregnancy in a cohort of pregnant mothers in Anuradhapura district.

Methods: The study was carried out in 22 Medical Officer of Health areas in Anuradhapura district. Pregnant women in the first trimester registered in the field antenatal clinics were recruited to this study as a part of a large cohort, Rajarata Pregnancy Cohort (RaPCo). A self-administered questionnaire was used to collect data on average pre-pregnancy household income and expenditure as well as the pregnancy cost during the first trimester.

Results: The mean age of the pregnant women ( $n=1206)$ was 28.2 years $(S D=5.6)$ and $85.5 \%(n=1031)$ of them were not employed. The mean monthly household income and expenditure were LKR $51,108.89$ ( $S D=39,537.16)$ and LKR 32,017.22 (SD=20,632.14) respectively. The corresponding median values were LKR 40,000.00 (IQR=30,000-58,000) and LKR 28,600.00 (IQR=19,450.00-40,200.00). The mean OOPE during the first trimester was LKR 3394.07 ( $S D=5446.34$ ), which accounted for $6.6 \%$ and $10.6 \%$ of the monthly household income and expenditure respectively. The highest proportion of OOPE is for booking visit (43.4\%) followed by, for pregnancy identification (29.1\%) and for cost for maternal ill-health (27.6\%). The OOPE during the first trimester was significantly higher $(p<0.001)$ among women who were employed than their counterparts. There was a statistically significant correlation between the monthly household income and the OOPE during the first trimester $(r=0.071, p<0.05)$.

Conclusions: On average, pregnant mothers in Anuradhapura district have to spend $6.6 \%$ of the monthly household income as OOPE during early pregnancy and the OOPE revealed a significant positive correlation with the household income. Hence, more exploratory studies are needed to identify reasons for OOPE associated with maternal health care to further improve the maternal health service provision in Sri Lanka.

Key words: early pregnancy, out-of-pocket expenditure, Rajarata pregnancy cohort

\title{
OP-14
}

Barriers and opportunities for implementation of Health Impact Assessment (HIA) in Sri Lanka: a case study

\author{
Yasaswi Walpita $^{{ }^{*}}$, Pramil Liyanage ${ }^{2}$, Malith Kumarasinghe ${ }^{2}$ \\ ${ }^{1}$ Department of Community Medicine, University of Colombo; ${ }^{2}$ Ministry of Health \& Indigenous Medical Services, Colombo, Sri \\ Lanka \\ *yasaswi@cmb.ac.lk
}

Background: Health Impact Assessment [HIA] is a systematic process used to evaluate the potential health effects of a policy, programme or a project on people, especially marginal and vulnerable groups. It is increasingly recognized around the world as a good governance tool to incorporate 'Health in all policies'. Whilst World Health Organization has taken several initiatives to incorporate HIA into the health systems in the South-East Asia region, it is still poorly recognized and practiced in the region, where its applicability is most appropriate considering the complexity of social determinants of health and inequalities. 
Objective: To explore the key evaluating question "what are the barriers and opportunities for implementing HIA in Sri Lanka [SL]"

Methods: The study followed a mixed methodology with concurrent triangulation, combining document analysis, interviews \& observations. The published literature on impact assessment in SL, including articles, reports and other related documents were collected using Google scholar and PubMed search engines followed by targeted searches on selected websites and hand searching of documents not available on-line. This was complemented by semi-structured interviews of purposefully selected key informants and author observations. The narration of literature and transcripts of interviews was an iterative process which followed a thematic analysis.

Results: The literature search yielded 32 documents including articles, reports, statutory documents, and statistical sheets related to impact assessments in SL. Four themes, namely, policy framework, institutional infrastructure, capacity building and inter-sectoral collaboration emerged from eight interviews \& observations, under which the literature was narrated further. Lack of a firm policy backed by legislation and standards, absence of a centrally dedicated unit/team for implementation of HIA, poor training on HIA, and lack of a mechanism for sustainable collaborations were the main barriers identified under four themes. The emerging government commitment to embrace 'Health in All Policies' approach supported by the 'National Strategic Framework for Development of Health Services (2016-2025)', existing potential in the preventive health system for a dedicated central expert team with peripheral counterparts, experience in other impact assessments (e.g.; Environment Impact Assessment), and the availability of structures such as National Health Development Committee to support collaborations, were the main opportunities identified under four themes for implementation of HIA in SL.

Conclusions \& recommendations: Sri Lanka has much potential to use HIA as a good governance tool to incorporate Health in All Policies as an inter-sectoral strategy. However, it is required to develop a central coordinating structure, address the need for capacity building and to develop country-specific tools including training material and HIA implementation tools, which would facilitate the establishment and sustainability of HIA process. Hence, it is high time that Sri Lanka tap the 'untapped' potential of HIA and incorporate it into its sustainability agenda.

Key words: Health Impact Assessment, Health in All Policies, Sri Lanka, barriers \& opportunities concurrent triangulation

\section{OP-15}

\section{Training needs assessment of Middle Level Managers (MLMs) for the MLM training programme}

\section{Chithramali Hasanthika Rodrigo ${ }^{1 *}$, Chintha Gunarathna ${ }^{2}$, Nilanthi Suraweera ${ }^{3}$, Yoganu Senarathna ${ }^{3}$, Ruwan} Ferdinando $^{3}$

${ }^{1}$ Ministry of Health and Indigenous Medical Services, ${ }^{2}$ district General Hospital, Kalutara, ${ }^{3}$ National Institute of Health Sciences, Kalutara

"mal_has@yahoo.com

Background: Middle Level Managers in Ministry of Health ( $\mathrm{MoH})$, Sri Lanka, play an important role implementing national health programs and are the link between top level managers and grass-root level staff. National Institute of Health Sciences (NIHS), Kalutara, conducts regular training programs for MLMs.

Objectives: To assess training needs of MLMs working in MoH for the MLM training programme at NIHS 
Methods: A descriptive cross-sectional study was conducted among 108 MLMs from three randomly selected districts in 2019. Participants were divided among districts proportionate to size and selected by simple random sampling using a list from Regional Director of Health Service Office. Self-administered questionnaires, on sociodemographic, service-information and training needs based on Hennessy-Hicks tools were mailed. Training need was defined as the gap between perceived importance of a skill for successful performance and current performance of the skill. Mean score differences (MSD) were calculated. Participants were categorized, performing 'well' or 'poor' based on a median score.

Results: Mean (SD) age of participants was $45.7(10.0)$ years. Among them $44 \%(n=48)$ were Medical Officers of Health, $72.1 \%(n=75)$ were females, $78.8 \%(n=81)$ were educated above diploma level and $59.6 \%(n=62)$ were in the current post for $=/>1$ year. MSD for training needs were: planning 16.0, organization and implementation 4.8, leadership 9.9, controlling 5.7 and staffing 20.9. Of them $32.7 \%(n=34)$ reported as performing 'poor' in planning while $94.7 \%(n=88), 30.2 \%(n=32), 92.6 \%(n=86)$ and $18.3 \%(n=19)$ reported as performing 'poor' in organization/implementation, leadership, controlling and staffing. Overall self-rated performance was 'poor' among $32.7 \%(n=34)$ and was significantly associated with designation $\left(\chi^{2}=11.74, d f=4, p=0.019\right)$ and duration in current post $\left(\chi^{2}=12.31, d f=3, p=0.006\right)$.

Conclusions and Recommendations: A higher percentage of MLMs reported 'poor' skills in organizing/implementing and controlling. By making MLM training program more designation-relevant and practically-oriented, management skills of MLMs could be improved.

Key words: management training needs, staff training, public health, middle level managers 


\section{FREE PAPER SESSON 4- HEALTH PROMOTION \\ CHAIRPERSONS: DR. PALITHA KARUNAPEMA \\ DR. MANOJ FERNANDO \\ 16.09.2020 / 10.00 AM TO 11.00 AM / HALL B}

\section{OP-16}

Different methods of cervical cancer screening among ever married women aged 35 and 45 years in Kalutara District

\section{N Mapitigama', BVSH Beneragama², Loshan Moonesinghe ${ }^{3}$, Ramani Punchihewa $^{4}$, KCM Perera ${ }^{5 *}$}

Background: Cervical cancer is the second commonest among the Sri Lankan females which accounts for nearly $10 \%$ of all female cancers. Almost all cervical cancers are associated with Human Papilloma Virus (HPV) infection which is essentially sexually transmitted. With HPV infection, it may take up to 20 to 30 years to develop precancerous lesions and subsequent cervical cancer. Globally, depending on the affordability and feasibility, different methods are used to screen for cervical cancer by detecting the presence of HPV and/or precancerous lesions, i.e. Visual Inspection with Acetic acid (VIA), Visual Inspection with Lugol's lodine (VILI), Pap smears (conventional cytology), Liquid Based Cytology (LBC) and HPV/ DNA PCR tests. Detection of cervical precancerous lesions followed by early action is expected to significantly reduce the incidence of cervical cancer. However, there seems to be no marked reduction in the incidence of cervical cancer over the past two decades in Sri Lanka since the inception of the screening for cervical cancer with pap smears in 1998. One of the major drawbacks of the pap smear screening is the suboptimal sensitivity (53\%) to detect Cervical Intraepithelial Neoplasia (CIN) which is a precancerous lesion. Another cytology-based test, Liquid Based Cytology (LBC), has a sensitivity of $79.1 \%$ to detect CIN II+. Therefore, it is necessary to assess the outcomes of new methods of cervical cancer screening with the pap smear to determine the most appropriate method for cervical cancer screening in Sri Lanka.

Objective: To describe results of Pap smear (Conventional cytology), Liquid Based Cytology (LBC), and HPV/DNA screening among cohorts of 35 and 45 year old ever married women in Kalutara district

Methods: Two women from each 35 and 45 year cohorts were selected from all Public Health Midwife areas $(n=413)$ in Kalutara district by random sampling. The eligible family registers were used to prepare the sampling frame. Pap smears and LBC specimens were collected by Medical Officers of Health or Public Health Nursing Sisters in Well Woman Clinics from 510 women aged 35 years and 502 women aged 45 years. The samples were sent to labs for reporting and women with positive results from any method were confirmed by colposcopy (i.e. the gold standard for the screening test).

Results: The response rate of 35 and 45 age cohort women was $90.7 \%$ and $90 \%$ respectively. Total of 32 women (6.2\%) among 35 and 24 women (4.8\%) among 45 year cohort were positive for HPV/DNA test. Nine women (1.8\%) among 35 year and 7 women (1.4\%) among 45 year had cytological abnormality (positive results) with pap smears. Thirteen women (2.5\%) among 35 year and 10 women (2\%) among 45 year age groups had cytological abnormality (positive results) with Liquid Based Cytology reports. The prevalence of Cervical Intraepithelial Lesions (CIN) among 35 and 45 year cohorts of women with positive results were confirmed on colposcopy.

Conclusions and Recommendations: Detection rate of cervical lesions by colposcopy was high by HPV/DNA screening whereas the detection rate by LBC is only marginally higher than conventional cytology (pap smears). Hence, Liquid Based Cytology is not feasible to be incorporated into the National Cervical Cancer Screening programme as an alternative to conventional cytology. Primary cervical cancer screening with HPV/DNA PCR tests should further be assessed for feasibility and affordability to improve the quality of the programme in Sri Lanka. 
Key words: screening methods for cervical cancer, Liquid Based Cytology, Conventional Cytology, pap smears, HPV DNA test

\section{OP-17}

\section{Utilization of healthy lifestyle centres and positive and negative influencers for participation}

\section{Thilini Herath $^{1,2} *$ Manuja Perera $^{3}$, Anuradhani Kasturiratne ${ }^{3}$}

${ }^{1}$ Department of Primary Health Care, Eastern University, Sri Lanka; ${ }^{2}$ Faculty of Graduate Studies, University of Kelaniya, Sri Lanka; ${ }^{3}$ Departemnt of Public Health, University of Kelaniya, Sri Lanka

*herathhmtp@gmail.com

Background: Healthy Lifestyle Centres (HLCs) initiative is a screening programme for Non-Communicable Diseases (NCDs) provided through primary health care institutions in Sri Lanka. Screening through public health services is a cost-effective and efficient strategy to control NCDs and reduce related out-of-pocket expenditure.

Objective: This study aimed to describe the prevalence of utilization of HLCs by its target population and reasons for non-utilization.

Methods: A community-based descriptive cross-sectional study was conducted in Gampaha and Kalutara districts among 1727 individuals above 35 years, recruited via a simple random sampling method. Data collected via an interviewer-administered questionnaire was analyzed using descriptive statistics.

Results: Only 35.1\% ( $n=606$ ) of the participants had ever heard of HLCs and the commonest source of information was a health professional attached to a primary health care institution or a Medical Officer of Health office (35.4\%, $n=257$ ). Prevalence of utilizing HLCs as either a first time or a follow-up client was $11.3 \%$ ( $n=195)$. Majority's stated reasons to utilize HLCs were related to positive attitudes of being healthy $(52.8 \%, n=103)$ while only 21 clients $(10.8 \%)$ stated their participation was merely due to the awareness about its presence. The commonest positive influence to utilize HLCs was the need to find out whether they have a disease $(87.2 \%$, $n=170)$. Being informed by a health professional $(54.4 \%, n=106)$ and HLCs being a free service $(34.4 \%, n=67)$ were the other common positive influences. The commonest reasons among nonusers for not utilizing HLCs were negative attitudes on health and wellbeing $(35.8 \%, n=190)$ and $20 \%(n=106)$ nonusers stated it was due to lack of awareness. Being asymptomatic is the commonest negative influence $(56.7 \%, n=301)$ even when they have heard about HLCs. Automatic transferring of priority to other commitments $(39.2 \%, n=208)$, being screened via other mechanisms (34.1\%, $n=181)$ and busy and crowded public health institutions $(31.6 \%, n=168)$ had also discouraged nonusers.

Conclusions \& Recommendations: There is an awareness gap related to HLC. However, positive attitudes on health seem to be more influential on its utilization than being aware of its existence. Utilization of HLCs could be improved by improving positive attitudes on being healthy especially targeting asymptomatic people.

Key words: healthy lifestyle centres, non-communicable diseases, screening, health-care utilization 
Perceptions and expectations of elders on community healthcare services delivered to the elderly in Colombo district

\author{
Nishani Fonseka ${ }^{{ }^{*}}$, Aindralal Balasuriya ${ }^{2}$ \\ ${ }^{1}$ Family Health Bureau, Ministry of Health, Sri Lanka: ${ }^{2}$ Department of Community Medicine, General Sir John Kotelawala \\ Defence University, Sri Lanka \\ *fony_14@yahoo.co.in
}

Background: The rapidly growing ageing population has led to varied health, social and economic concerns in Sri Lanka. Although it is proven that, community-based support and services are useful in improving the health status of elderly in developed countries we need to explore which programme components are more effective for our community setting.

Objective: To describe the perceptions and expectations of elders on community healthcare services for the elderly in Colombo District

Methods: Four focus group discussions were carried out to describe the perception and expectations of the elders on community healthcare services. Purposive sampling method was used. Each focus group comprised of ten elders and discussions were conducted until the principal investigator was satisfied that the theoretical data saturation point was reached. Even though socio-economic characteristics of the participants differed between the groups, to a possible extent homogeneity within the group was maintained. Questions to explore the perceptions and expectation of the elderly were incorporated into the focus group discussion guide as main subheadings. Thematic data analysis was done.

Results: The mean age was 69.0 years $(S D=6.0)$. Majority of the participants were Sinhalese $(n=26,63 \%)$, females $(n=22,55 \%)$ and represented urban sector $(n=30,75 \%)$ while $45 \%(n=18)$ were having educational qualification of G.C.E O/L or above. Only $20 \%(n=8)$ were currently employed. Long waiting hours, inadequate time spent by the healthcare provider, poor financial status, distance to healthcare facility, need assistance to seek treatment were identified as barriers for access. Many were unaware of the importance of screening and disease prevention. Almost all were of the opinion of the need for healthcare personnel for elderly care in the community. Majority of the participants highlighted the need for health education programs for elderly and caregiver training at community level.

Conclusions and Recommendations: Strengthening of the primary health care system and geriatric health services at community level need to be optimized.

Key words: elders, community healthcare services, focus group discussions

\title{
OP-19
}

Knowledge of guardians on immunization of their children aged five years and below in Medical Officer of Health area Kolonnawa, Colombo, Sri Lanka

\author{
Shermi Jayasumana ${ }^{1 *}$, Kasun Wasala ${ }^{2}$, Niroshan Senavirathna ${ }^{3}$, Rasika Dassanayake $^{3}$, Asanka Sakalasooriya $^{3}$ \\ ${ }^{1}$ Postgraduate Institute of Medicine, University of Colombo; ${ }^{2}$ Apeksha Hospital, Maharagama, ${ }^{3}$ Teaching Hospital, Kurunegala \\ *shermi.dilshara@gmail.com
}

Background: Immunization is the process which makes a person immune or resistant to an infection by 
administering a vaccine. It not only protects the recipient, but also other children by increasing the herd immunity and minimizing the spread of infection.

Objective: To describe the knowledge of guardians on immunization of their children aged five years and below in Medical Officer of Health area of Kolonnawa

Methods: A clinic-based descriptive cross-sectional study was conducted among 398 guardians of children aged five years and below attending child welfare clinics at Medical Officer of Health area Kolonnawa. Pre-tested selfadministered questionnaire was used to assess the knowledge on immunization. Each question of the questionnaire was analyzed separately as percentages and $95 \% \mathrm{Cl}$.

Results: Response rate was $93.2 \%$ ( $n=398)$. Majority of respondents were mothers of children $(95.7 \%, n=381)$. Less than two fifth of the participants had G.C.E. Advanced Level or higher educational qualifications (38.9\%, $\mathrm{n}=155$ ). Leading source of information on immunization was Public Health Midwive (94.9\%, 95\% Cl: 92.8-97.1, $\mathrm{n}=$ 378). Less than one fourth of the guardians $(22.8 \%, 95 \% \mathrm{Cl}: 18.7-26.9, \mathrm{n}=91)$ were aware of the disease(s) prevented by the vaccine due on the current visit. Almost all $(98.5 \%, 95 \% \mathrm{Cl}: 97.2-99.6, \mathrm{n}=392)$ knew that immunization schedule is started at birth. None of the guardians had a complete picture of the National Immunization Schedule. All the participants stated fever as an adverse event while the percentages stating other adverse events were as follows: $78.1 \%$ (95\% Cl: 74.0-82.2, $\mathrm{n}=311$ ) allergy, $28.9 \%(95 \% \mathrm{Cl}: 24.4-33.3, \mathrm{n}=115)$ fits and $23.6 \%$ (95\% Cl: 19.4-27.7, $\mathrm{n}=94$ ) abscess. Fever was identified as a contraindication for vaccination by $98.9 \%$ (95\% Cl: 98.0-99.9, $\mathrm{n}=394$ ) of guardians. Only a few of guardians identified mild local reactions following previous vaccinations $(2.7 \%, 95 \% \mathrm{Cl}: 1.2-4.4, \mathrm{n}=11)$, minor illnesses $(7.2 \%, 95 \% \mathrm{Cl}: 4.7-9.8, \mathrm{n}=29)$, family history of fits $(31.2 \%, 95 \% \mathrm{Cl}: 26.6-35.7, \mathrm{n}=124)$ as false contraindications for vaccination.

Conclusions \& Recommendations: Knowledge of the guardians on immunization of their children aged five years and below in Medical Officer of Health area Kolonnawa is low. This is to be properly addressed to improve the immunization activities of children. Public Health Midwives can be utilized as a reliable source to deliver the necessary information.

Key words: child immunization, guardians, knowledge

OP-20

Effects of spinach on change in blood pressure among adults: A systematic review and meta-analysis

Thathsara Weerathunge ${ }^{1}$, Nathasha Obeyesekara ${ }^{1}$, Buddhika Mahesh ${ }^{2}$, Mahendra Arnold ${ }^{3}$, Ruwan Ferdinando ${ }^{4}$, Wasantha Gunathunga ${ }^{5}$

${ }^{1}$ Post Graduate Institute of Medicine, University of Colombo, Sri Lanka; ' University of Melbourne, Australia; ${ }^{3}$ Ministry of Health, Sri Lanka; ${ }^{4}$ National Institute of Health Sciences, Sri Lanka; ${ }^{5}$ University of Colombo, Sri Lanka

*thathsaraweerathunge@gmail.com

Background: Increased blood pressure is a global public health problem. It is a risk factor for other conditions such as stroke and myocardial infarction. Spinach (Spinacia oleracea) is a functional food traditionally known for its effects on many disease conditions, including those related to the cardiovascular system.

Objective: To systematically-review and meta-analyse the effect of spinach on change of blood pressure

Methods: The protocol was registered in International-Prospective-Register-of-Systematic-Reviews (PROSPERO ID-CRD42020182534) and followed Preferred-Reporting-Items-for-Sytematic-Reviews-and-Meta-Analysis (PRISMA) guidelines. PubMed, EMBASE, CINAHL, AGRICOLA and Cochrane-library databases were searched, and 
eligible studies were selected with the following three criteria, "human studies on spinach", "blood pressurerelated outcomes" and "quantifiable measurements", by two independent reviewers. Change in systolic-bloodpressure (SBP) prior to and following interventions was considered as the primary-outcome while secondaryoutcomes included change in diastolic-blood-pressure (DBP) and arterial stiffness. Risk-of-bias assessments were done with Grading-of-Recommendations-Assessment-Development-and-Evaluation (GRADE) criteria. Heterogeneity was assessed and meta-analyses were done for SBP and DBP with inverse-variance method and random-effect assumption. Review-Manager (version 5.4) was used.

Results: Out of 244 articles, 126 in first round, 82 in second round and 14 in third round were excluded respectively by each selection criterion with de-duplication. Six studies were selected for systematic review. In five studies, the intervention mainly included spinach while in the remainder spinach was a component of a combined product. The study population comprised healthy adults of 18-70 years. The comparisons included lownitrate diets and placebos. Three randomized cross-over interventional studies including 77 healthy adults contributed in meta-analysis. Pooled Summary estimate showed that intake of spinach was associated with significantly lower post-intervention reduction of systolic- blood- pressure ( $\mathrm{MD}=-3.52,95 \% \mathrm{Cl}=(-6.62)-(-0.42)$, $p=0.03$ ) while that of diastolic-blood pressure was not significant $(p=0.72)$. The augmentation index measuring arterial stiffness showed significant reduction from baseline after 7 days $(p<0.001)$ following high-nitrate intervention which included spinach. Considering the other three studies, SBP was significantly lower with spinach in two studies $(p=0.01, p<0.001)$ while the remainder showed significantly lower post-interventional SBP $(p<0.001)$ with a combined product.

Conclusions and Recommendations: There is a potential utility of spinach intake in the control of blood pressure. Further research is needed to support this outcome.

Key words: spinach, spinacia oleracea, blood pressure, arterial stiffness 
FREE PAPER SESSON 5 - COVID-19

CHAIRPERSONS: PROF. CARUKSHI ARAMBEPOLA, DR. SUMAL NANDASENA

16.09.2020 / 11.00 AM TO 12.00 PM / HALL A

\section{OP-21}

Grass root level experiences in COVID-19 management in the field practice area of the National Institute of Health Sciences, Kalutara

Vidura Jayasinghe ${ }^{1 *}$, Mahesh Karunatilake ${ }^{1}$, Rasanthi Jayasundera ${ }^{1}$, Nilanthi Suraweera ${ }^{1}$, Tamara Kalubowila $^{1}$, Ruwan Ferdinando ${ }^{1}$

${ }^{1}$ National Institute of Health Sciences, Kalutara, Sri Lanka

*vidura.jayasinghe@yahoo.com

Background: The COVID-19 pandemic has become a major public health concern in this millennium and Sri Lanka also in a challenging position with regards to the disease control process. The administrative district of Kalutara has been considered as a high-risk area throughout and one cluster was identified in the Field Practice Area (FPA) of National Institute of Health Sciences (NIHS), Kalutara. It has been a new challenge for health care providers of NIHS FPA to combat COVID-19. A number of successful public health interventions implemented have ensured a successful mitigation of the COVID-19 in this area.

Objective: To describe public health approach to mitigate outbreak of COVID-19 at FPA, NIHS

Methods: Data available at the Regional Epidemiologist office was obtained. Key informant interviews were conducted among health care providers participated in COVID-19 management at FPA, NIHS. Semi-structured interview guide was used to obtain their experiences in outbreak management. All interviews were transcribed and analysed to identify main areas in COVID-19 management at FPA, NIHS.

Results: The case identification among the permenant residents of NIHS area can be divided in to 3 phases. In the initial phase, cases were identified in the community while cases were identified at Punnani qurantine center in the $2^{\text {nd }}$ phase. In the $3^{\text {rd }}$ phase cases were identified among Navy soldiers from Welisara Navy Base. Five Gramma Niladari divisions were declared as a complete lockdown area based on epidemiological grounds. From the lockdown area, 219 were sent to Punnani quarantine centre and out of them 30 became positive for COVD-19. Application of sound public health interventions, community participation and intersectoral collabaration were the key strategies in disease mitigation. There were many difficulties in adopting quarantine law in the area but it was successfully implemented with the assistance of the community leadres and other stakeholders. Further, mass media were also helpful to enhance public awareness and compliance towards mitigating activities. Continuous supply of essential services was maintained throughout the period by health care providers with the support of other sectors.

Conclusions and Recommendations: COVID-19 outbreak has successfully been controlled up to now with multiple public health interventions. Surveillance, contact tracing and quarantine, active case detection in the community, multi-sectoral support were the highlights in the disease mitigation. The public health measures adopted in the FPA, NIHS may be replicable in other localities to prevent a possible community transmission.

Key words: COVID-19 Outbreak, public health interventions, multisectoral collaboration, cluster transmission, public awareness 
Effect of COVID-19 outbreak on maternal and child health services: the experience of pregnant mothers in Anuradhapura District

Imasha Jayasinghe ${ }^{1}$, Ayesh Hettiarachchi ${ }^{1}$, Yashoda Wickramasinghe ${ }^{1 *}$, Dilanka Kurera ${ }^{1}$, Nisansala Samarakoon ${ }^{1}$, Ishani Rupasingha ${ }^{1}$, Priyanka Ponmalay ${ }^{1}$, Nuwan Wickramasinghe ${ }^{1}$

${ }^{1}$ Department of Community Medicine, Faculty of Medicine and Allied Sciences, Rajarata University of Sri Lanka.

*yashodhayaw@gmail.com

Background: Evidence suggests that during the COVID-19 pandemic, health services have been partially or completely disrupted in many countries. In Sri Lanka, national guidelines have been developed during the initial stages of the country epidemic, to provide essential maternal and child health $(\mathrm{MCH})$ services.

Objective: To describe the effect of COVID-19 outbreak on maternal and child health services in Anuradhapura district.

Methods: This cross-sectional study was conducted among 712 pregnant women, who have been enrolled in an on-going large cohort in Anuradhapura district before 12 weeks of gestation between July to September 2019, namely Rajarata Pregnancy Cohort (RaPCo). The pregnant women were from ten $\mathrm{MOH}$ areas in Anuradhapura district. Data was collected through telephone interviews by five trained pre-intern medical officers using a pretested interviewer guide.

Results: Of the 712 pregnant women, 359 (50.4\%) were contactable and responded. Mean age of the sample of women who responded was 28.4 years $(S D=5.3)$. Forty-seven mothers $(13.2 \%)$ complained that their scheduled clinic visits were affected due to the COVID-19 outbreak. Only six mothers (1.7\%) had reported that their previously decided place of delivery was changed due to the prevailing COVID-19 situation. Except, for one mother, all others ( $n=358,99.7 \%$ ) had not changed their pre-determined mode of delivery. Only three mothers $(0.8 \%)$ claimed that they did not receive anticipated family support due to various COVID-19 related restrictions. All mothers were satisfied with the services provided by Public Health Midwife (PHM). None of the mothers complained that the expected service provision from the PHM was affected during the outbreak.

Conclusions and Recommendations: Despite the restrictions imposed with the COVID-19 outbreak and its control procedures, $\mathrm{MCH}$ care services at the field level were satisfactorily delivered. Grass root level health service delivery system has been a major strength during the COVID-19 pandemic to maintain highest quality $\mathrm{MCH}$ care, which should be protected, strengthened and expanded to other primary care services.

Key words: COVID-19, maternal and child health services, Anuradhapura

\section{OP-23}

Clinical and epidemiological characteristics of the COVID-19 patients in the initial case series: is Sri Lanka an outlier?

Nuwan Wickramasinghe ${ }^{1^{*}}$, Carukshi Arambepola ${ }^{2}$, Sumudu Hewage ${ }^{3}$, Surangi Jayakody ${ }^{4}$ Ananda Wijewickrama ${ }^{5}$, Nalika Gunawardena ${ }^{6}$, Shamini Prathapan ${ }^{4}$

${ }^{1}$ Department of Community Medicine, Rajarata University of Sri Lanka; ${ }^{2}$ Department of Community Medicine, University of Colombo; ${ }^{3}$ National Program for Tuberculosis Control and Chest Diseases, Ministry of Health and Indigenous Medical Services; ${ }^{4}$ Department of Community Medicine, University of Sri Jayewardenepura; ${ }^{5}$ National Institute of Infectious Diseases; ${ }^{6}$ WHO Country Office, Colombo 5

*nuwick74@yahoo.com 
Background: The epidemiology of COVID-19 varies between countries due to many reasons; thus, populationspecific knowledge on the exposure, clinical course and outcomes is pivotal for advocating an evidence-based health sector response.

Objective: To describe the presentation of COVID-19 patients to hospital, their clinical course, outcome categories and factors associated with disease fatality in Sri Lanka

Methods: A retrospective study was conducted using secondary data extracted from bed head tickets and investigation reports from the first 100 COVID-19 confirmed patients who had been discharged or dead following their hospital stay in three designated COVID-19 treating hospitals in Sri Lanka. Clinical outcomes were categorized as mild, severe and critical as per the international classification. Frequency distributions with Kruskal-Wallis $\mathrm{H}$ test and Fisher's exact test were used to compare differences between variables.

Results: There were 94 discharges and six deaths. Mean age (SD) was 40.7 (17.7) years. Majority was males (65.0\%). A recent history of returning from abroad was reported by $51.0 \%$, while $24.0 \%$ of the patients had been close contacts of confirmed COVID-19 patients. Forty-three patients (43.0\%) had at least one co-morbidity. Fever was the commonest symptom (66.0\%) followed by dry cough $(48.0 \%)$ and sore throat $(29.0 \%)$. On average, patients presented early to hospital with a median duration of pre-hospital clinical course of 3.0 days (IQR=1.05.0). However, the median duration of hospital stay and total clinical course were 18.0 (IQR=14.0-20.0) and 19.0 (IQR=17.0-23.0) days. With regard to severity, 'mild' disease was predominant (92.0\%), while 'severe' and 'critical' disease were present in only $2.0 \%$ and $6.0 \%$ respectively. Poorer outcome ('severe' or 'critical') was significantly associated with age $>60$ years $(p=0.034)$ and having $>2$ co-morbidities $(p=0.012)$, but not with delayed presentation $(p=0.073)$. Only five patients required ventilation and all five did not survive the illness.

Conclusions \& Recommendations: In contrast to countries at increased risk of COVID-19, the younger age and milder disease portrayed in local patients may reflect the early public health response to the pandemic in Sri Lanka. However, the factors determining disease fatality remain the same as in other countries.

Key words: COVID-19, Sri Lanka, patient outcomes, associations

OP-24

Effect of COVID-19 outbreak on household economic status of pregnant mothers in Anuradhapura district

Sajaan Gunarathne ${ }^{1^{*}}$, Nuwan Wickramasinghe ${ }^{1}$, Thilini Agampodi ${ }^{1}$, Imasha Jayasinghe ${ }^{1}$, Ayesh Hettiarachchi ${ }^{1}$, Joel Jeevethan ${ }^{1}$, Hasantha Banduwardana ${ }^{1}$, Suneth Agampodi ${ }^{1}$

${ }^{1}$ Department of Community Medicine, Faculty of Medicine and Allied Sciences, Rajarata University of Sri Lanka

*sajaanpraveen7@gmail.com

Background: The COVID-19 pandemic is having a devastating effect on all social and economic sectors across the globe. In Sri Lanka, national COVID-19 control measures have affected household economy of most of the families due to barriers to continue their routine income generating activities.

Objective: To describe how the COVID-19 outbreak has affected the household economic status of pregnant women in Anuradhapura district

Methods: This cross-sectional study was conducted among a sub-sample of pregnant women, who have been enrolled in an on-going large cohort in Anuradhapura, namely, Rajarata Pregnancy Cohort (RaPCo). Data was collected through telephone interviews by trained pre-intern medical officers using a pre-tested interviewer guide consisting of questions on household economical status during the COVID-19 outbreak. Altogether, 712 pregnant women from ten $\mathrm{MOH}$ areas in Anuradhapura district were contacted initially. Data analysis was conducted using SPSS version 25.0. Chi-squared test was used to assess the statistical significance. 
Results: Household economic data were gathered from 225 pregnant women. The mean age was 27.9 years ( $S D=4.8)$. The mean and median monthly household income of the sample were LKR $43,821.08(S D=25,979.59)$ and LKR 40,000.00 (IQR=30,000.00-50,000.00) respectively. Sixty-nine participants (30.7\%) have reported that their monthly household income was affected during the COVID-19 outbreak. The lowest income quintile was mostly affected $(46.7 \%, n=35)$. There was a statistically significant association between income quintiles and effect of COVID-19 on household income $\left(x^{2}=18.741, d f=4, p=0.001\right)$. Among the families whose income were affected, the mean and median affected income were LKR 27,673.47 ( $S D=14,070.34$ ) and LKR 30,000.00 (IQR $=15,000.00-35,000.00$ ) respectively, which represented $63.1 \%$ of monthly household income. Only twenty participants $(28.9 \%)$ had received the financial assistance of LKR 5000.00 from the government, which approximately covers $18.1 \%$ of the affected income.

Conclusions and Recommendations: Approximately, one third of pregnant mothers' household income have been affected by the COVID-19 outbreak and the affected income accounts for more than half of their total monthly income. Only one quarter of families have received government financial assistance. Further assessments are needed to explore how the affected household economy has impacted on health and wellbeing of pregnant women to provide equitable health services to affected families.

Key words: COVID-19, household income, pregnant mothers

\section{OP-25}

\section{Clinical course of asymptomatic, pre-symptomatic, and symptomatic COVID-19 patients in Sri Lanka}

Sumudu Hewage ${ }^{1}$, Shamini Prathapan ${ }^{2}$, Nuwan Wickramasinghe ${ }^{3}$, Surangi Jayakody ${ }^{2}$, Ananda Wijewickrama ${ }^{4}$, Nalika Gunawardena ${ }^{5}$, Carukshi Arambepola ${ }^{6}$

${ }^{1}$ National Program for Tuberculosis Control and Chest Diseases, Ministry of Health and Indigenous Medical Services ${ }^{2}$ Department of Community Medicine, University of Sri Jayewardenepura, ${ }^{3}$ Department of Community Medicine, Rajarata University of Sri Lanka ${ }^{4}$ National Institute of Infectious Diseases ${ }^{5}$ WHO country office for Sri Lanka ${ }^{6}$ Department of Community Medicine, University of Colombo

*sumuduavanthi@gmail.com

Background: COVID-19 patients presenting with symptoms are likely to have worse clinical outcomes than others. However, this evidence, which could change the current recommendations on early testing, is not yet conclusive.

Objective: To describe the COVID-19 patients by their symptom status at diagnosis and assess its relationship with clinical outcome in Sri Lanka

Methods: A retrospective study was conducted at all three hospitals which were designated for COVID care at the initial phase of outbreak in Sri Lanka. Data from bed head tickets and investigation reports of 100 confirmed COVID-19 cases who were discharged or died first at one of the selected hospitals were extracted. Patients were grouped as: 'symptomatic' if they were symptomatic at the first positive PCR test for COVID-19; 'pre-symptomatic' if they were asymptomatic at the first positive PCR test but developed symptoms subsequently; and 'asymptomatic' if they remained asymptomatic following a positive PCR test. Clinical outcomes were categorized as mild, severe and critical as per the international classification.

Results: Mean age (SD) was 40.7(17.7) years. Approximately two thirds were males (65.0\%). Majority (76.0\%) were symptomatic at the diagnosis. Pre-symptomatic and asymptomatic presentations were seen in $13.0 \%$ and $11.0 \%$, respectively. Symptomatic patients most commonly developed fever $(84.2 \%, \mathrm{n}=64)$ and dry cough $(55.2 \%$, $\mathrm{n}=42)$ while the 'pre-symptomatic' group developed dry cough $(46.1 \%, \mathrm{n}=6)$ followed by headache $(23.1 \%, \mathrm{n}=3)$ and productive cough $(23.1 \%, n=3)$. Median days since positive test result to the first symptom was $4.0(I Q R=3.0-$ 
6.0). Median days taken for the second consecutive negative PCR result was 15.0 (IQR=12.0-17.0), 17.0 (IQR=14.019.0) and 19.0 (IQR=16.0-24.0) days among asymptomatic, pre-symptomatic and symptomatic groups, respectively. The difference of the median duration to achieve the second consecutive negative PCR result between patients who were symptomatic (19; IQR=16.0-24.0) and asymptomatic at the time of diagnosis (16; IQR $=13.5-18.0)$ was statistically significant $(\mathrm{p}=0.002)$. All 'severe' and 'critical' patients were symptomatic at diagnosis, while all asymptomatic and pre-symptomatic patients had 'mild' disease. This association between symptom status at diagnosis and disease outcome was not statistically significant (Fisher exact test $p=0.193$ ).

Conclusions \& Recommendations: 'Asymptomatic' and 'pre-symptomatic' patients seemed to have 'mild' disease and clear off the virus sooner than symptomatic patients. Further, symptom status at diagnosis is unlikely to be associated with poorer outcomes. However, research with larger sample size is recommended to confirm this evidence.

Key words: COVID-19, Sri Lanka, asymptomatic, pre-symptomatic, symptomatic, clinical course 
FREE PAPER SESSON 6 - CHILD HEALTH

CHAIRPERSONS: DR. DHAMMIKA ROWEL, DR. DULANI SAMARANAYAKE

16.09.202 / 11.00 AM TO 12.00 PM / HALL B

\title{
OP-26
}

Sinhala Pedi-EAT questionnaire to detect feeding difficulties in children with disabilities: evidence from a university clinic in Sri Lanka

\author{
Supun Priyadarshana ${ }^{{ }^{*}}$, Isuru Dharmarathna ${ }^{2,3}$ \\ ${ }^{1}$ Undergraduate Student, Faculty of Medicine, University of Kelaniya, Sri Lanka, ${ }^{2}$-Lecturer / Speech- Language Therapist, \\ Department of Disability Studies, Faculty of Medicine, University of Kelaniya, Sri Lanka, ${ }^{3}$ Doctoral Candidate, Department of \\ Speech Science, School of Psychology, The University of Auckland, New Zealand \\ *supunshyaman4@gmail.com
}

Background: Dysphagia in children with disabilities leads to aspiration and has a long-term impact on child's development. Due to increased survival rates of children with complex and medically fragile conditions prevalence of feeding and swallowing disorders is increasing. Therefore, early identification is crucial to improve quality-of-life of children with dysphagia. The Pediatric Eating Assessment Tool (PediEAT) is a parent-report instrument developed to assess symptoms of feeding problems in children aged 6 months to 7 years. It has been adapted to Sinhala (Sinhala Pedi-EAT). It may be useful as a screening tool of a comprehensive dysphagia assessment battery in Sri Lankan context.

Objectives: To describe the feeding difficulties and to determine the association between the concern level of feeding difficulties with the diagnosis of dysphagia among children with disabilities between 6 months-7 years at the Multi-Disciplinary Team (MDT) Clinic for children with disabilities and their families at the Faculty of Medicine, University of Kelaniya, Sri Lanka

Methods: A descriptive cross-sectional survey was conducted at the Multi-Disciplinary Team (MDT) Clinic for children with disabilities and their families at the Ayati, Faculty of Medicine, University of Kelaniya, Sri Lanka. The study population included parents of children between 6 months-7 years attending the MDT clinic from November to December 2019. Four hundred ten $(n=410)$ parents of children with disabilities were selected using selective sampling method. Sinhala Pedi-EAT questionnaire was used to assess the feeding difficulties. It has four sections: physiologic symptoms, problematic mealtime behaviors, restricted eating, oral processing. The diagnosis of dysphagia has been given by the Consultant Speech and Language Therapist and it was obtained through the clinic records. Quantitative analysis of data was conducted using SPSS.

Results: The most prevalent feeding concerns under the physiologic symptoms were cough during or after meal time $(71 \%, n=291)$, cough for liquids $(69 \%, n=282)$ and drooling during meal time $(81 \%, n=332)$. Under the problematic mealtime behaviors the following were the commonest: rejection of the foods $(54 \%, n=221)$, severe stress at meal time $(88 \%, n=360)$, stress for smell from food $(22 \%, n=90)$ and meal time longer than 30 minutes $(89 \%, n=364)$. Under the restricted eating, the following were observed: spitting out food from the mouth $(81 \%$, $\mathrm{n}=332$ ), restricted for extreme cool, hot or colored foods $(76 \%, \mathrm{n}=311)$. Biting the spoon/fork during eating (34\%, $n=139)$, presence of teeth grinding $(40 \%, n=164)$, getting 30 seconds per each spoon $(58 \%, n=237)$ were the most frequent oral processing issues. Mealtime was longer than 45 minutes for the majority of the children (61\%, $\mathrm{n}=149$ ). They were red flagged for a diagnosis of dysphagia. However, the association between the red flagged Pedi-EAT cases and the diagnosis of dysphagia given in the clinic was not statistically significant (The chi-square 
statistic with Yates correction $=0.1961, p=0.657894)$. Children who were diagnosed with developmental disorders $(72 \%, n=296)$ presented higher risk for having dysphagia.

Conclusions \& Recommendations: Highest scored feeding difficulties were under the problematic mealtime behaviors of Pedi-EAT questionnaire. Educating parents / caregivers regarding helpful and unhelpful behaviors on child's feeding will aid in managing problematic feeding behaviors in children. Pedi-EAT can be reliably used to screen feeding difficulties in children in Sri Lankan clinical context.

Key Words: feeding and drinking difficulties, Pedi-EAT, children with disabilities, MDT clinic

\title{
OP-27
}

Nutrition literacy, its associated factors and nutrition-related practices among grade 12 students in Walapane Education Zone

\author{
Nathasha Obeyesekera ${ }^{{ }^{*}}$, Dulani Samaranayake ${ }^{2}$ \\ ${ }^{1}$ Postgraduate Institute of Medicine, University of Colombo; ${ }^{2}$ Department of Community Medicine, University of Colombo \\ *hithaishi87@gmail.com
}

Background: Nutrition literacy is a set of skills that empower a person to improve their nutrition-related practices and behaviours. Limited nutrition literacy is a challenge. Adolescent period provides a window of opportunity to inculcate positive behaviours.

Objective: To describe the level of nutrition literacy, its associated factors and nutrition-related practices among Grade 12 students in Walapane Education zone

Methods: A cross-sectional study was conducted in all the grade 12 classes of government schools in Walapane education zone, including the total population of 620 students with a response rate of $100 \%$. A self-administered questionnaire was used. Based on an expert-validated cut-off, nutrition literacy was categorized into 'Adequate' and 'Limited'. Relationships between nutrition literacy and associated factors and nutrition-related practices were assessed using Chi-square test and odds ratios.

Results: Majority were studying in Arts stream (62.6\%, $n=388)$. Mean age (SD) was $16.72(0.495)$ years and $62.1 \%$ were females. About one-third (30.2\%, 95\% Cl:26.6\%-33.8\%) had 'limited' nutrition literacy. Non-Sinhalese ethnicity (OR=3.295, 95\% Cl:2.280-4.76, $\mathrm{p}<0.001$ ), non-Buddhist religion (OR=3.275, 95\% $\mathrm{Cl}: 2.269-4.727$, $p<0.001)$, larger family size $(O R=2.031,95 \% C l: 1.263-3.264, p=0.003$ and $O R=1.521,95 \% C l: 1.007-2.298$, $\mathrm{p}=0.046)$, studying in Arts stream ( $\mathrm{OR}=2.822,95 \% \mathrm{Cl}: 1.065-7.478, \quad \mathrm{p}=0.037)$, non-participation in nutritionrelated activities at school $(\mathrm{OR}=1.835,95 \% \mathrm{Cl}: 1.297-2.594, \mathrm{p}=0.001)$, inability to speak Sinhala $(\mathrm{OR}=3.335$, 95\%Cl:2.152-5.166, $\mathrm{p}<0.001$ ), speaking Tamil ( $\mathrm{OR}=2.433,95 \% \mathrm{Cl}: 1.710-3.464, \mathrm{p}<0.001)$, inability to speak English (OR=1.511, 95\%Cl:1.010 -2.261, $p=0.044$ ), inability to read and write Sinhala (OR=3.307, 95\%Cl:1.985 -5.509 , $\mathrm{p}<0.001)$, absence of chronic ailments in family ( $\mathrm{OR}=1.619,95 \% \mathrm{Cl}: 1.094-2.398, \mathrm{p}=0.016)$ no recent contact with a health care worker (OR=1.543, 95\% Cl:1.074-2.215, $\mathrm{p}=0.018$ ), poor nutrition knowledge (OR=1.992, 95\%Cl:1.358$2.922, p<0.001)$, non-participation in nutrition-related programmes ( $\mathrm{OR}=2.373,95 \% \mathrm{Cl}: 1.564-3.601, p<0.001)$ and non-use of printed media (OR=1.445, 95\%Cl:1.024-2.039, $p=0.036$ ) or television (OR=1.784, 95\%Cl:1.257$2.531, \mathrm{p}=0.001$ ) as a source of nutrition information were significantly associated with limited nutrition literacy. Consuming lunch from outside $(36 \%, n=226)$, unhealthy snacking $(23 \%, n=145)$, consuming energy drinks frequently ( $30 \%, n=185)$, consuming processed food frequently $(30 \%, n=184)$, frequent skipping of meals ( $34 \%$, $n=216)$ and daily consumption of sugar-sweetened beverages $(26 \%, n=160)$ were unsatisfactory behaviours reported. Students with 'limited' nutrition literacy preferred unhealthy snacks (OR=1.788, 95\% $\mathrm{Cl}: 1.212-2.638$, $\mathrm{p}=0.003)$, as opposed to healthy snacks $(\mathrm{OR}=0.522,95 \% \mathrm{Cl}: 0.369-0.739, \mathrm{p}<0.001)$ and consumed sugar sweetened beverages daily ( $\mathrm{OR}=3.179,95 \% \mathrm{Cl}: 2.179-4.637, \mathrm{p}<0.001)$. 
Conclusion and Recommendations: Nutrition literacy is limited in $30 \%$ and is associated with socio-demographic, education-related, literacy-related, health-related and information-related factors. Several unsatisfactory nutrition-related behaviours are reported and some were associated with limited nutrition literacy. Targeted health and educational interventions to overcome limited nutrition literacy among adolescents in rural and estate sector are recommended.

Key words: nutrition literacy, factors, nutrition-related practices, adolescents

\title{
OP-28
}

\author{
Neonatal hypothermia and its aftermath in babies less than 34 weeks gestation \\ Deepal Nawarathne ${ }^{1 *}$, Sinha De Silva ${ }^{2}$, Kanchana Kumuduni $^{3}$, Nishani Lucas ${ }^{4}$, Saman Kumara ${ }^{5}$ \\ ${ }^{1}$ Neonatal Unit, CSHW; ${ }^{2}$ Faculty of Medicine, University of Colombo; ${ }^{3}$ Neonatal Unit, DSHW, Sri Lanka \\ *m27989@pgim.cmb.ac.lk
}

Background: Neonatal mortality is the major contributor for infant mortality. Hypothermia during the neonatal period is a major factor affecting neonatal morbidity and mortality in developing countries. Identification of incidence of neonatal hypothermia and its aftermath is important to reduce morbidity and mortality.

Objectives: To describe the incidence of hypothermia, morbidity and mortality among preterm-neonates of less than 34 weeks of gestation and to determine the association of the hypothermic state at the time of admission with subsequent complications and mortality.

Methods: Descriptive, prospective study was carried out at the neonatal unit of Castle Street Hospital for Women Colombo for a duration of one year (2017 - 2018) among 146 preterm new-borns less than 34 weeks who were recruited by using systematic sampling technique. The descriptive statistics were analyzed with numbers and percentages. Associations between status of hypothermia on admission ( $\mathrm{HoA}$ ) and outcomes were determined by using chi square test and degree of severity of associations were presented with odds ratios with $95 \% \mathrm{Cls}$.

Results: Out of 146 total neonatal admissions, about one fifth $(21.2 \%, n=31)$ were <28weeks, majority $(54.1 \%$, $\mathrm{n}=79)$ were $28-32$ weeks and one fourth $(24.7 \%, \mathrm{n}=36)$ were $32-34$ weeks. In this study, majority $(40.4 \%, \mathrm{n}=59)$ had normal temperature on admission (ToA) $\left(36.5-37.5^{\circ} \mathrm{C}\right)$, followed by cold stress $\left(36-36.4^{\circ} \mathrm{C}\right)(35.6 \%, n=52)$, moderate hypothermia $\left(32-35.9^{\circ} \mathrm{C}\right)(24 \%, n=35)$ and no severe hypothermia $\left(<32^{\circ} \mathrm{C}\right)$. Out of $65(44.6 \%)$ blood culture and/or CRP proven sepsis cases, majority $(78.8 \%, n=46)$ were late onset sepsis and the rest of cases $(29.2 \%, n=19)$ were early onset sepsis. There is a statically significant association between status of HoA and status of onset infection $(\rho=0.002)$. Those who had HoA had 7.4 times odds of getting early onset sepsis as opposed to those had normal ToA (95\%, Cl: 2.1-25.7). There were no statistically significant associations between status of HoA with neonatal complications including having surfactant deficient lung disease, transfusion, chronic lung disease and Necrotizing enterocolitis.

Conclusions: The incidence of neonatal hypothermia was high among preterm new-borns and there is an increased risk of getting early onset sepsis if hypothermic on admission.

Key words: neonates, hypothermia 


\title{
OP-29
}

Management at first contact care level and referral practices of children treated for dengue fever in teaching hospital Karapitiya

\author{
A Chandrasiri ${ }^{1}$, R Vithanage ${ }^{2^{*}}$, UGC Saranga ${ }^{2}$, HMAK Kodithuwakku ${ }^{2}$, DNP Kumarasiri ${ }^{2}$ \\ ${ }^{1}$ Post Graduate Institute of Medicine, University of Colombo; ${ }^{2}$ Teaching Hospital, Karapitiya \\ *amilachan@yahoo.com
}

Background: Dengue has emerged as one of the most significant public health issues in Sri Lanka with a considerable morbidity and mortality. Proper early management is essential to prevent complications and death.

Objective: This study was conducted to describe management at first contact care level and referral practices of children treated for dengue fever in a Teaching hospital (TH) Karapitiya.

Methods: A Descriptive cross-sectional study was done involving all paediatric wards in TH Karapitiya. All the children aged 1-12 years who were treated in any of paediatric ward with the diagnosis of dengue fever/dengue hemorrhagic fever/dengue shock syndrome were considered as the study population. The total sample consisted of 465 subjects. Data were collected at 2 points. An interviewer-administered questionnaire was used first. Information about investigation reports and referrals were extracted from available clinical notes by using a data extraction sheet. Ethical clearance was obtained from the Ethics Review Committee, Faculty of Medicine, Karapitiya.

Results: A total number of 455 subjects taken for analysis where completed data was available. Mean age of study population was 7.2 years with a SD of 3.1 years. Most of the subjects belonged to the 7-9 age category. A larger proportion (44.6\%) first sought advice from a General Practitioner while taking treatment from Government hospital OPD (38.5\%). $90 \%$ of patients were admitted within 48 hours of the onset of fever. Among the study population, $95.6 \%$ had a Full Blood Count while only $19.3 \%$ were ordered NS - 1 Antigen test at the time of admission. The largest proportion of NS -1 were requested by Consultant Paediatricians. Among those who were seen by Consultant Paediatricians majority were requested for NS -1 . Out of the total study population, a large majority $(95.4 \%)$ were referred by a medical practitioner and only $4.6 \%$ had self-referral.

Conclusions and Recommendations: Among paediatric dengue cases, the majority belonged to the 7-9 age group. Most parents sought medical advice from General practitioners and also within the first 48 hours of the onset of fever. Almost all patients had FBC before admission and performing NS -1 was not common.

Key words - first contact care, children, dengue

\section{OP-30}

\section{Association between obesity of five year old children and parenting stress of their parents}

HBPW Wickramanayake ${ }^{{ }^{*}}$, HBSSK Wijesundara ${ }^{2}$. TD Paranagama ${ }^{2}$, OC Ranasinghe $^{2}$, SK Walisinghe ${ }^{2}$

${ }^{1}$ Consultant Paediatrician (Act) Sirimavo Bandaranayake Specialized Children's Hospital Peradeniya; ${ }^{2}$ Medical Officer, Sirimavo Bandaranayake Specialized Children's Hospital Peradeniya.

*wijesiri77@yahoo.com

Background: Childhood obesity creates a broad variety of severe complications and increases the risk for subsequent diseases in older ages and for premature deaths. Parental stress is an accepted component of the experience of parenting. It occurs when parenting requirements exceed the anticipated and real resources available to parents to enable them to succeed in parenting. Increased levels of parental stress impair reactive 
parenting and result in very strict care-giving to the child. Parental stress also has a negative impact on the connection between parent and child, while it predicts deviated cognitive, emotional and social consequences for children and adolescents.

Objective: To describe the association between obesity of five years old children and parenting stress of their parents in Sirimavo Bandaranayake Specialized Children's Hospital Peradeniya, Sri Lanka.

Methods: Descriptive cross-sectional study was conducted at Children's Hospital Peradeniya. Systematic random sampling technique was applied to select 426 children at the age of 5 years. Children with congenital abnormalities and children with chronic illnesses were excluded. Interviewer administered questionnaire and a parenting stress scale were used as study instruments. Statistical Package for Social Sciences version 25:0 was used for data analysis. Probability cut off at the level of 0.05 and $95 \%$ confidence interval were considered to elicit statistical significance.

Results: In a majority ( $\mathrm{n}=266,62.14 \%$ ) of the children body mass index ranged from $12.1 \mathrm{~kg} / \mathrm{m}^{2}$ to $18.0 \mathrm{~kg} / \mathrm{m}^{2}$ ( $m e a n=2.87 \mathrm{~kg}: \mathrm{SD}=0.47 \mathrm{~kg}$ ). Marks allocated for parenting stress ranged from 29 to 60 (mean=42.1: $\mathrm{SD}=6.83$ ). Mild and moderate stress levels were identified. Severe and extremely severe stress statuses were not detected among study participants. Moderate stress level among parents showed non-significant association for developing a higher body mass index (OR=1.08: $95 \% \mathrm{Cl}=0.69-1.71)$. A non-significant association is observed between delivering babies through LSCS and developing overweight at the age of five years $(\mathrm{OR}=1.27: 95 \% \mathrm{Cl}=0.83-1.94)$. Not providing exclusive breast-feeding within the first six months of life shows positive association for developing overweight at the age of five years $(\mathrm{OR}=1.32: 95 \% \mathrm{Cl}=0.83-2.12)$. Attending preschool or day-care centres before completing four years of age significantly associates with overweight (OR=2.22:95\% $\mathrm{Cl}=1.19-4.14)$.

Conclusions \& Recommendations: It is possible to observe a contributory association between parenting stress and significant overweight among children above five years of age. It is observed that, weight of children is deviated towards obesity with reduction of parents' contribution towards caregiving of their children. Special attention should be paid regarding parenting stress and its impact on the nutritional status of children during planning and implementing guidelines on development of early childhood of children.

Key words: parenting stress, obesity, childhood 
FREE PAPER SESSON 7 - YOUTH AND NEWLY MARRIED

CHAIRPERSONS: PROF. WASANTHA GUNATHUNGA, DR. CHITHRAMALEE DE SILVA

17.09.2020 / 1.00PM TO 2.00 PM / HALL A

\title{
OP-31
}

Pre-conceptional knowledge, attitudes and utilization of pre-conceptional care services among newly married females in Maharagama medical officer of health area

\author{
Shanika WanniArachchi ${ }^{{ }^{*}}$,Sriyani Ranasinghe ${ }^{2}$ \\ ${ }^{1}$ Postgraduate Institute of Medicine, University of Colombo; ${ }^{2}$ Teaching Hospital, Rathnapura \\ *spwanniarachchi@gmail.com
}

Background: Pre-conception care is a key component in the continuum of maternal and child health. It consists of risk screening, targeted interventions and reproductive health promotion.

Objective: To assess pre-conceptional knowledge, attitudes and utilization of pre-conceptional care services among newly married females in Maharagama Medical officer of Health area, Sri Lanka.

Methods: A community based descriptive cross-sectional study was conducted among 454 females married within last one year prior to the study. Clusters were selected using population proportionate to size method and house to house survey was conducted to recruit individual participants. A pretested self-administered questionnaire was used to collect data. SPSS version 21 was used and chi square test was performed to analyze associated factors. A p value of $<0.05$ was considered as statistically significant.

Results: Mean age (SD) of the sample was 28 (4) years. Majority were Sinhalese ( $96.3 \%, n=437)$, Buddhists $(92.3 \%, n=419)$, educated up to $A / L$ or above $(80.9 \%, n=367)$ and were employed $(72.5 \%, n=329)$. There were $31.1 \%$ ( $n=141)$ who were pregnant. Majority of participants $(61.9 \%, n=281)$ had a good knowledge and favourable attitudes $(61.9 \%, n=281)$. The mean knowledge was $86.91 \%$ and out of seven sources, referring consultant gynaecologist and obstetrician was the common source $(41.2 \%, n=187)$ to obtain pre conception knowledge. Passing Advanced level ( $O R=4.383(95 \% \mathrm{Cl} 2.665-7.206), p=<0.05)$, being employed (OR=2.430(95\% Cl 1.596$3.701), p=<0.05)$ and being a health professional( $O R=3.815(95 \% \mathrm{Cl} 1.564-9.304), \mathrm{p}=<0.05)$ were significantly associated with good knowledge and pregnancy status was not associated with good knowledge(OR $=0.868(95 \%$ $\mathrm{Cl} 0.578-1.304), \mathrm{P}=0.495)$. Utilization of pre-conceptional care services was $24.8 \%(\mathrm{n}=113)$. Nearly $15 \%(14.6 \%$, $\mathrm{n}=66$ ) has participated to clinic for newly married couples, conducted by the Medical Officer of Health office and $10.3 \%(n=47)$ has used other places. Private hospitals $(78.8 \%, n=37)$ were the common place used to get services other than Medical Officer of Health office and Consultant gynaecologist and obstetrician was the common service provider $(65.9 \%, n=31)$. Services include medical examination, targeted investigations and management and health education.

Conclusions and Recommendations: Knowledge and attitudes on preconception care were good but utilization of services was suboptimal. Awareness on preconception care services among newly married females should be increased to optimize utilization of services.

Key words: preconception, utilization 
When the reflection lies: body image perception and satisfaction among adolescent school children in an urban setting in Sri Lanka

Priyangha Thevatheepan ${ }^{1^{*}}$, Lakshaniya Jeyarajah', Thadchajini Karunainathan ${ }^{1}$, Sorubini Markandayar', Mathury Thavendra ${ }^{1}$, Guwani Liyanage ${ }^{2}$, Maheeka Seneviwickrama ${ }^{3}$

${ }^{1}$ 23rd batch of Medical Students, Faculty of Medical Sciences, University of Sri Jayewardenepura; ${ }^{2}$ Professor, Department of Paediatrics, Faculty of Medical Sciences, University of Sri Jayewardenepura; ${ }^{3}$ Senior Lecturer, Department of Community Medicine, Faculty of Medical Sciences, University of Sri Jayewardenepura

*priyanghat1993@gmail.com

Background: Body image is the self-attitude towards one's body, with respect to its size, shape and general appearance. Adolescence is a highly vulnerable stage of life for body image issues.

Objectives: The present study aimed at describing the perception and satisfaction with current body image among adolescent school children in an urban setting in Sri Lanka.

Methods: A descriptive cross sectional study was conducted in two selected government schools in Colombo educational zone among 245 adolescents ( $53.8 \%$ girls) aged $15-16$ years. Weight, height, waist circumference and body mass index (BMI) were obtained according to the WHO guidelines. Body size ideals and satisfaction with current body image were assessed using self-administered Stunkard figure rating scale (SFRS) judgmentally validated by a panel of experts. The SFRS is comprised of nine silhouettes numbered from 1 (extreme underweight) to 9 (severely obese). Subjects were asked to identify the pictures that represented their current and ideal body size. These silhouettes were classified as underweight (1-3), normal weight (4) and overweight/obese $(\geq 5)$.

Results: More than $50 \%$ in each BMI category were able to correctly identify their body image. Majority (74\%, $\mathrm{n}=180$ ) were not satisfied with their current body image. Thin figure was the preferred ideal body size by the majority $(62 \%, n=152)$. Statistically significant associations were found between body image satisfaction and BMI, $X^{2}(2, n=245)=7.914, p=0.019$; perceived body image and BMI, $X^{2}(4, n=245)=60.781, p=0.001$, and perceived body image and waist circumference, $X^{2}(4, n=245)=44.153, p=0.001$. A higher proportion of boys (33.6\%) perceived themselves to be thin compared to girls $(27.3 \%)$ while the vice versa was true when the perceived image was fat ( $28 \%$ versus $15 \%$ ) which was found to be statistically significant, $X^{2}(2, n=245)=6.033, p=0.049$.

Conclusions \& Recommendations: Body image dissatisfaction is common. Normal BMI adolescents had higher body image satisfaction. Thinness was the majority preferred body size ideal. Gender differences were observed in the body image perception. Interventions are needed to promote healthy body size ideals and body esteem among Sri Lankan adolescents.

Key words: body mass index, body dissatisfaction, ideal body image, adolescent, Stunkard Figure Rating Scale 


\title{
OP-33
}

Knowledge, attitudes and practices on healthy lifestyle related behaviours among youth trainees attached to youth training centres in Sri Lanka

\author{
${ }^{*}$ Dilini Mataraarachchi ${ }^{1}$, P.V.S.C. Vithana ${ }^{2}$, A. Lokubalasooriya ${ }^{3}$, C.J. Jayasundara ${ }^{4}$, S.A. Suranutha ${ }^{5}$, C. De Silva ${ }^{6}$ \\ ${ }^{1,2,3,4,6}$ Family Health Bureau, ${ }^{6}$ Provincial Director of Health Services office-Jaffna \\ *dilmatara84@gmail.com
}

Background: Youth health module was introduced in the training curriculum of youth training institutions functioning under the Ministry of Youth Affairs in 2017 by Ministry of Health.

Objectives: To assess the knowledge, attitudes, practices on healthy life-style related behaviours among youth trainees attached to youth training centers in Sri Lanka.

Methods: A descriptive, cross-sectional study was carried out among a sample of 425 youth studying in selected youth training centers where youth health module was included in their training program using a pre-tested, selfadministered questionnaire. Study subjects were retrieved from selected youth training centers using simple random sampling technique. Data analysis was done using SPSS-21. The scoring system was developed for measuring knowledge, attitude and practices on healthy lifestyles and percentage scores were calculated and presented with median and IQR. Cut off levels for the acceptable level of scores were taken as $50 \%$. Associated factors for accepted levels were identified using Chi-Square test or Fisher's Exact test at $p<.05$.

Results: Response rate was $98 \%$. Majority ( $n=365 ; 85.9 \%$ ) were Sinhalese while 355(83.6\%) were Buddhists. Mean age of the respondents was 18.6 years $(S D=1.82)$. Nearly sixty percent had an education level up to grade 11 . Participants' knowledge on healthy lifestyle behaviors was satisfactory with a median percentage score of 65 (IQR:52.2-69.6). However, the knowledge on healthy dietary habits was not acceptable. Only $59.8 \%(n=254)$ of the youth knew that bread with dhal is a high carbohydrate diet and only $5.2 \%(n=22)$ knew fish and chicken are good sources of iron. Although participants' knowledge on physical activity was satisfactory only $59.3 \%$ ( $n=252)$ had ever heard of Body Mass Index. Median percentage score for attitudes on healthy life-style related behavior (33.3, IQR:25.0-50.0) was substandard, while practices had a percentage score of 58.5 (IQR:48.1-66.0). Thirty one percent $(n=125)$ couldn't find time to engage in physical activity while $51.1 \%(n=208)$ stated it's okay for a boy to take alcohol during his teens but not girls. Only $23.8 \%(n=101)$ were having their breakfast everyday whereas $24.9 \%(n=106)$ had not consumed any fruit during the past 7 days. Out of the sample $6.1 \%(n=26)$ had taken dietary supplements without doctors' prescription during the past week expecting muscle mass, hair growth or improvement in skin complexion. Those having an education level of grade 11 or above ( $n=333,82 \%)$ were having a significantly higher level of scores for knowledge at $p<0.05$. Age category of 20-27 years compared to $16-19$ years was significantly associated with acceptable level of knowledge, attitudes and practices at $p<.05$.

Conclusions and Recommendations: Youth trainees had satisfactory knowledge on healthy lifestyle related behaviors. However, the attitudes of the trainees over healthy lifestyle related factors need to be improved. Youth Health module in the current curriculum needs revision with more focus on developing healthy attitudes.

Key words: youth, youth training centers, healthy lifestyle related behaviors 
Correlates of bullying victimization among early adolescents in government schools in the Kegalle Educational Zone

\author{
Dilini Rupananda ${ }^{{ }^{*}}$, Devani Dissanayake ${ }^{2}$, Nuwan Wickramasinghe ${ }^{3}$ \\ ${ }^{1}$ Postgraduate Institute of Medicine, University of Colombo, ${ }^{2}$ Department of Community Medicine, Faculty of Medicine, \\ University of Peradeniya, ${ }^{3}$ Department of Community Medicine, Faculty of Medicine and Allied sciences, Rajarata University \\ of Sri Lanka. \\ *rupananda_dilini@yahoo.com
}

Background: Bullying victimization has resulted in various forms of detrimental effects on wellbeing of adolescents all over the world. Global evidence suggests that socio-demographic, individual, school environment, family and living society related factors can affect bullying victimization.

Objective: To determine the correlates of bullying victimization among early adolescents in government schools in the Kegalle educational zone

Methods: A cross-sectional analytical study was conducted among students in grade 7, 8, 9 in 28 Sinhala medium government schools in the Kegalle educational zone. The study sample was randomly selected from the participants of a prevalent study conducted to assess bullying victimization using validated Sinhala version of the Olweus Bully/Victim Questionnaire. The sample consisted of 1445 students of whom, 754 were subjected to bullying and 691 were not subjected to bullying. A pre-tested and validated self-administered questionnaire was used to gather details on possible correlates of bullying victimization in the sample. Multiple logistic regression model using backward stepwise method was used to identify the statistically significant correlates of bullying victimization. Adjusted odds ratios (AOR) were calculated and correlates which were significant at $p<0.05$ were noted.

Results: The majority of the sample was female students ( $n=752,55.5 \%)$. The mean (SD) age was 13.2 (0.8) years. Male students (AOR=1.64;95\% $\mathrm{Cl}=1.31-2.07$ ), students who were hospitalized due to illnesses during the past year ( $A O R=1.84 ; 95 \% \mathrm{Cl}=1.37-2.46$ ), students possessing families with single parent ( $\mathrm{AOR}=1.82 ; 95 \% \mathrm{Cl}=1.24$ 2.67), students who do not receive support from their parents ( $A O R=1.41 ; 95 \% \mathrm{Cl}=1.11-1.80$ ), students coming from families with frequent conflicts among parents ( $A O R=1.44 ; 95 \% \mathrm{Cl}=1.13-1.84)$, students who were subjected to peer pressure at school ( $A O R=2.76 ; 95 \% \mathrm{Cl}=2.00-3.83)$, students who feel embarrassed to attend extracurricular activities at school $(A O R=1.75 ; 95 \% \mathrm{Cl}=1.34-2.28)$ and students who were subjected to frequent scolding by teachers ( $A O R=1.51 ; 95 \% \mathrm{Cl}=1.04-2.08)$ were identified as statistically significant correlates $(p<0.05)$ of bullying victimization.

Conclusions and Recommendations: A multitude of personal, family-related and school-environment related factors emerged as significant correlates of bullying victimization in early adolescents in the study setting. Hence, school-based bullying prevention programs and interventions need to be developed focusing on identified correlates to minimize bullying victimization among school going adolescents.

Key words: bullying victimization, correlates, early adolescence 


\title{
OP-35
}

\section{Magnitude of dating violence among state university undergraduates in the Western Province}

\author{
Hasarali Fernando $^{1}$; Aindralal Balasuriya ${ }^{2^{*}}$, Pushpa Jayawardena ${ }^{3}$ \\ ${ }^{1}$ National Cancer Control Programme, ${ }^{2}$ Department of Community Medicine, General Sir John Kotelawala Defence University, \\ ${ }^{3}$ Department of Public Health, University of Kelaniya; \\ *dr.balasuriya@yahoo.com
}

Background: Dating violence is an emerging public health issue which has failed to gain recognition in the country. It was never studied in the local setting despite the higher prevalence/incidence reported in other countries.

Objective: To determine the magnitude of dating violence and types of violent acts among undergraduates in selected state universities in the Western Province.

Methods: The study was a descriptive study. Three out of the seven state universities in the Western Province were selected applying simple random sampling (SRS). It was conducted among both male and female second year undergraduates who had an established heterosexual relationships of $\geq$ six months prior to the main survey. The sample size computed was 1296 to determine the incidence of violent acts and types following dating violence. Multi-staged stratified cluster sampling method was used to select 27 clusters. Questionnaires used were SAQ I (screening questionnaire to identify study units with heterosexual relationships) and SAQ II (questionnaire on dating violence) as a combined self - administered questionnaire (SAQ) which were validated and pre tested in a university with similar settings. Incidence (related to past six months) was considered when either the respondent or the partner has committed any type of violent act. This was described in terms of cumulative incidence of violent acts with $95 \%$ confidence intervals considering acts of violence as new events. Types were described as percentages and $95 \%$ confidence intervals.

Results: Response rate was $95.4 \%(\mathrm{n}=2219)$ at the screening stage. Overall cumulative incidence of violent acts was $78.2 \%$ (95\% Cl: $75.8-80.4 \%, n=1013$ ) during the immediate six months prior to the survey. The incidence of violent acts of controlling behaviours was the highest $64.8 \%(95 \% \mathrm{Cl}: 62.2-67.4 \%, \mathrm{n}=840$ ) followed by verbal abuse $56.9 \%$ (95\% Cl: $54.2-59.7 \%, n=738)$, physical violence $13.3 \%(95 \% \mathrm{Cl}: 11.5-15.2 \%, \mathrm{n}=172$ ) and sexual violence $1.1 \%(95 \% \mathrm{Cl}: 0.6-1.8 \%, \mathrm{n}=14)$.

Conclusions and Recommendations: Incidence of dating violence is considered high. It can be taken as evidence to advocate the need to strengthen the importance of developing healthy dating relationships among undergraduates.

Key words: dating violence, incidence of violent acts, types of violent acts 
FREE PAPER SESSON 8 - MENTAL WELLBIENG

CHAIRPERSONS: DR. ROHAN RATHNAYAKE, DR. JAYAMAL DE SILVA

17.09.202 / 1.00PM TO 2.00 PM / HALL B

\section{OP-36}

Is behaviour related stigma among men, who have sex with men, associated with their HIV testing uptake?

Mekala Fernando ${ }^{1 *}$, Janaki Vidanapathirana ${ }^{1}$

${ }^{1}$ National Cancer Control Programme

*meksfdo@gmail.com

Background: Men who have sex with men (MSM) are identified as a key population (KP) group due to the highest risk of acquiring and transmitting HIV. They have become a hidden population due to the high level of self, perceived and enacted stigma vested upon them due to having sex with men. Stigma and discrimination are identified as key obstacles on universal access to HIV prevention, treatment and care. Stigma among KP lowers the access to health care services, and lowers HIV testing among these groups. In this study self and perceived stigma is collectively called as behaviour related stigma.

Objective: to determine the HIV testing uptake and its association with behaviour related stigma among MSM in Western province in Sri Lanka

Methods: The study was conducted among 564 MSM in Western province in Sri Lanka. They were recruited using respondent driven sampling. HIV testing uptake was operationalized as ever being tested for HIV. The level of stigma was assessed using "Behaviour Related Stigma Scale" developed and validated by the investigators in another component of the original study. The level of stigma was dichotomized as high and low level of stigma from the $25^{\text {th }}$ centile of its distribution. Data analysis was done using RDS-A 7.0 and SPSS version 22. Population percentage of study participants who were ever tested for HIV was calculated using version 7.0 of RDS-A software. Univariate analysis was done to assess the association between level of behaviour related stigma and HIV testing uptake among men who sex with men. Data was collected using an interviewer administered questionnaire.

Results: The Majority of MSM were in the age group of below 40 years $(n=346,61.3 \%)$ and were Sinhalese ( $n=$ 498, 88.3\%). The proportion of HIV testing uptake among MSM, 87.1\% (95\% Cl 84.4 -89.7). The association between HIV testing uptake and level of stigma among MSM was statistically significant $(\mathrm{OR}=0.7,95 \% \mathrm{Cl}: 0.5-$ $0.99 ; p=0.04)$.

Conclusions \& Recommendations: Ever being tested for HIV is shown to be negatively associated with behaviour related stigma among MSM. Measures to minimize behaviour related stigma among MSM should be implemented.

Key words: behaviour related stigma, HIV testing uptake, men who sex with men 


\title{
Psychological distress and psychosocial needs of caregivers of children with cancer, attending the main cancer treatment centre in Sri Lanka
}

\author{
Sachintha Dilhani ${ }^{1^{*}}$, Sivagurunathan Sivayogan ${ }^{2}$, Jayamal De Silva $^{3}$ \\ ${ }^{1}$ National Cancer Control Programme, Ministry of Health and Indigenous medical Services; ${ }^{2}$ Department of Community \\ Medicine, Faculty of Medical Sciences, University of Sri Jayawardenepura; ${ }^{3}$ Department of Psychiatry, Faculty of Medical \\ Sciences, University of Sri Jayawardenepura
}

navarathnasachi@gmail.com

Background: Psychosocial needs and psychological distress of caregivers of children with cancers is an emerging public health issue. It is necessary to address these in a comprehensive cancer care programme.

Objectives: To describe the psychological distress and psychosocial needs among primary caregivers (PCGs) of children with cancer attending Apeksha hospital, Sri Lanka

Methods: This study consisted of two components. In the first component, a qualitative study was conducted to explore the psychosocial needs among caregivers and based on those findings, a questionnaire was developed and validated to assess their needs and knowledge. In the second component, a single centred descriptive crosssectional study was conducted among 180 caregivers of children with cancer diagnosed for one to four months duration, attending Apeksha hospital. The questionnaire developed in the first component was administered to assess the needs and knowledge, while General Health Questionnaire-30 was used to assess the distress level. Chi-square test was used in bivariate analysis and binary logistic regression in multivariate analysis to assess the associations. In addition to that, the relationship between individual needs, distress and knowledge were investigated using Spearman's rank correlation.

Results: A total of 170 PCGs completed the questionnaire with a response rate of $94 \%$. Among the study participants, majority of the caregivers were Sinhalese $(79 \%, n=135)$, mothers $(84 \%, n=143)$ of the age of below $40(73 \%, n=123)$. Almost all the caregivers were found to be psychologically distressed during the early postdiagnosis stage ( $97.6 \%, \mathrm{Cl}: 95.3 \%$ - 99.9\%). Furthermore, it was found that only $18 \%(n=30)$ of primary caregivers had a good overall knowledge level on childhood cancer caregiving. Higher distress level was significantly associated with poor knowledge on cancer caregiving $(O R=2.55,95 \%$ C.I.: $1.13-5.74)$ and being the mother of the sick child $(\mathrm{OR}=2.38,95 \% \mathrm{Cl}: 1.02-5.56)$. When needs were considered, all study participants had at least one item of unmet psychosocial needs; and consecutively emotional needs, financial needs, informational needs, practical needs and need of family and social support were identified as top five. Both emotional and informational need categories showed a statistically significant positive correlation with each other $(r=0.47, p$ $<0.01$ ) and with almost all other need categories.

Conclusions \& Recommendations: Almost all childhood cancer caregivers were found to be distressed, had many unmet psychosocial needs, and the majority had poor knowledge of cancer caregiving. Strengthening the caregiver education on childhood cancer caregiving and addressing their informational needs and emotional needs is recommended to mitigate psychological distress and needs among them at the early post-diagnosis stage.

Key words: childhood cancer, caregivers, psychological distress, psychosocial needs, informational needs, emotional needs, knowledge on cancer caregiving 
Prevalence of depression, anxiety and stress following dengue infection among adults in Colombo district Nadeeka Perera ${ }^{1 *}$ Shamini Prathapan ${ }^{2}$, Dulshika Wass ${ }^{3}$, Ananda Wijewickrama $^{4}$

${ }^{1}$ School Health Unit, Family Health Bureau; ${ }^{2}$ Department of Community Medicine, Faculty of Medical Sciences, University of Sri Jayawardenepura; ${ }^{3}$ Department of Psychiatry, Faculty of Medical Sciences, University of Sri Jayawardenepura; ${ }^{4}$ Institute for Infectious Diseases, Angoda

*dnadeekaperera@yahoo.com

Background: Post-infection period of Dengue fever is fairly less studied. A few studies have described that psychological distress and depression can be present for several weeks following Dengue infection.

Objective: To determine the prevalence of depression, anxiety and stress at discharge from hospital and at one month follow up among adults confirmed with Dengue infection admitted to selected healthcare institutions in Colombo district.

Methods: A longitudinal study was conducted from July 2018 to January 2019. The study population was adult patients confirmed with Dengue infection. Data were collected on discharge from hospital and at one month after day one of fever. The calculated sample sizes to detect prevalence of depression, anxiety and stress were 364, 371 and 384 respectively. The maximum sample size was 384 and $20 \%$ loss to follow up was added with a final sample size of 480. Data were collected using a pre-tested interviewer-administered questionnaire. Locally validated tools were used to assess the three conditions. The prevalences of depression, anxiety and stress were presented with $95 \% \mathrm{Cl}$.

Results: Response rate was $84.58 \%$. The mean age (SD) was 30.78 (11.5) years and median age (IQR) was 27 (21.75-39.0) years. The sex ratio of male: female was 1.5:1.0. Majority of the study population $(53.7 \%, n=218)$ had passed G.C.E A/L examination or attained higher educational qualifications. Prevalence of depression, anxiety and stress associated symptoms were $13.1 \%$ (95\% Cl:9.9-16.7), 23.4\% (95\% $\mathrm{Cl}: 19.4-27.8)$ and 13.8\% (95\%Cl:10.6-17.5) respectively on discharge and at follow up was $2.7 \%$ (95\%Cl:1.4-4.8), 3.2\% (95\%Cl:1.7-5.4) and $7.9 \%$ (95\% Cl:5.5-10.9) correspondingly. Wilcoxon signed-rank test was performed comparing the median scores of each condition at discharge and at follow up and the difference in the median scores of each condition was significant $(p<0.001)$.

Conclusions and Recommendations: The prevalence of depression, anxiety and stress on discharge from hospital was higher than at one month following a Dengue infection. Psychological well-being of Dengue patients at institutional level and at follow up requires due attention.

Key words: dengue infection, psychological distress, depressive symptoms

OP-39

Effectiveness of an educational intervention to promote psychosocial wellbeing of school-going adolescents in the Western Province, Sri Lanka

Ayesha Lokubalasooriya ${ }^{1}$, Chiranthika Vithana ${ }^{1}$, Ganeshamoorthy Pragasan ${ }^{1 *}$, Kanchana Mahagamage ${ }^{1}$, Kumudu Nanayakkara ${ }^{1}$, Himali Herath ${ }^{1}$, Priyani Karunarathna ${ }^{2}$, Dushyanthi Jayawardane ${ }^{3}$, Nuwan Wickramasinghe ${ }^{4}$

${ }^{1}$ Family Health Bureau, Ministry of Health and Indigenous Medical Services; ${ }^{2}$ RDHS Office, Kalutara; ${ }^{3}$ Department of Community Medicine, Faculty of Medicine, University of Colombo; ${ }^{4}$ Department of Community Medicine, Faculty of Medicine and Allied Sciences, Rajarata University of Sri Lanka

*g.pragasan@gmail.com 
Background: Growing trend in psychosocial health issues has been observed among school-going adolescents. Therefore, evidence-based interventions are needed to promote psychosocial well-being of adolescents.

Objective: To assess the effectiveness of an educational intervention to promote the psychosocial wellbeing of school-going adolescents in grade nine in the Western Province, Sri Lanka.

Methods: A quasi-experimental study was conducted among grade nine students in Western Province in 2019. Medical Officer of Health $(\mathrm{MOH})$ area, Panadura was randomly selected from Kalutara district as interventional area (IA) and Kelaniya $\mathrm{MOH}$ area was identified as control area (CA) from Gampaha district. MOH staff of IA was trained on psychosocial health promotion package and they trained school teachers. Attitudes and practices on psychosocial well-being among students and their perception of teaching targeting psychosocial wellbeing were assessed using a pre-tested self-administrated questionnaire at the base line as well as after three months of the intervention. Sample size was 260 for one area per one assessment. A scoring system to measure attitude on psychosocial wellbeing was developed. Mann-Whitney $U$ test was applied to find statistically significant differences of scores. Categorical data were compared using Chi-Square or Fisher's Exact test.

Results: Total of 1050 responded. Median score for attitude on psychosocial wellbeing was significantly increased in IA from 180 (IQR:166-188) to 18 (IQR:173.00-191.75) over time(p0=.004) while that in CA slightly decreased from 180 (IQR:171.0-187.0) to179(IQR:167.0-189.8) [p=.735]. The number of bullied adolescents in past 30 days were significantly reduced from $14.8 \%(n=38)$ to $7.9 \%(n=20)$ in IA $(p 0=.03)$ whereas there was a slight reduction from $17.1 \%(n=44)$ to $11.3 \%(n=26)$ in $C A(p 0=.17)$. Adolescents who never felt lonely within past 30 days increased from $75(29 \%)$ to $96(37.5 \%)$ in $\mathrm{IA}(\mathrm{p} 0=.36)$ while there was a slight decline from $91(35.1 \%)$ to $88(35.1 \%)$ in CA [p0=.54) There was an increase from $150(57.9 \%)$ to $165(64.5 \%)$ in teaching anger management in IA $(\mathrm{p} 0=.12)$ whereas that figure in CA remained same over time with respective figures of $171(66.3 \%)$ at baseline and $170(66.5 \%)$ at post-intervention $(\mathrm{p} 0=0.4)$. Adolescents received activity-based life skill teaching in IA were significantly increased from $189(74.1 \%)$ to $210(81.7 \%)$ [p=.04] and that figure for CA slightly reduced from 222 (86.0\%) to 207 (83.1) [p0=.37].

Conclusion and Recommendations: Findings suggest that educational intervention is effective in promoting psychosocial wellbeing in school-going adolescents. The intervention package can be introduced in other districts.

Key words: adolescents, psychosocial wellbeing, educational intervention

\section{OP-40}

A systematic approach in mental health assessment in early pregnancy: an experience from Rajarata pregnancy cohort

Imasha Jayasinghe ${ }^{1}$, Thilini Agampodi ${ }^{1}$, Gayani Amarasinghe ${ }^{1}$, Ayesh Hettiarachchi ${ }^{1}$, Janith Warnasekera ${ }^{1 *}$ Ravindu llangasinghe ${ }^{1}$, Nuwan Wickramasinghe ${ }^{1}$, Suneth Agampodi ${ }^{1}$

${ }^{1}$ Department of Community Medicine, Faculty of Medicine and Allied Sciences, Rajarata University of Sri Lanka

*jwarnasekara@yahoo.com

Background: Maternal mental health during the first trimester has a huge influence on fetal outcomes. Pregnant women are not systematically screened for mental health in Sri Lanka and the global and local evidence-based on early pregnancy mental health care is scarce.

Objective: To describe the yield and observations of simple approaches in mental health assessment in the early pregnancy in Anuradhapura district. 
Methods: The mental health status of first trimester pregnant women recruited to Rajarata Pregnancy Cohort (RaPCo) was systematically assessed using validated Edinburgh Postpartum Depression Scale (EPDS) and a selfadministered questionnaire related to mental wellbeing (developed for the present study). Data collection was carried out in 326 special field clinics during the period of July to September 2019, covering the district. Mothers having a high EPDS (cut off 10) scores were assessed using a short interview and a simple discussion by a medical officer to identify the need for referral for the psychiatrist.

Results: Completed EPDS was available for 3233 pregnant women. Of them, $23.8 \%$ ( $n=768$ ) had high EPDS scores $(>9)$ with $8.8 \%(n=283)$ reporting self-harm ideation within preceding two weeks. Prevalence of suicidal ideation was $4.1 \%$ ( $n=150)$. Fifty-five (1.8\%) women were unhappy of being pregnant. Ethnic and geographical disparities were observed in mental health status $(p<0.001)$. Women with unplanned pregnancy, nausea and vomiting and being physically abused during pregnancy reported significantly higher EPDS scores $(p<.001)$. The short clinical interviews revealed that high scores as well as self-harm ideation were mainly due to anxiety caused by unplanned pregnancy, minor ailments, socioeconomic issues and lack of support rather than depression. They were able to be support at primary care level. We also observed that having EPDS scores between 10-14 either did not have or rarely had mental health issues that needed referral to a specialist.

Conclusions and Recommendations: A systematic approach in screening for mental health status in early pregnancy is required and field maternal care programme needs strengthening to promote maternal mental wellbeing.

Key words: mental health, early pregnancy, screening 
FREE PAPER SESSON 9 - SEXUAL AND REPRODUCTIVE HEALTH

CHAIRPERSONS: DR. SUJATHA SAMARAKOON, DR. HEMANTHA HERATH

17.09.2020 / 2.00PM TO 3.00 PM / HALL A

\section{OP-41}

Factors associated with behaviour related stigma among female sex workers in Western Province

Mekala Fernando $^{1^{*}}$, Janaki Vidanapathirana ${ }^{1}$

${ }^{1}$ National Cancer Control Programme

*meksfdo@gmail.com

Background: Key populations (KP) are the groups who are at highest risk of acquiring and transmitting HIV due to their risk behaviour. Female sex workers (FSW) are identified as a key population internationally as well as in Sri Lanka. Thus, they face high level of self, perceived and enacted stigma. They face numerous adverse health outcomes due to the stigma they face due to their key behaviour.

Objectives: The objective of the study is to determine the factors associated with behaviour related stigma among FSW in Western province, Sri Lanka.

Methods: A community based cross sectional study was conducted among 508 female sex workers using respondent driven sampling, in Western province in Sri Lanka in 2018. The level of stigma was dichotomized to high and low level from the $25^{\text {th }}$ centile according the distribution of the total score of stigma obtained by the study participants, Statistical analysis was done using RDS - A version 7.0 and SPSS version 22. The independently associated factors were identified using binary logistic regression.

Results: Mean age of the study participants was 40.9 years (SD=11.7). Majority of them were educated upto grade $10(71.8 \%, n=365)$. Experience of desertion from the family $(a O R=3.4,95 \% \mathrm{Cl}=1.3-9.3)$, experience of induced abortion $(\mathrm{aOR}=0.4,95 \% \mathrm{Cl}=0.18-0.9)$, ever given birth to a child $(\mathrm{aOR}=2.2,95 \% \mathrm{Cl}=1.05-4.7)$, finding clients through friends $(\mathrm{aOR}=0.4,95 \% \mathrm{Cl}=0.24-0.7)$, initiation of sex work for pleasure $(\mathrm{aOR}=0.2,95 \% \mathrm{Cl}=0.11-0.6)$ and being arrested by police for more than once during the past one year $(\mathrm{aOR}=2.2,95 \% \mathrm{Cl}=1.05-4.7)$ were independently associated with behaviour related stigma among FSW.

Conclusions \& Recommendations: There are internal and external modifiable factors which contribute to behaviour related stigma among female sex workers. Raising awareness on contraceptive methods among FSW, and repealing of laws affecting sex workers which make them highly vulnerable to get arrested are recommended.

Key words: behaviour related stigma, female sex workers, associated factors

\section{OP-42}

\section{HPV/DNA screen positive follow-up at the colposcopy clinic Family Health Bureau}

\section{Ruwan Silva ${ }^{1}$, Ramani Punchihewa ${ }^{2}$, KCM Perera $^{3}$, SADJ Kanchana ${ }^{4 *}$, LRB Pathirana ${ }^{5}$}

Family Health Bureau ${ }^{14,5}$; National Hospital for Respiratory Diseases, Welisara; Non Communicable Diseases, Ministry of Health \& Indigenous Medicine ${ }^{3}$

Janani.suraweera.9@gmail.com 
Background: Cervical cancer is the second commonest female cancer in Sri Lanka and the National Cervical Cancer Screening method is conventional cytology (sensitivity 53\%) since 1998. All cervical cancers are associated with Human papillomavirus infection (HPV), and HPV genotypes 16 and 18 contributes for $70 \%$ of all cervical cancers. Other high risk carcinogenic genotypes of HPV infection are genotypes $31,33,35,39,45,51,52,56,58$, 59, 66 and 68 (12 pooled high risk). Human papillomavirus/DNA (HPV/DNA) screening test (sensitivity 92.9\%) can be used as a primary cervical cancer screening method and screened positive women are followed-up according to the Asia-Oceania guidelines. In HPV/DNA screening HPV/DNA screen positive women with cytology $\geq$ Atypical Squamous Cells of Undetermined Significance (ASCUS) women only are referred for colposcopy, therefore the burden of colposcopy will be reduced for $40 \%-50 \%$ in a country.

Objective: To describe colposcopy results carried out at Family Health Bureau (FHB) colposcopy clinic for HPV/DNA screen positive women in Medical Officer of Health areas in Kalutara district

Methods: Descriptive longitudinal study design was used to follow-up HPV/DNA screened positive women. HPV/DNA screening pilot project was carried out among 35 and 45 year age cohort ever married women in Kalutara district. All HPV/DNA screen positive women with cytology results $\geq A S C U S$ were referred to colposcopy clinics at Kethumathie Maternity Hospital, Panadura and FHB, Colombo. Total number of 106 (86.8\%) were referred to FHB colposcopy clinic. Colposcopy was carried out by using digital colposcope with $1 \%$ acetic acid or $5 \%$ Lugol's iodine. Total number of 95 women were subjected to biopsy and biopsy screening was carried out by a Consultant Histopathologist at National Hospital for Respiratory Diseases-Colombo.

Results: Percentage of women subjected to biopsy was $89.6 \%$ (95/106). Percentage of overall biopsy tissue abnormality was $81.05 \%$ (77/95).HPV/DNA genotypes in the two categories $16 / 18$ and 12 pooled high-risk women with cytology $\geq$ ASCUS were $92.7 \%$ (51/55) and 65\% (26/40) respectively. Among all biopsy screened 5.3\% (5/95) were cervical cancers, while 8\% (8/95) were Cervical Intraepithelial Neoplasia (CIN) III and 67.4\% (64/95) were CIN I and II.

Conclusions and Recommendations: HPV/DNA screen positive women with cytology $\geq A S C U S$ were given very high detection of CIN by colposcopy and biopsy as the sensitivity of HPV/DNA test was very high. Therefore, HPV/DNA screening as a primary cervical cancer screening method should be considered as the suitability of HPV/DNA screening was well proven at Sri Lankan setting.

Key words: cervical cancer screening, HPV/DNA test, diagnostic test, colposcopy

\title{
OP-43
}

Postpartum family planning practices and associated factors among mothers of infants attending Child Welfare Clinics: a comparison of two urban and rural settings in Polonnaruwa district \\ ${ }^{1}$ Postgraduate Institute of Medicine, University of Colombo; ${ }^{2}$ Family Planning Unit, Family Health Bureau, Ministry \\ of Health \\ *fernando.chathu87@gmail.com
}

Background: Postpartum family planning is critical for health and wellbeing of the mother and the child. It is the use of a family planning method during the first year postpartum and its prevalence or associated factors between urban and rural communities have not been compared in the few studies done locally.

Objective: To compare postpartum family planning practices and associated factors among mothers of infants attending Child Welfare Clinics in two urban and rural settings in Polonnaruwa district 
Methods: A clinic-based comparative cross-sectional study was conducted in two urban and rural settings in Polonnaruwa district. Consecutive sampling method was used in the urban setting and systematic sampling method was used in the rural setting to recruit 198 participants from each setting. Data were collected using an interviewer-administered questionnaire and analysed using SPSS version 23.0. Chi-square test was used to compare the postpartum family planning practices. Unadjusted odds ratio and $95 \%$ confidence interval were used to determine associated factors. P value less than 0.05 was considered as significant.

Results: The response rate was $100 \%$. In the urban and rural settings $77.8 \%(n=154)$ and $73.2 \%(n=145)$ of mothers respectively adhered to the national recommendations on family planning. However, the difference was not statistically significant $(p=0.293)$. In the urban setting, younger age $(\mathrm{OR}=1.98,95 \% \mathrm{Cl}: 1.00-3.90)$ and higher level of education of mother ( $\mathrm{OR}=0.45,95 \% \mathrm{Cl}: 0.21-0.94)$, having nuclear family ( $\mathrm{OR}=2.37,95 \% \mathrm{Cl}: 0.17-4.83$ ), with low income (OR=2.57,95\% Cl:1.25-5.3) and receiving of family planning counselling at the place of delivery $(\mathrm{OR}=3.16,95 \% \mathrm{Cl}: 1.57,6.35)$ and in the rural setting, having a younger partner (OR=2.21,95\%Cl:1.16-4.21) and partner's higher level of education (OR=0.34, 95\% Cl:0.18-0.66), higher level of education of mother $(\mathrm{OR}=0.51,95 \% \mathrm{Cl}: 0.27-0.97)$ and low income $(\mathrm{OR}=2.22,95 \% \mathrm{Cl}: 1.17-4.22)$ were associated significantly $(\mathrm{p}<0.05)$ with the compliance to postpartum family planning whereas knowledge, attitudes, and myths on family planning were not associated significantly with postpartum family planning in both settings. The associations did not show significant differences between urban and rural settings.

Conclusions and Recommendations: Postpartum family planning was satisfactory in both settings. The compliance to it was significantly associated with several socio-demographic and health service-related factors. It is recommended to focus on family planning counselling at the place of delivery.

Key words: postpartum family planning, family planning, contraception.

\title{
OP-44
}

Knowledge, attitudes, practices regarding breast, cervical and thyroid cancer screening and associated factors of utilization of Well Woman Clinic services in the Moratuwa Medical Officer of Health area

\author{
Vijaya Kumari Radhakrishnan ${ }^{1} *$ Loshan Moonesinghe $^{2}$ \\ ${ }^{1}$ Postgraduate Institute of Medicine, MSc Community Medicine; ${ }^{2}$ Family Health Bureau, Ministry of Health
}

vjayardh3@yahoo.com

Background: Breast, cervical, and thyroid cancer are the most common types of cancers seen among women in Sri Lanka. Knowledge, attitudes, and practices (KAP) of screening of these cancers are important factors in determining the utilization of the Well Woman Clinic (WWC) services in Sri Lanka especially among the target age groups of 35 and 45 years.

Aims: The purpose of this study was to assess the knowledge, attitudes, and practices of the breast, cervical, and thyroid cancer screening and factors associated with utilization of the Well Women Clinic services among women aged 35 and 45 years.

Methods: A community-based descriptive cross-sectional study was conducted among 423 females of the 35 year age cohort (35C) and 45 year age cohort $(45 \mathrm{C})$ in the Eligible Family Register, using simple random sampling according to the proportions in the $35(n=275,65 \%)$ and $45(n=148,35 \%)$ year age cohort at the Moratuwa Medical Officer of Health area, from March 2019 to January 2020. A pre-tested, interviewer administered questionnaires were used to collect data. Results were analyzed using a scoring system with SPSS 23 . Associations were carried out using Chi-square test with significance level at $\mathrm{p}=0.05$. 
Results: Majority of the participants were Sinhalese (35C:96.7\%; 45C:98.6\%), and Buddhist (35C:86.5\%; 45C:79.7\%). The majority of the study population had poor knowledge on breast (35C:68\%; 45C:81.1\%), cervical (35C:95\%; 45C:100\%), and thyroid gland (35C:84\% and 45C:100\%) cancer screening. Although the majority of the study population had poor practice on breast (35C:54.5\%: 45C:66.2\%) and thyroid cancer screening (35C:77.8\%; 45C:84.5\%) there was good practice on cervical Pap smear screening (35C:68\%; 45C:61.5\%). The majority had poor knowledge-seeking behaviour of all three cancers (35C:68.7\%; 45C:73.6\%). There was a statistically significant association between knowledge on breast cancer screening and WWC attendance among 35 year age cohort $(p<0.001)$.

Conclusions and Recommendations: The study concluded that awareness about common cancers affecting women in Sri Lanka was poor among the study population. Therefore, it is imperative to raise awareness among women in the target age group about breast, cervical, and thyroid cancer screening and the services provided at the Well Woman Clinics.

Key words: breast cancer, cervical cancer, thyroid gland cancer, Well Woman Clinic, knowledge, attitude, practice, Pap test.

\section{OP-45}

\section{Knowledge on family planning and use of contraceptives among women working in Avissawella Export Processing Zone}

\section{Saman Pathirana ${ }^{{ }^{*}}$, Arunasalam Pathmeswaran ${ }^{2}$, Kapila Jayaratne $^{3}$}

${ }^{1}$ district General Hospital, Gampaha; ${ }^{2}$ Department of Public Health, Faculty of Medicine, University of Kelaniiya; ${ }^{3}$ Family Health Bureau, Ministry of Health

samanpathiranad@gmail.com

Background: Women working in export processing zones (EPZs) are reported to have risky sexual behaviors leading to unwanted pregnancies which are associated with high maternal morbidity, mortality and many psychosocial issues.

Objective: The purpose of this study was to describe the level of knowledge on family planning (FP) and estimate the prevalence of contraceptive use among reproductive-age women workers of Avissawella EPZ.

Methods: A descriptive cross-sectional study was conducted to assess knowledge on FP and use of contraceptives among 515 unmarried and 515 married women selected by stratified random sampling from factories in Avissawella EPZ. Pretested, self-administered questionnaire was used for data collection. Statistical associations were assessed by chi-square test.

Results: Forty two per cent ( $\mathrm{Cl}$ 37.7- 46.3) of married and 7\% ( $\mathrm{Cl} 4.8$-9.3) of unmarried women had "satisfactory overall knowledge" on family planning. Knowledge on condoms was reported by the majority $(64.2 \%, n=317)$ of married and $18 \%(n=92)$ of unmarried women. A significantly higher knowledge was observed among married women $(\mathrm{OR}=8.3 ; \mathrm{Cl}=5.5-12.5)$, who were over 35years $(\mathrm{OR}=2.2 ; \mathrm{Cl}=1.5-3.3)$, having passed $\mathrm{GCE}(\mathrm{O} / \mathrm{L})$ examination $(\mathrm{OR}=1.7 ; \mathrm{Cl}=1.2-2.4)$, residing with family members $(\mathrm{OR}=1.7 ; \mathrm{Cl}=1.1-2.5)$ and having a monthly income of more than SLR. 30,000 $(\mathrm{OR}=2.2 ; \mathrm{Cl}=1.2-4.0)$. Contraceptive prevalence rate $(\mathrm{CPR})$ for married women for any method and any modern method were $47.8 \%$ ( $\mathrm{Cl} 43.4 \%-52.2 \%)$ and $40.9 \%(\mathrm{Cl} 36.6 \%-45.2 \%)$ respectively. Oral contraceptive pill $(11 \%, n=53)$, intrauterine device $(8 \%, n=38)$ and injectable $(6 \%, n=31)$ were the most commonly used methods by married women. Having "satisfactory overall knowledge" on $\mathrm{FP}(\mathrm{OR}=2.6 ; \mathrm{Cl}=1.7$ $3.9)$, age below 35 years $(\mathrm{OR}=2.2 ; \mathrm{Cl}=1.3-3.9)$ and having two or more children $(\mathrm{OR}=2.7 ; \mathrm{Cl}=1.6-4.5)$ were 
Silver Jubilee Special Issue

independently associated with higher CPR. Prevalence of unmet need for any modern contraceptive method among married women was $41.9 \%$ (95\% Cl: $37.6 \%$ - $46.3 \%)$.

Conclusions \& Recommendations: Knowledge on FP and use of contraceptives were low among women of Avissawella EPZ. Further studies to identify effective interventions to improve knowledge and use of FP are recommended.

Key words: knowledge, family planning, working women, export processing zones 
FREE PAPER SESSION 10 - ELDERLY HEALTH AND WELLBEING

CHAIRPERSONS: DR. AINDRALAL BALASURIYA, DR. SHIROMI MADUWAGE

17.09.2020 / 2.00PM TO 3.00 PM / HALL B

\title{
OP-46
}

Patterns, related conditions of unintentional home injuries and selected factors associated with its severity among elderly in the Medical Officer of Health area Battaramulla

\author{
Samantha Ananda ${ }^{{ }^{*}}$, Vindya Kumarapeli ${ }^{1}$ \\ ${ }^{1}$ Ministry of Health in Indigenous Medical Services \\ *samanthaananda@yahoo.com
}

Background: Unintentional home injuries among elderly people represent an emerging public health concern with the increase of the elderly population in Sri Lanka. These worsen the quality of life of elderly and are associated with a high social and economic burden.

Objective: To describe patterns, related medical and environmental conditions of unintentional home injuries, knowledge and perceptions on prevention and selected factors associated with its severity among elderly in Battaramulla Medical Officer of Health $(\mathrm{MOH})$ area.

Methods: A community-based descriptive cross-sectional study was carried out among elderly (age 60 years and above) residing in Battaramulla $\mathrm{MOH}$ area. Five hundred and ten elders experiencing at least one injury within the past three months were recruited using probability proportionate to population size cluster sampling technique. Data were collected through pre-tested interviewer administered questionnaire (IAQ) and an observatory check list of environmental factors. The socio-demographic characteristics, types and circumstances of injuries, environmental conditions, treatment seeking, functional health status, medical conditions, disability, knowledge and perception on prevention of unintentional home injuries were recorded. Data were analyzed using SPSS 21 and associations were explored with Chi squared test at $5 \%$ significance level.

Results: Response rate was 93.3\% ( $n=476)$. Most common types were: falls $(62.8 \%, n=299)$, cuts $(11.6 \%, n=55)$ and strike against an object $(10.1 \%, \mathrm{n}=48)$. Most common places of injury: kitchen $(26.1 \%, \mathrm{n}=124)$ garden $(22.3 \%$, $\mathrm{n}=106)$ and bathroom/toilet $(10.1 \%, \mathrm{n}=48)$. Slippery floor was the most common environmental factor for falls $(39.5 \%, n=188)$ followed by stairs $(9.7 \%, n=46)$ and poor lighting conditions $(9.7 \%, n=46)$. Majority of the participants had no limitation on activities of daily living. One third of participants $(33.4 \%, n=159)$ had experienced moderate to severe injuries. There were statistically significant associations between the moderate to severe injuries and being a male $(37.7 \%, n=97)$, being unmarried $(51.4 \%, n=38)$, unavailability of a companion at time of injury $(26.7 \%, n=20)$, day time of occurrence $(34.9 \%, n=140)$, having visual or hearing defects $(25.2 \%$, $n=31)(p<0.05)$. Participants with favourable perception on injury prevention had significantly less moderate to severe injuries compared to those with unfavourable perceptions $(p<0.05)$.

Conclusion and Recommendations: Common characteristics and circumstances of unintentional home injuries were identified. When considering the increase in the elderly population, home injury prevention and awareness strategies should be established and implemented.

Key words: unintentional home injuries, elderly, injury severity 


\title{
Poly-pharmacy, medication adherence and associated factors among elderly patients in National Hospital of Sri Lanka
}

\author{
Thathsara Weerathunge ${ }^{1 *}$, Thilanga Ruwanpathirana ${ }^{2}$ \\ ${ }^{1}$ Postgraduate Institute of Medicine, University of Colombo; ${ }^{2}$ Epidemiology Unit, Ministry of Health \\ *thathsaraweerathunge@gmail.com
}

Background: With the observed increase in elderly living with multi-morbidity, global trend of poly-pharmacy is on the rise. Medication non-adherence is considered a common consequence of poly-pharmacy, especially among the elderly.

Objective: To describe poly-pharmacy, medication adherence and associated factors among elderly patients attending general medical clinics in the National Hospital of Sri Lanka (NHSL)

Methods: A descriptive cross-sectional study was conducted among elderly patients attending general medical clinics of NHSL, in August 2019. A pretested, interviewer-administered questionnaire was given to 426 participants selected by systematic random sampling. Polypharmacy was defined as the daily use of five or more medications. Medication adherence was measured by an adapted Medication Adherence Questionnaire. Descriptive statistics, Chi-square test and multivariate logistic regression were used in the analysis. Results interpreted at $95 \%$ confidence interval.

Results: The majority of the study sample was female (54\%, $n=230)$, married $(77.7 \%, n=331)$ and aged between $65-70$ years $(61.5 \%, n=262)$ with $29.6 \%$ ( $n=108)$ of them currently employed. Poly-pharmacy was $81.75 \%(n=348)$, while $24.2 \%$ ( $n=103$ ) of the participants had extreme poly-pharmacy. The mean number of medications used by a patient (SD) was 8.41 (3.17). Odds of poly-pharmacy were high with multi-morbidity (OR=6.57, 95\%Cl: 3.79 11.38), including ischemic heart disease $(\mathrm{OR}=4.25,95 \% \mathrm{Cl}: 2.45-7.39)$, diabetes mellitus (OR=2.58, $95 \% \mathrm{Cl}: 1.54$ 4.31), and hypertension ( $\mathrm{OR}=1.99,95 \% \mathrm{Cl}$ : 1.17-3.39). Single status, unemployment, and moderate-income increased the likelihood of extreme poly-pharmacy along with multi-morbidity. Extreme poly-pharmacy was associated with constipation, insomnia, and loss of appetite. A majority of participants $(63.4 \%, n=270)$ were adherent to medication. Unintentional and purposeful non-adherence were $28.4 \%(n=121)$ and $4.0 \%(n=17)$ respectively. Medication adherence reduced with delays in drug intake $(\mathrm{OR}=0.36,95 \% \mathrm{Cl}: 0.23-0.55)$, beliefs on organ damage ( $\mathrm{OR}=0.49,95 \% \mathrm{Cl}: 0.31-0.75)$, poor accessibility to drugs ( $\mathrm{OR}=0.36,95 \% \mathrm{Cl}: 0.23-0.55)$, and diseaserelated factors as regurgitation ( $O R=0.27,95 \% \mathrm{Cl}: 0.10-0.74)$. Increased odds were observed with the necessity $(O R=2.56)$, effectiveness ( $O R=2.29)$ and the identification of drugs $(O R=1.59)$.

Conclusions \& Recommendations: Poly-pharmacy was high among the elderly and was associated with multimorbidity. Despite negative connotations, poly-pharmacy neither decreased medication adherence nor was associated with its consequences except at extreme poly-pharmacy. The multi-disciplinary approach in developing a combined management plan would reduce poly-pharmacy while improving health literacy would increase medication adherence among the participants.

Key words: elderly, polypharmacy, extreme polypharmacy, medication adherence 
OP-48

\title{
Status of under-nutrition and associated factors among the elderly in Colombo district
}

\section{Samantha Vijewardane ${ }^{1^{*}}$, Aindralal Balasuriya ${ }^{2}$}

Nutrition Division, Ministry of Health; Department of Public Health and Family Medicine, Sir John Kotelawala Defence University

*samanthachampika@gmail.com

Background: Under-nutrition is a global and local challenge as a major contributor to morbidity and mortality among the elderly. Health and economic burden due to under-nutrition are public health concerns. The cut-off age for the elderly was taken as 60 years.

Objectives: To describe the status of under-nutrition and associated factors among the elderly in Colombo district

Methods: A community based descriptive cross sectional study was conducted among 800 elderly, recruited through multistage cluster sampling, using probability proportionate to size technique. Pre-tested interviewer administered questionnaire and, anthropometric measurements (Body Mass Index (BMI) and Mid Upper Arm Circumference (MUAC)) and body composition measurements (body fat percentage and body muscle percentage) were used to collect data. Defined criteria composed of anthropometric and body composition measurements was used to categorize the elderly as undernourished. Probability level of 0.05 was taken as the significant level. Bivariate analysis followed by logistic regression was conducted to find significantly associated factors of under-nutrition after adjusting for confounders. Data analysis was conducted using SPSS version 22.

Results: According to $\mathrm{BMI}, 8 \%$ ( $n=64,95 \% \mathrm{Cl}: 5.8 \%-0.2 \%$ ) of the elderly were undernourished. According to MUAC, it was $4.1 \%$ ( $n=33,95 \% \mathrm{Cl}: 0.22 \%-7.98 \%)$. Only $1.9 \%$ ( $n=14,95 \% \mathrm{Cl}: 0.9 \%-2.8 \%)$ of the elderly were undernourished according to body fat percentage and it was $28.8 \%$ ( $n=230,95 \% \mathrm{Cl}: 24.6 \%-31.7 \%$ ) according to body muscle percentage. When considering all the above criteria, $35.3 \%(n=282,95 \% \mathrm{Cl}: 31.8 \%-38.7 \%)$ were undernourished. After adjusting for confounders, the factors significantly associated with under-nutrition were, female sex (adjusted odds ratio $(\mathrm{aOR})=8.6,95 \% \mathrm{Cl}: 5.2-14.09$ ), not having a monthly income (aOR=1.51, 95\% Cl: 1.06-2.14) and little or no responsibility on food shopping ( $\mathrm{aOR}=1.89,95 \% \mathrm{Cl}: 1.3-2.73$ ).

Conclusions and Recommendations: Relevant stakeholders should be made aware of the consequences of under-nutrition to formulate preventive strategies. It is recommended to have a composite criterion to measure under-nutrition among community elderly as there is no accepted criterion at the moment. Financial assistance or insurance schemes should be introduced by mediating through the government.

Key words: elderly, under-nutrition, associated factors, anthropometric measurements, body composition measurements

\section{OP-49}

Health related problems and factors associated with health-seeking behaviour among the elders in Colombo district

\author{
Nishani Fonseka ${ }^{1^{*}}$, Aindralal Balasuriya $^{2}$ \\ ${ }^{1}$ Family Health Bureau, Ministry of Health, Sri Lanka: ${ }^{2}$ Department of Community Medicine, General Sir John Kotelawala Defence \\ University, Sri Lanka \\ *fony_14@yahoo.co.in
}


Background: Sri Lanka is one of the fastest ageing countries in the world. The old age illnesses are expected to rise and the ageing population will increasingly put huge pressure on the health system. Determining the health related problems and health-seeking behaviour among elders are vital in the provision of need-based health care services. In Sri Lanka, age 60 years and above is considered as an elderly.

Objectives: To describe the health related problems, health seeking behaviour and factors associated with health seeking behaviour among elders in Colombo district

Methods: Community based cross sectional descriptive study was carried to describe self-reported health related problems and health seeking behaviour among 793 elders, selected by multi-stage, stratified, probability proportionate to size method. An interviewer administered questionnaire was used to collect data and Chisquare test was used to find a significant association between two categorical variables. Simultaneously in the same study sample, a cross sectional analytical study was carried out to identify the factors associated with health seeking behaviour of the elders, expressed as Odds Ratios.

Results: The response rate was $96.3 \%$ ( $n=764)$. Prevalence of having at least one chronic disease in the study population was $91.2 \%$ (95\% Cl: 87.1-93.2). Most prevalent chronic illness was hypertension $44.2 \%$ (95\% Cl: 40.647.7), followed by diabetes $34.3 \%$ ( $95 \% \mathrm{Cl}$ : 31.0-37.7), heart disease $10.1 \%(95 \% \mathrm{Cl}: 7.9-12.2)$ and arthritis $7.6 \%$ (95\% Cl: 5.7-9.4). Only $40.4 \%$ ( $n=282$ ) attended the clinic regularly for chronic illnesses. The majority $(n=594,89 \%)$ of those having chronic illnesses visited government hospitals. Those who belonged to civil status other than married ( $A O R=2.9 ; 95 \% \mathrm{Cl}=1.4-5.9$ ), rural by sector of residence ( $\mathrm{AOR}=9.8 ; 95 \% \mathrm{Cl}=5.7-16.6$ ), those who cannot seek treatment by themselves ( $A O R=7.4 ; 95 \% \mathrm{Cl}=3.0-18.2$ ) and diagnosed with more than one chronic disease condition (AOR=4.7; 95\% Cl=1.7-12.5) were significantly associated with inappropriate health seeking behaviour after adjusting for confounders.

Conclusions and Recommendations: Prevalence of chronic illness among elders is alarmingly high with majority of the elders not attending clinics regularly. The rural sector should be given higher propriety in resource allocation related to the strengthening of the primary health care system.

Key words: elderly, health related problems, health seeking behaviour

\title{
OP-50
}

Menopause Specific Quality of Life and associated factors among post-menopausal women in Kalutara district, Sri Lanka

\author{
Chithramali Hasanthika Rodrigo ${ }^{1 *}$, Ruwan Ferdinando ${ }^{2}$, Rohini de Alwis Seneviratne ${ }^{3}$ \\ ${ }^{1}$ Ministry of Health and Indigenous Medical Services, ${ }^{2}$ National Institute of Health Sciences, Kalutara, ${ }^{3}$ Faculty of Medicine, \\ General Sir John Kotelawala Defence University \\ *mal_has@yahoo.com
}

Background: Menstruation permanently stops during menopause. The declining ovarian hormone levels cause distressing menopausal symptoms. Menopause specific quality of life is assessed based on the distress caused by menopausal symptoms.

Objective: To describe menopause specific quality of life and correlates among post-menopausal women aged 45-55 years in Kalutara district, Sri Lanka.

Methods: A community based cross sectional study was conducted in Kalutara district among 756 postmenopausal women aged 45-55 years using multistage stratified cluster sampling. Data were collected using a structured questionnaire on socio-demographic, reproductive, lifestyle characteristics and the menopause specific quality of life questionnaire validated for Sri Lanka (MENQOL-S). There was no predefined cut-off 
MENQOL score and participants were categorized as 'good'/'poor' based on median since the data were not normally distributed. Binary multiple logistic regression identified independent predictors of menopause specific quality of life.

Results: Mean age of participants was 52.1 years ( $S D=2.2$, median 52$)$. Mean age at menopause was 48.7 years ( $S D=2.8$, median 49). Among participants, 84.7\% $(n=640)$ were married, 51.6\% $(n=390)$ had an educational level above ordinary Level while $66.4 \%(n=502)$ were unemployed and $80.9 \%(n=612)$ were of Sinhala ethnicity. Of them $96.8 \%$ reported at least one menopausal symptom and mean MENQOL-S score was 70.2 (SD=31.7, median $65)$. Out of the participants $63.8 \%(n=483)$ had 'poor' menopause specific quality of life. Sinhala ethnicity (adjusted $\mathrm{OR}=6.891,95 \% \mathrm{Cl}=4.756$ to 9.985 ), history of premenstrual syndrome (adjusted $\mathrm{OR}=2.893$, $95 \% \mathrm{Cl}=1.750-4.782$ ), poor perceived health status (adjusted $\mathrm{OR}=3.670,95 \% \mathrm{Cl}=1.695-7.946$ ) and having $\mathrm{BMI}>25$ $\mathrm{kgm}^{-2}$ (adjusted OR=1.77, 95\%Cl=1.094-2.865) were significant correlates of poor menopause specific quality of life.

Conclusions and Recommendations: Majority of menopausal women aged 45-55 years in Kalutara district had 'poor' menopause specific quality of life. Impact of menopause on quality of life and health, should be considered when developing policies and planning healthcare programmes for women in this age group.

Key words: post reproductive health, quality of life, menopause 


\title{
FREE PAPER SESSIONS 11 - ENVIRONMENTAL AND OCCUPATIONAL HEALTH \\ CHAIRPERSONS: DR. S.M. ARNOLD, DR. SAVEEN SEMAGE \\ 18.09.2020 / 2.00 PM TO 3.00 PM / HALL A
}

\section{OP-51}

Self-reported occupational safety practices, the awareness and its associated factors on occupational hazards and safety practices among medical laboratory technologists in Colombo district

\author{
Bhumini Karunarathna ${ }^{{ }^{*}}$, Manuj Weerasinghe $^{2}$ \\ ${ }^{1}$ Ministry of Health and Indigenous Medical Services, Sri Lanka; ${ }^{2}$ Department of Community Medicine, Faculty of Medicine, \\ University of Colombo, Sri Lanka \\ *bhumini_janani@yahoo.com
}

Background: Medical laboratory technologists (MLTs) are at risk of numerous occupational hazards. Hence their awareness of occupational health and safety is of utmost importance.

Objective: To describe the self-reported occupational safety practices and to assess the level of awareness and its associated factors on occupational hazards and safety practices among MLTs working in government tertiary care health institutions in Colombo District

Methods: A census was carried out recruiting all eligible MLTs $(n=358)$ currently employed during the data collection period in all the government tertiary care health institutions in Colombo district. A pretested selfadministered questionnaire, consisting questions on knowledge, attitudes and practices of occupational health and safety, was used to collect data. Associates of the awareness level were determined using the odds ratio and the chi-square test placing the significance level at 0.05 . Ethical clearance for the study was obtained.

Results: Response rate was $91.1 \%(n=326)$. The majority of the respondents $(57.4 \%, n=187)$ had satisfactory level awareness of occupational hazards and safety practices. Association between the awareness level and the sociodemographic characteristics was not statistically significant ( $p>0.05$ ). Of the occupation-related factors, only the experience of the respondents at the current station and the number of training sessions they had participated revealed statistically significant associations with the awareness level ( $p=0.047$ and $p=0.039$ respectively). The majority of the respondents had reported that they always or frequently follow standard precautions $(79.8 \%$, $n=260)$, wear laboratory coat $(89.2 \%, n=291)$, wear gloves $(97.3 \%, n=317)$, wash hands properly $(93.6 \%, n=305$ \& $98.1 \%, n=320$ before and after each procedure respectively), and apply first-aid after occupational injuries $(98.7 \%, n=322)$. However, a sizable proportion $(21.8 \%, n=71)$ had reported that they never record occupational injuries. The majority $(68.4 \%, \mathrm{n}=223)$ had perceived, "heavy workload" as a barrier for better practice of occupational safety.

Conclusions \& Recommendations: The majority had satisfactory level awareness of occupational hazards and safety practices. Although the majority of the participants had reported good laboratory safety practices, record maintenance on occupational injuries within the laboratories was inadequate. Therefore, occupational safety and health of the MLTs should be prioritized, further strengthened and regularly monitored at the institutional level.

Key words: Medical Laboratory Technologists, awareness, occupational hazards, occupational safety practices 
Knowledge, attitudes and practices on dengue and dengue control and the factors associated with the utilization of Dengue School Card

\section{TD Bandara ${ }^{1 *}$, M Cader $^{2}$, DSAF Dheerasinghe ${ }^{3}$}

${ }^{1}$ National Dengue Control Unit; ${ }^{2}$ National Programme for Tuberculosis Control and Chest Diseases; ${ }^{3}$ Office of the Provincial Director of Health Services -Western Province

*thilankaattidiya@gmail.com

Background: Surveillance data shows that nearly $30 \%$ of dengue patients are of school-going age. Abundance of breeding places in schools puts students at higher risk. Interventions were done in schools to improve the knowledge, attitudes, and practices on Dengue in order to empower schoolchildren on prevention and control of Dengue.

Objective: The objective of the study was to describe the knowledge, attitudes and practices on dengue and dengue control, and to describe the factors associated with the utilization of Dengue School Card (DSC) among grade 9 students in government schools in Horana Education Zone of the district of Kalutara.

Methods: A descriptive cross-sectional study was conducted among 782 grade 9 students in the selected Zone. The calculated sample size (768) was selected using a multi-stage cluster-sampling technique. A pretested selfadministered questionnaire was used to collect information on the knowledge, attitudes and practices on dengue and dengue control, and to describe the factors associated with the utilization of DSC. The analysis was done using frequencies and the Chi-square test.

Results: The majority $(85.7 \%, \mathrm{n}=670)$ of the schoolchildren demonstrated adequate knowledge on Dengue and its control. Further, the overall attitude on Dengue control in relation to the burden, human behaviour and source reduction was good among $85.7 \%(n=670)$ of the participants. Overall reported practice was good among $86.2 \%$ ( $n=674$ ) with a good understanding of the dynamics of Dengue mosquito vectors. There is a statistically significant association between the utilization of the DSC and being a student of Type $2 \mathrm{school}(\mathrm{p}=0.003)$, the level of knowledge $(p<0.001)$ and the reported current practice on dengue and dengue control $(p=0.003)$.

Conclusions and Recommendations: Grade 9 government school children in Horana Educational Zone had adequate knowledge on Dengue and Dengue control, good attitude towards Dengue control, and good reported practices on prevention and control of Dengue. The utilization of the DSC was associated with being a student of a Type 2 school, good levels of knowledge and reported practice on dengue control. Continuous improvement of knowledge and practice and adaptation of good practices among schools would lead to a better behavioural outcome on prevention and control of Dengue.

Key words: dengue, knowledge attitudes and practices, utilization of Dengue School Card, associations

\section{OP-53}

Compassion fatigue and self-care among nursing officers working at the National Cancer Institute of Sri Lanka

\section{Chathurika Herath ${ }^{1^{*}}$, Anoma Basnayake ${ }^{2}$}

${ }^{1}$ Postgraduate Institute of Medicine, University of Colombo; ${ }^{2}$ Nutrition Division, Ministry of Health and Indigenous Medical Services

*chathurika_herath@hotmail.com 
Background: Cancer related deaths are one of the commonest in-hospital deaths in Sri Lanka. Nursing officers working at the National Cancer Institute of Sri Lanka are continuously exposed to patients' suffering and deaths. Compassion fatigue describes the negative psychosocial effects of such exposure. It has two components: burnout and secondary traumatic stress. Practicing self-care has been shown to mitigate its effects. However, studies on oncology nursing officers' burnout and secondary traumatic stress levels and associated self-care practices are scarce.

Objectives: to determine the prevalence of compassion fatigue in terms of burnout and secondary traumatic stress and associated practice of self-care among nursing officers working at the National Cancer Institute.

Methods: A descriptive cross-sectional study was performed among nursing officers directly involved in patient care, with more than 6 months' work experience at the National Cancer Institute. All eligible nursing officers ( $n=$ $445)$ were invited to participate, and the response rate was $95.7 \%(n=426)$. Prevalence of burnout and secondary traumatic stress levels were assessed using the Professional Quality of Life Scale (Version 5). Self-care practices were assessed by the self-care assessment questionnaire. Descriptive statistics, chi-square test of significance and correlation were used in data analysis.

Results: Participants were predominantly female $(93 \%, n=396)$ and their mean age (SD) was $30.8(6.78)$ years. Majority $(78.9 \%, n=336)$ had worked for less than 5 years at National Cancer Institute. They had low $(47.2 \%, n=$ $200)$ to average $(52.8 \%, n=224)$ burnout; and low $(36.6 \%, n=155)$ to average $(63.4 \%, n=269)$ secondary traumatic stress. Five domains of self-care i.e. physical, psychological, emotional, spiritual and professional were significantly associated $(p<0.05)$ with burnout, while secondary traumatic stress was associated only with psychological self-care among study sample and physical self-care among unmarried/widowed participants. Burnout and secondary traumatic stress correlated positively with each other $(r=0.520, p<0.001)$.

Conclusion and Recommendations: The nursing officers had low to moderate burnout and secondary traumatic stress. No participant had high levels of burnout or secondary traumatic stress. However, there is a need for interventions to further reduce burnout and secondary traumatic stress through improvement of self-care among the study population.

Key words: compassion fatigue, burnout, secondary traumatic stress, self-care, oncology nurses

\title{
OP-54
}

Work related factors associated with the level of positive mental health among medical officers in teaching hospital, Kandy

\author{
PTS Prasanga $^{1^{*}}$, Wasantha Gunathunga ${ }^{2}$ \\ ${ }^{1}$ Postgraduate Institute of Medicine, University of Colombo; ${ }^{2}$ Department of Community Medicine, Faculty of Medicine, \\ University of Colombo \\ *ptsprasanga@gmail.com
}

Background: Positive mental health is the presence of emotional, psychological and social well-being. When an individual is experiencing positive emotions and functioning well, both psychologically and socially, it is called flourished level of positive mental health while feeling empty and stagnant is called languished level. Working environment affects the mental health of workers in many ways. Promoting positive mental health among medical officers in work setting can result in improvement of job satisfaction and more importantly the quality of patient care. 
Objective: To determine the work-related factors associated with the level of positive mental health among medical officers in Teaching Hospital, Kandy

Methods: A descriptive cross sectional study was conducted among medical officers employed in Teaching Hospital Kandy. A pretested self-administered questionnaire was administered among randomly selected 427 medical officers. Judgmentally validated Mental Health Continuum short form (MHC-SF) was used to assess the level of positive mental health. The burnout of the medical officers was assessed using the abbreviated Maslach Burnout Inventory (aMBI). The level of positive mental health was categorized as Flourished, Moderate and Languished, and the associations with work related factors were investigated using chi square statistic and correlation coefficient at the $p=.05$ level of significance.

Results: Among 369 respondents (response rate $=86.4 \%), 35.8 \%(n=132)$ were flourished and $10.6 \%(n=39)$ were languished, while the majority $(n=198,53.7 \%)$ were having a moderate level of positive mental health. There was a significant association between the level of positive mental health and the different units they are attached to ( $p$ $=0.027$ ). Medical officers who claimed that their workload was moderate $(p=0.005)$ and their working environment was good ( $p<0.001$ ), were significantly flourished. The total burnout score and the total positive mental health score were negatively correlated, and the association was significant. $(r(d f=367)-0.37, p<0.001)$.

Conclusions and Recommendations: The working unit, work load and the working environment were factors affecting the positive mental health of medical officers and the level of burnout was significantly associated with the level of positive mental health. When planning mental health promotion programs for medical officers the findings can be used in prioritization.

Key words: Positive mental health, Medical officers, workplace

\section{OP-55}

This abstract was not presented in the conference, hence removed. 
This abstract was not presented in the conference, hence removed. 
FREE PAPER SESSIONS 12 - ADOLESCENT HEALTH

CHAIRPERSON: DR.CHIRANTHIKA VITHANA, PROF. ANURADHANI KASTURIRATNE

18.09.2020 / 2.00 PM TO 3.00 PM / HALL B

\title{
OP-56
}

Risk factors for upper limb fractures among adolescents attending selected government hospitals in the Colombo district

\author{
Hemali Jayasekera ${ }^{1^{*}}$, Samitha Siritunga ${ }^{2}$, Upul Senarath \\ ${ }^{1}$ Family Health Bureau, Ministry of Health, ${ }^{2}$ Non Communicable Disease unit, Ministry of Health, ${ }^{3}$ Department of \\ Community Medicine, Faculty of Medicine, University of Colombo \\ "hemalisenatilleke@gmail.com
}

Background: Injuries are the number one cause for morbidity and mortality among adolescents. Adolescent fractures are a hidden public health problem in Sri Lanka. Injury to upper limb can cause disruption of all domains of wellbeing of the adolescent. Risk factors for upper limb fractures are common in the present era, however, research in this regard is few and far between in Sri Lanka.

Objective: To determine the risk factors for upper limb fractures among adolescents aged 10 to 19 years attending selected government hospitals in the Colombo district

Methods: A case control study was carried out among 450 cases who were newly diagnosed adolescent victims with upper limb fractures treated at Lady Ridgeway Hospital for Children, National Hospital Sri Lanka, Colombo South Teaching Hospital and three Base Hospitals at Homagama, Awissawella and Mulleriyawa. Cases were matched with controls with their sociodemographic background. Cases were recruited consecutively excluding victims with road traffic crashes and 450 controls were selected purposively from apparently healthy adolescents from the community. An interviewer administered questionnaire was used to collect data. Bivariate analysis followed by logistic regression analysis identified the risk factors for fractures adjusted for confounding effect.

Results: Multivariate analysis revealed that equal or less than 14 years of age $(\mathrm{OR}=2.02,95 \% \mathrm{Cl}=1.7-2.71)$, being a male adolescent ( $\mathrm{OR}=3.89,95 \% \mathrm{Cl}=2.87-5.29)$, one of the parents are employed ( $\mathrm{OR}=3.1 ; 95 \% \mathrm{Cl}=1.21-7.91)$, high social class category (social class I \& II) $(\mathrm{OR}=2.58,95 \% \mathrm{Cl}=1.7-3.92)$ and low monthly income status (monthly income less than $30,000 \mathrm{SLR})(\mathrm{OR}=0.12,95 \% \mathrm{Cl}=0.35-0.39)$ were independently associated with having a upper limb fracture among adolescents. Further, multivariate analysis revealed that engaged in sports or physical activity in mild to moderate intensity $(\mathrm{OR}=1.48 ; 95 \% \mathrm{Cl}=1.11-1.96)$ and physical activity with heavy intensity $(\mathrm{OR}=$ 9.36; $95 \% \mathrm{Cl}=3.31-26.47)$, watching television during weekdays $(\mathrm{OR}=1.95 ; 95 \% \mathrm{Cl}=1.18-3.22)$, playing video games on weekends $(\mathrm{OR}=2.35 ; 95 \% \mathrm{Cl}=1.7-3.24)$ and exposure to violence $(\mathrm{OR}=13.3 ; 95 \% \mathrm{Cl}=4.75-37.25)$ were independently associated with having a upper limb fracture among adolescents. In the risk prediction model, few significant effect modifications between having a sibling and attending extra classes $(p=0.01)$, having a sibling and playing video games $(p<0.001)$, having high standard of living and watching television on weekends $(p<0.001)$ were observed.

Conclusions \& Recommendations: Risk factors specific for adolescent fractures were mainly individual and lifestyle related factors. Policy makers need to make important decisions to prevent such injuries utilizing the individual and lifestyle related risk factors uncovered. A comprehensive preventive, curative and promotive care should thus be implemented.

Key words: adolescents, injuries, upper limb fractures, riskfactors 


\section{OP-57}

Levels of aggression, its patterns and associated factors among school going adolescents of grade-10, in the Negombo Educational Division.

Dhivya Nathanie $1^{{ }^{*}}$, Chiranthika Vithana ${ }^{2}$

${ }^{1}$ Postgraduate Institute of Medicine, University of Colombo; ${ }^{2}$ Adolescent Health Unit, Family Health Bureau, Ministry of Health

*dhivs18@gmail.com

Background: Adolescence is the transition from childhood to adulthood where mental, behavioural and physical changes can have a detrimental influence on adolescents to display increasingly aggressive behaviour.

Objective: To assess the levels, patterns and associated factors of aggression among school-going adolescents of Grade 10 in the Negombo Educational Division.

Methods: A school-based descriptive cross-sectional study was conducted among 640 Grade 10 students from schools within the Negombo Educational Division using clusters selected proportionate to size of the student population. Pre-tested self-administered questionnaire consisting of the globally used Buss and Perry Aggression Questionnaire (BPAQ), and a questionnaire on associated factors were used. The BPAQ has been validated for use in several countries. Scoring system was developed. Cut-off score for aggression was identified using Receiver Operating Characteristic in a separate sample. Analysis was conducted using SPSS21. Associations were identified using chi-square test and fishers test for categorical data and independent two sample t-test for quantitative data with significance level at 0.05 .

Results: Majority participants were 15 years old $(67.7 \%, n=433)$, female $(53.0 \%, n=339)$, Sinhalese $(81.7 \%, n=523)$ and Catholic (55.2\%, $n=353)$. Mean score (SD) for aggression was 82.8 (14.1). Levels of high aggression with score $>92$ was found in $27.2 \%$ ( $n=175)$. High level of aggression was more among females compared to males $(p<0.001)$. Physical aggression was more in males $(p=0.002)$ while anger and hostility were more in females $(p<0.001)$. There were no significant differences by sex for verbal aggression. Internet use, having trouble sleeping, often feeling lonely, consumption of alcohol in the past 30 days, distant relationship with siblings, punishment by parents, parental abuse towards partner, inadequate parental time spent with participant, being made fun of and being bullied, and presence of people in participant's neighbourhood that may hurt them or their family were significantly associated with high level of aggression $(p<0.05)$.

Conclusions \& Recommendations: Prevalence of high aggression was $27.3 \%$ with females having higher figure than males. Several factors were associated with high aggression. One of the limitations was the BPAQ had not been validated in Sri-Lanka previously. Study recommends focusing on interventions targeting good parenting, developing life skills and teacher training on psychosocial health and counselling.

Key words: Aggression, Adolescents, Aggression questionnaire

OP -58

Prevalence and correlates of interpersonal violence among Sri Lankan adolescents: Results from the 2016 Sri Lankan Global School-based Health Survey

Aruni Gallage ${ }^{1^{*}}$, Sashimali Wickramasinghe ${ }^{2}$, Shanthi Gunawardena ${ }^{2}$, Champika Wickramasinghe ${ }^{2}$, Nalika Sepali Gunawardena ${ }^{3}$, Ayesha Lokubalasooriya ${ }^{2}$, Renuka Peiris ${ }^{4}$, Sameera Jayan Senanayake ${ }^{5}$

${ }^{1}$ Department of Community Medicine, Faculty of Medicine, University of Colombo; ${ }^{2}$ Ministry of Health; ${ }^{3}$ World Health Organization; ${ }^{4}$ Ministry of Education; ${ }^{5}$ Queensland University, Australia

*aruni@commed.cmb.ac.lk 
Background: Interpersonal violence among adolescents is a global public health concern. It was the second commonest cause of death among males aged 15 to 19 years in 2015. Violence also contributes to adverse physical and psychological outcomes.

Aims: This analysis aimed at estimating the prevalence of violence and correlates among school-going adolescents of ages 13 to 17 years using the data of the Global School-Based Health Survey conducted in Sri Lanka in 2016.

Methods: The Global School-Based Health Survey was a cross-sectional study conducted among 3,262 adolescents attending government schools, using a self-administered questionnaire, which inquired about active engagement in a fight and physical attacks by peers. Two-stage cluster sampling technique was used to select the sample. In the first stage, 40 schools were selected from all schools with grades $8-12$, using probability proportional to school enrolment size. Then, classes were selected as clusters using systematic equal probability sampling with a random start. Weighted prevalence was calculated, correlates were identified by conducting bivariable and multi-variable logistic regression.

Results: Of the 3262 participants, $35.1 \%$ (95\% Cl: 31.0-39.5) were physically attacked and $44.2 \%$ (95\% Cl: $39.2-$ 49.4) were in a fight with peers, one or more times during the 12 months before the survey. Physical fights were significantly common among boys $(55.4 \%, 95 \% \mathrm{Cl}$ : $50.5-60.1)$. Students aged $13-15$ years $(46.3 \%, 95 \% \mathrm{Cl}$ : $40.9-$ 51.8) were significantly involved more in fights than students aged $16-17$ years (38.3\%,95\% Cl: $32.0-45.0)$. Multivariable analysis revealed that being bullied by peers ( $\mathrm{aOR}=2.9,95 \% \mathrm{Cl}: 2.5-3.5$ ), male sex (aOR=2.0, 95\% $\mathrm{Cl}: 1.7-2.4), 13-15$ years age group(aOR=1.5, 95\% Cl:1.3-1.8), smoking ( $\mathrm{aOR}=2.5,95 \% \mathrm{Cl}: 1.2-5.1)$ and alcohol use (aOR=2.0, 95\% Cl:1.1-3.9), considering or attempting suicide ( $a \mathrm{OR}=1.6,95 \% \mathrm{Cl}: 1.2-2.1$ ), missing classes without permission (aOR=1.3, 95\% Cl:1.1-1.6), and parents not being aware of students' activities (aOR=1.3, 95\% Cl:1.11.5) were independently associated with violence.

Conclusion and Recommendations:: This analysis demonstrated that the proportion of students who reported being physically attacked and being involved in a physical fight were unacceptably high which flags a major public health problem in Sri Lanka. Existing school-based violence prevention programs should be evaluated and strengthened to ensure zero tolerance for bullying and violence.

Key words: violence; adolescents; Global School based Health Survey; Sri Lanka

\title{
OP-59
}

Prevalence and correlates of behaviour problems among grade eight (early adolescents) school students in the Jaffna District, Sri Lanka

\author{
J.T. Sivashankar ${ }^{1 *}$, Nalini Sathiakumar ${ }^{2}$, Rajendra Surenthirakumaran ${ }^{3}$ \\ ${ }^{1}$ Postgraduate Institute of Medicine, University of Colombo; ${ }^{2}$ Department of Epidemiology, School of Public Health, University \\ of Alabama at Birmingham; ${ }^{3}$ Department of Community and Family Medicine, University of Jaffna \\ *thirumagalsiva1966@gmail.com
}

Background: Though adolescent age group is said to be the happiest and the healthiest in human life cycle, behavioural problems of adolescents is a major issue globally. The post conflict situation in Jaffna, usage of internet and smart phones without proper parental control and inadequate skills among teachers to guide the adolescents could lead to behavioural problems in this population group.

Objective: Determine the prevalence, correlates of behaviour problems of Grade 8 (early adolescent) school children in Jaffna district. 
Methods: A cross sectional study was carried out to determine the prevalence of abnormal behaviour and the risk factors for the behaviour problems among the grade eight students. The study was carried out between January to July in 2018. A multi stage cluster sampling, probabilty proportionate to size was used ( $n=1328)$. Parents, teacher and self- report of Strengths and Difficulties Questionnaire, validated for Jaffna students, was used to differentiate behaviourally normal and abnormal children. Associated factors were assessed using a complementary questionnaire. Multi stage binary regression model was used to determine the significant risk factors for the behaviour problems.

Results: Behaviourally abnormal students assessed by parents, teachers and students were $10.1 \% 95 \% \mathrm{Cl}=8.5$ $11.8), 32.1 \%(95 \% \mathrm{Cl}=29.6-43.6)$ and $26.5 \%(95 \% \mathrm{Cl}=24.2-28.9)$ respectively by Jaffna cut off points developed earlier. Multivariate analysis revealed that female sex, age 14 years and above, studying in type $1 \mathrm{C} /$ type 2 schools, having an uneducated mother and unfavourable learning environment in schools were independently significantly associated with abnormal behaviour (female sex: $\mathrm{aOR}=1.5,95 \% \mathrm{Cl}=1.1-1.9$; age $>14$ years: $\mathrm{aOR}=2.2$, 95\% Cl=1.0-5.0; type 2 school: aOR=3.8, 95\%Cl=2.9-4.9; uneducated mother: $a \mathrm{OR}=0.8,95 \% \mathrm{Cl}=0.6-1.2$; unfavorable school environment: $\mathrm{aOR}=4.2,95 \% \mathrm{Cl}=1.6-10.8)$.

Conclusions \& Recommendations: Female sex, age 14 years/above, studying in type $1 \mathrm{C} /$ type 2 schools, having an uneducated mother and unfavourable learning environment in schools were associated with abnormal behaviour in Jaffna District. Further improving the female education in Sri Lanka and wilfully creating a favourable learning environment in schools which are modifiable factors will help reduce the behavioural problems of grade eight students.

Key words: adolescent behavioural problems, Strengths and Difficulties Questionnaire, factors associated with behaviour problems.

\title{
OP-60
}

\section{Behavioural and emotional problems and their associated factors among grade 10 students in Regional Director of Health Services area, Ampara} \\ ${ }^{1}$ Postgraduate Institute of Medicine, University of Colombo; ${ }^{2}$ Department of Community Medicine, University of Sri \\ Jayewardenapura \\ *sajaninadeeka@yahoo.com'
}

Background: Adolescence is an extremely sensitive stage of the life with many physical and psychological changes, sometimes at a rate that the individual is emotionally unprepared to face.

Objective: To identify the behavioural and emotional problems and their associated factors among grade 10 students in Regional Director of Health Services (RDHS) area, Ampara.

Methods: A school based descriptive cross-sectional study was conducted among 1340 grade 10 students studying in 43 government schools in Ampara RDHS area. A multistage stratified cluster sampling with cluster allocation according to the proportion of student population in each educational zone was done. Strengths and Difficulties Questionnaire (SDQ) was used to assess the mental health status of the students. Prevalence of behavioural and emotional problems were summarized as percentages. Associated factors of the mental health status were examined using chi square test and binomial logistic regression.

Results: Response rate was $97.5 \%(n=1374)$. Approximately $54.6 \%(n=732)$ were females. According to the Sri Lankan cut offs, $11.9 \%(\mathrm{n}=160)$ of the participants had behavioural and emotional problems. Emotional problems were the most common problem $(15.2 \%, n=204)$ followed by conduct problems $(12.9 \%, n=172)$, peer problems 
$(12.1 \%, n=162)$ and hyperactive/inattention problems $(11.7 \%, n=157)$. Not involving in religious activities regularly ( $\mathrm{OR} 2.395 \% \mathrm{Cl}=1.3-4.3, \mathrm{p}<0.01$ ), stressful life events during the last six months ( $\mathrm{OR} 1.9,95 \% \mathrm{Cl}=1.1-3.4$, $\mathrm{p}=0.01)$, mothers low education level $(\mathrm{OR} 1.995 \% \mathrm{Cl}=1.1-3.4, \mathrm{p}=0.01)$, not having a family member to discuss the problems ( $\mathrm{OR} 2.4,95 \% \mathrm{Cl}=1.3-4.2, \mathrm{p}<0.01$ ), tobacco consumption by father ( $\mathrm{OR} 2.9,95 \% \mathrm{Cl}=1.2-6.6, \mathrm{p}=0.01$ ) and difficulties in academic activities (OR 5.9, 95\% Cl= 2.5-13.6, $p<0.01$ ) were significantly associated with abnormal total SDQ scores.

Conclusions and Recommendations: Behavioural and emotional problems are common among the grade 10 students in Ampara RDHS area and most of them are associated with the family-related modifiable factors. Screening programmes to identify behavioural and emotional problems among students should be incorporated into School Medical Inspection and children should be empowered with life skills to face such problems.

Key words: Behavioural and emotional problems, associated factors 
SUMMARY OF ABSTRACTS FOR POSTER PRESENTATIONS 


\section{POSTER SESSION 01- HEALTH PROMOTION}

PP-01

JOB SATISFACTION, JOB STRESS AND BURNOUT AMONG THE HEALTH STAFF AT NATIONAL EYE HOSPITAL COLOMBO.

Wijeratne M.P., Kumaratilake W.L.L.U.C., Sahabandu M.P.W., Shifa M.R.F., Nanayakkara H.D.

PP-02

EFFECTS OF PUMPKIN IN BENIGN PROSTATIC HYPERPLASIA: A SYSTEMATIC REVIEW AND META-ANALYSIC

Rangika J.W.T., Ekneligoda A.M.W.B.M.T.M., Rathnayake R.M.M.P., Kumbukage M.P., Mahesh P.K.B., Arnold S.M., Ferdinando R., Gunathunga W.

PP-03

COMPARISON BETWEEN LEG-TO-LEG AND HAND-TO-HAND BIOELECTRICAL IMPEDANCE ANALYSIS IN THE ASSESSMENT OF FAT PERCENTAGE OF MALE ATHLETES IN SRI LANKA

Perera M., Ariyasinghe A., Ekanayake H., Kariyawasam A.

PP-04

PROMOTING KNOWLEDGE AND AWARENESS FOR DIABETES PREVENTION AMONG SCHOOL CHILDREN THROUGH A PARTICIPATORY APPROACH WITH INTER-SECTORAL COLLABORATION

Chandrasiri A., Samarage S., Sirithunga C., Athukorala C., Jayasekara D.

This will be presented by Chulasiri P. as requested.

POSTER SESSION $02-$ COVID 19

PP-05

MEDICAL UNDERGRADUATES' PERCEPTION OF THEIR ROLE AND WILLINGNESS TO ASSIST IN COVID-19 HEALTH SECTOR RESPONSE

Wickramasinghe N., Jayarathne W., Pilapitiya S.

PP-06

CHANGES IN ADMISSIONS, DEATHS AND DISEASE PATTERNS DURING COVID 19 OUTBREAK IN TEACHING HOSPITAL KARAPITIYA

Ubeysekara N., Ranaweera S.

PP-07

\section{This abstract was not presented in the conference, hence removed.}

PP-08

This abstract was removed from presentations.

PP-09

SURVEY ON ADEQUACY OF HAND HYGIENE FACILITIES IN FIELD CLINIC CENTERS OF BADULLA DISTRICT IN RESPONSE TO PREPAREDNESS OF COVID-19

Kasturiaratchi K., Kumarasinghe M., de Silva S.G.D., Samarasinghe S.V.W.S., Senanayaka S.D.P.S., Jayawardena R., Jayatilake A.M.A., Irfaan S., Mubarak F.S., Hariyaram J.J. 
PP-10

ACCEPTABILITY, RELEVANCE AND SIMPLICITY OF NEW HPV/DNA SCREENING IMPLEMENTATION AMONG 35 YEAR OLD EVER MARRIED WOMEN IN KALUTARA DISTRICT

Perera K.C.M., Abeysena C., Mapitigama N.

PP-11

HEALTH SEEKING PATTERNS OF ADOLESCENTS WITH UPPER LIMB FRACTURES

Jayasekera H., Siritunga S., Senarath U.

PP-12

PREVALENCE AND ASSOCIATED PSYCHOSOCIAL FACTORS OF ABUSE AND VIOLENCE AMONG PREGNANT WOMEN IN ANURADHAPURA DISTRICT

Hettiarachchi A., Amarasinghe G., Jayasinghe I., Koralagedara I., Wickramasinghe N., Agampodi T.

PP-13

COMPETENCIES IN DETECTING CHILD MENTAL HEALTH ISSUES AMONG GOVERNMENT PRIMARY SCHOOL TEACHERS OF SAMMANTHURAI EDUCATIONAL DIVISION OF SRI LANKA

Ahamed R., Disanayake O., Mohamed W., Andagala L., Gajmer J., Wijesinghe D., Perera M.

PP-14

PARENT REPORTED MEALTIME EATING PROBLEMS IN 3- 6 YEARS OLDS WITH AUTISM SPECTRUM DISORDER: PILOT STUDY

Weerasekara P., Hettiarachchi S., Gunathilake S,

\section{POSTER SESSION 04 - COMMUNICABLE DISEASES}

PP-15

DISTRIBUTION OF LEPTOSPIROSIS IN A HIGH ENDEMIC DISTRICT OF SRI LANKA - AN ANALYSIS OF SURVEILLANCE DATA

Singarachchi W., Chulasiri P., Hemalage A.

PP-16

\section{This abstract was not presented in the conference, hence removed.}

PP-17

SURGE CAPACITY OF THE PUBLIC SECTOR PREVENTIVE HEALTHCARE INSTITUTIONS FOR THE MANAGEMENT OF DENGUE IN KURUNEGALA DISTRICT

Rajapaksha N., Abeysena C., Balasuriya A.

PP-18

RISK STRATIFICATION INDEX OF DISTRIBUTING PERSONAL PROTECTIVE EQUIPMENT WITHIN A HEALTH CARE INSTITUTION

Ranasinghe D., Rathnayake D., Pathirana E., Rajapaksha N.U. 
POSTER SESSION 05 - HEALTHY LIFE STYLES

PP-19

VALIDATING A REGRESSION MODEL TO PREDICT CARDIO-RESPIRATORY FITNESS (VO $\mathrm{MAX}_{2}$ OF PROFESSIONAL SPORTSMEN IN SRI LANKA

Perera M., Ariyasinghe A., Kariyawasam A.

PP-20

BREAKFAST PATTERNS, FACTORS ASSOCIATED AND SATISFACTION ON CANTEEN BREAKFASTS OF MEDICAL UNDERGRADUATES IN A UNIVERSITY OF SRI LANKA

Nawarathna L., Samarasekera A., Senanayake S., Wijesooriya L., Wijewardana T., Perera M.

PP-21

EFFECTS OF BLACK PEPPER ON WEIGHT MANAGEMENT: A SYSTEMATIC REVIEW

Karunarathna B., Muthumala T., Mahesh P.K.B., Arnold S.M., Ferdinando R., Gunathunga W.

PP-22

EFFECTS OF BEETROOT PREPARATIONS ON EXERCISE ENDURANCE: A SYSTEMATIC REVIEW

Gallage A., Prasanga P.T.S., De Silva G., Senanayake S., Wellappuli N., Mahesh P.K.B., Arnold S.M., Ferdinando R., Gunathunga W.

\section{POSTER SESSION 06- NON-COMMUNICABLE DISEASES}

PP-23

WEB-BASED MECHANISM FOR DOOR-STEP DELIVERY OF MEDICINES TO THE PATIENTS WITH NONCOMMUNICABLE DISEASES (NCDS) USING THE STATE AND PRIVATE PHARMACY NETWORK DURING THE COVID 19 OUTBREAK IN SRI LANKA

Wickramasinghe C., Kumarapeli V, Wickramasinghe A., Fernando N., Perera U., Senaratne A., Samarakoon Y., Talagala I., Gunawardena S., Sirithunga S., Rodrigo C.H., Perera C., Abeygunathilaka D., Nilaweera L., Galagedara T.K., Marikkar T.N., Kumari P., Rajasinghe S., Kandasamy C., Mohideen S.

PP-24

GUAVA AND ITS GLYCEMIC CONTROL PROPERTIES: A SYSTEMATIC REVIEW

De Lanerolle N., Ananda S., Mahesh P.K.B., Arnold S.M., Ferdinando R., Gunathunga W.

PP-25

SYSTEMATIC REVIEW OF EFFECT OF PHYLLANTHUS EMBLICA IN GLYCEMIC CONTROL

Karawita U.G., Lakshima W.D.S., Shanaz M.T.Q.F., Amarasena W.D.J.K., Mahesh P.K.B., Arnold S.M., Ferdinando R., Gunathunga W.

PP-26

EFFECTS OF BITTER GOURD (MOMORDICA CHARANTIA) ON BLOOD SUGAR CONTROL: A SYSTEMATIC REVIEW Bandara T.D., Wasala S.A., Jayawickrama W.I.U., Mahesh P.K.B., Arnold S.M., Ferdinando R, Gunathunga W.

PP-27

VALIDITY OF USING ANTHROPOMETRY OVER BIOELECTRICAL IMPEDANCE ANALYSIS TO PREDICT OVERWEIGHT IN SRI LANKAN ATHLETES

Perera M., Ariyasinghe A., Kariyawasam A. 
PP-28

QUALITY OF CAUSES OF DEATHS DATA IN SRI LANKA: AN EVALUATION OF COMPLETENESS, TIMELINESS AND GARBAGE CODED DEATHS.

KumariH.M.N.S., Dharmaratne S.D.

PP-29

AVAILABILITY OF FACILITIES AT MEDICAL OFFICER OF HEALTH (MOH) OFFICES AND THE TRAINING NEEDS OF MOH TEAM IN SRI LANKA

Gunatilake I., Hettiarachchi J., Ranathunga R., Thenuwara N., Silva R.

PP-30

CERVICAL CANCER SCREENING: COMPARISON OF SCREENING RESULTS BETWEEN CERVICAL AND VAGINAL METHODS OF HPV/DNA SPECIMEN COLLECTION AMONG 35 YEAR OLD EVER MARRIED WOMEN IN KALUTARA DISTRICT

Perera K.C.M., Abeysena C., Mapitigama N.

PP-31

STREAMLINING UNDERGRADUATE RESEARCHES TO GENERATING EVIDENCE FOR HEALTH PLANNING: A COLLABORATION BETWEEN HEALTH AND HIGHER EDUCATION SECTORS

Chandrasiri A., Amarasena S., Sirithunga C., Kotapola I., Chulasiri P., Weerathunga E.

\section{POSTER SESSION 08 - NUTRITION}

PP-32

EFFECTS OF PINEAPPLE ON WOUND HEALING: SYSTEMATIC REVIEW

Priyadarshani P.H.M.G.M., Niroshana O.P.D., Galappaththi D.J., Premachandra K.L., Peiris D., Mahesh P.K.B., Arnold S.M., Ferdinando R., Gunathunga W.

PP-33

EFFECT OF CARROT ON SERUM CAROTENOID LEVEL: A SYSTEMATIC REVIEW

Herath A., Janapriya N., Nagendran P., Jayasinghe V., Mahesh P.K.B., Arnold S.M., Ferdinando R., Gunathunga W.

PP-34

KNOWLEDGE OF IRON DEFICIENCY, DIETARY IRON INTAKE AND ASSOCIATED FACTORS AMONG ADVANCED LEVEL STUDENTS IN AN URBAN COMMUNITY IN WESTERN PROVINCE

Nadeesha D., Wijesinghe C.J.

PP-35

EFFECT OF MORINGA OLEIFERA ON HAEMATOLOGICAL PARAMETERS: SYSTEMATIC REVIEW

Perera C., Galappatti D., Thrimavithana A., Mahesh P.K.B., Jayawickrama I., Arnold S.M., Ferdinando R., GunathungaW. 
ABSTRACTS FOR

POSTER PRESENTATIONS 


\section{POSTER SESSION 1- HEALTH PROMOTION}

17.09.2020

10 AM TO 10.30 AM

\section{PP-01}

\section{Job satisfaction, job stress and burnout among the health staff at National Eye Hospital, Colombo}

MP Wijeratne ${ }^{1 *}$, WLLUC Kumaratilake ${ }^{1}$, MPW Sahabandu ${ }^{1}$, MRF Shifa ${ }^{2}$, HD Nanayakkara ${ }^{3}$.

${ }^{1}$ National Eye Hospital, Colombo; ${ }^{2}$ Postgraduate Institute of Medicine, University of Colombo; ${ }^{3}$ The National Hospital of Sri Lanka, Colombo.

*monika.wijeratne@gmail.com

Background: National Eye Hospital Colombo (NEHC) is the premier tertiary care institution for eye care, draining 1500 to 2000 outpatients daily. The care provided by this institution extends from simpler eye infection to severe ophthalmic complications such as retinal and corneal surgeries. The health staff work at their maximum capacity to cater to the patient needs. Due to the heavy workload along with limited resources there may be a tendency for the health staff to undergo stress.

Objectives: To assess the level of job satisfaction, job stress and burnout among health staff working at NEHC.

Methods: A descriptive cross-sectional study was carried out among the health staff at NEHC. A self-administered questionnaire was adopted for data collection over a period of eight weeks from February to March 2020. The study population consisted of medical officers, nursing officers, paramedical staff, health attendants and laborers. Following a comprehensive literature review, the data collection tools were developed by combining several qualitative methods including focus group discussions with the health staff and consultative meetings with experts. All health staff members who have been working at the present station for more than two years were enrolled for this study.

Results: Out of the total study participants ( $n=426), 50 \%(n=213)$ respondents were satisfied with their job, 23\% $(n=98)$ had job stress while $0.9 \%(n=4)$ had burnout. Fifty nine percent $(n=251)$ believed they are overloaded with work, $27.9 \%(n=119)$ not satisfied with salary, $50 \%(n=213)$ not satisfied with the physical environment of workplace. Perceived work overload $(p<0.001)$ and conflicts with supervisors $(p<0.05)$ were associated with job stress. Perceived good relationship with co-workers $(p<0.05)$ and ability to perform the required task at expected level $(p<0.005)$ were significantly associated with job satisfaction.

Conclusions \& Recommendations: The workload allocated to each healthcare worker should be analyzed and redistributed to address the job stress caused by work overload. Supervisors should be empowered with managerial and conflict resolution skills. Physical environment of the workplace should be modified to improve working conditions. Stress management programmes should be conducted to help the staff for coping with stress.

Key words: Job satisfaction, Job stress, Burnout, Healthcare staff 


\section{PP-02}

\section{Effects of pumpkin in benign prostatic hyperplasia: a systematic review and meta-analysis}

JWT Rangika ${ }^{1 *}$, AMWBMTM Ekneligoda ${ }^{1}$, RMMP Rathnayake$^{1}$, MP Kumbukage ${ }^{2}$, PK Buddhika Mahesh ${ }^{3}$, SM $^{2}$ Arnold $^{4}$, Ruwan Ferdinando ${ }^{5}$, Wasantha Gunathunga ${ }^{6}$

${ }^{1}$ Post Graduate Institute of Medicine; ${ }^{2}$ Family Health Bureau; ${ }^{3}$ University of Melbourne; ${ }^{4}$ Ministry of Health; ${ }^{5}$ National Institute of Health Sciences; ${ }^{6}$ University of Colombo

*thamali.rangika@gmail.com

Background: Benign prostatic hyperplasia (BPH) is a common condition affecting aging men worldwide. It is characterized by Lower-Urinary-Tract-Symptoms (LUTS) due to bladder outflow obstruction. Pumpkin (genus: Cucurbita) is a popular vegetable all over the world. Pumpkin and its extracts are enriched with antioxidant, antiandrogenic, and anti-inflammatory properties.

Objective: To systematically-review the effect of pumpkin on BPH

Methods: Review was registered in International-prospective-register-of-systematic-reviews (PROSPERO ID: CRD42020181395). Electronic-bibliographic-databases of PubMed, EMBASE, Cochrane-Library, CINAHL and AGRICOLA were searched. Study selection was done in three rounds independently by two reviewers according to four criteria: being a pumpkin-related human study, having BPH-related outcomes and including quantifiable measurements. Risk-of-bias assessments were done with Grading-of-Recommendations-AssessmentDevelopment-and-Evaluation (GRADE) and Risk-Of-Bias-In-Non-randomized-Studies-of-Interventions (ROBINSI) criteria. After assessing the clinical, methodological and statistical heterogeneity, meta-analysis was performed for one outcome with mean difference (MD) using inverse-variance method with Review-Manager 5.4 software. Reporting was done according to PRISMA (Preferred-Reporting-Items-for-Systematic-Reviews-and-MetaAnalysis) guidelines.

Results: Of 242 articles, with de-duplication and with screening-questions 151, 11, 67 articles were rejected respectively in each round (three articles were not accessible). At the end of the third round, ten articles were selected. Majority of the participants were more than 50 years. Pumpkin-seeds alone comprised of the intervention in eight studies and in two, it was a combined product containing pumpkin seeds. Subjects of all studies were adult males with LUTS. International-Prostate-Symptoms-Score (IPSS) was described in nine articles. Other outcomes (no of studies) were: Quality-of-Life (QOL) (8), prostate volume (5), Prostate-Specific-Antigen (PSA) (4), uroflow rate (5), post-voidal-residual volume (5), frequency of micturition during day-and-night (4), nocturia (1)and International-index-of-erectile-dysfunction (1). Meta-analysis of three studies was performed for IPSS reduction with total of 650 and 631 subjects in experimental and control groups. Pooled MD $\left(I^{2}=0 \%\right)$ was 1.41(95\% Cl: -1.97 to -0.85$)$ with random-effect assumption. Related to IPSS reduction and QOL, in all relevant studies the intervention-group demonstrated favorable outcomes. PSA showed no significant difference in any study. Prostate volume, residual volume each was significantly reduced in one study while the uroflow rate was significantly reduced in three studies.

Conclusions and Recommendations: Pumpkin seeds seem to be beneficial for the outcomes in relation to the control of BPH in general. Further studies are recommended to strengthen the hypothesis.

Key words: Benign Prostatic Hyperplasia (BPH), pumpkin, cucurbita, International Prostate Symptoms Score (IPSS), Quality of Life (QOL) 


\title{
PP-03
}

Comparison between leg-to-leg and hand-to-hand bioelectrical impedance analysis in the assessment of fat percentage of male athletes in Sri Lanka

Madhawa Perera $^{1 *}$, Anoja Ariyasinghe ${ }^{1}$, Harshani Ekanayake ${ }^{1}$, Anula Kariyawasam ${ }^{1}$

${ }^{1}$ Department of Physiology, University of Peradeniya

*madhawadrck@gmail.com

Background: Body fat percentage is a predictor of sports performance in athletes. Leg-to-leg and hand-to-hand are commonly used bioelectrical impedance methods of assessing body fat percentage. Possibility of using leg-toleg and hand-to-hand bioelectrical impedance interchangeably to predict body fat percentage has not been studied adequately, although their interchangeable use is common in middle income countries like Sri Lanka.

Objective: To compare leg-to-leg and hand-to-hand bioelectrical impedance analysis in assessing body fat percentage of male athletes in Sri Lanka.

Methods: A sample comprising of 105 male athletes in the age range 18 to 39 years were recruited. Only the athletes involved in endurance and non-endurance team sports were included in the sample. Standing height and weight were measured using stadiometer and balance beam scale respectively. Omron HBF-306 body fat analyzer was used as the hand-to-hand bioelectrical impedance analysis instrument and Tanita UM-051 body fat monitor was used as the leg-to-leg bioelectrical impedance analysis instrument to measure body fat percentages. The Shapiro-Wilk test was used to assess the normality and Pearson correlation test was used to assess the association between the two methods. Bland-Altman analysis was used to assess the agreement between leg-to-leg and hand-to-hand bioelectrical impedance analysis.

Results: Mean height (SD) and weight (SD) was $174.3(8.1) \mathrm{cm}$ and 71.9 (11.4) kg respectively. Body fat percentages assessed by the two methods and the mean differences were normally distributed. Average fat percentage measured via hand-to-hand bioelectrical impedance analysis (SD) was 19.2 (5.9) \% and leg-to-leg bioelectrical impedance analysis (SD) was 17.9 (6.4) \%. There was a strong significant association between fat percentages measured by hand-to-hand and leg-to-leg bioelectrical impedance analysis $(r=0.85$ and $p<0.001)$. The bias (mean difference) was small (1.3\%) and the agreement between the two methods was acceptable as shown in the Bland-Altman plots.

Conclusions \& Recommendations: Body fat percentage measured using leg-to-leg and hand-to-hand bioelectrical impedance analysis is strongly correlated and is comparable to each other among Sri Lankan male athletes who are involved in endurance and non-endurance team sports.

Key words: body fat percentage, bioelectrical impedance analysis, athletes

\section{PP-04}

Promoting knowledge and awareness for diabetes prevention among school children through a participatory approach with inter-sectoral collaboration

\author{
Amila Chandrasiri ${ }^{1}$, Sarath Samarage ${ }^{2}$, Chandima Sirithunga ${ }^{3}$, Chinthaka Athukorala ${ }^{3}$, Dilum Jayasekara ${ }^{4}$ \\ ${ }^{1}$ Post Graduate Institute of Medicine, University of Colombo; ${ }^{2}$ Institute of Health Policy; ${ }^{3}$ Regional Director of Health Services Office, \\ Galle; ${ }^{4}$ Department of Education, Southern Province \\ amilachan@yahoo.com
}


Background: Non communicable diseases (NCDs) are rising as a major health issue globally. Due to its complications diabetes stands out as one of the most disconcerting NCDs. Unhealthy dietary practices and lack of physical activities are recognized as the leading modifiable risk factors and these practices are established during school life. Inculcating knowledge and awareness among school children, hence, becomes a priority need to promote healthy life style practices. Rather than conventional health education approaches, motivating students to explore knowledge through a participatory approach will be efficient. Inter-sectoral collaboration is essential for successful implementation of such a programme.

Objective: The intended output of the program was to improve the knowledge and awareness for diabetes prevention among school children.

Methods: Galle Regional Director of Health office (RDHS) in collaboration with Southern Provincial Department of Education and Lions Club district - 306 A1 conducted an inter school quiz competition. RDHS office provided technical guidance while Education sector did coordination and organizing. Lions club contributed by financial support. Key objective was to encourage students to explore knowledge on key aspects of diabetes and NCD prevention by a participatory approach. A project steering committee was established and an activity plan was drafted with a time frame. Key stakeholders were identified and advocated to ensure their support. The competition was held according to 'Table quiz' format, which is recognized as a very effective and time saving method of conducting team quizzes.

Results: Twenty-one schools took part. Questions were prepared covering the areas like epidemiology, risk factors and prevention of NCDs. An expert panel consisting both health and education officials set questions. Winning teams were awarded with trophies and each student was given book vouchers and medals. All the participants were given certificates. Each team was given a pack of health education materials to be kept in the school library.

Conclusion and Recommendations: Collaborating with education sector and obtaining financial contribution from lions club were identified as key factors for the success. Rather than a one way lecture, this strategy worked well as many participants attended the competition after reading recommended material. It was good to see that students answered very impressively showing a high level of knowledge. Every team were requested to make a presentation at school assembly to disseminate knowledge and sustain the impact.

Key words - diabetes prevention, school children, inter-sectoral collaboration 


\title{
POSTER SESSION 2 - COVID-19
}

17.09.2020

12.00 NOON TO 1.00 PM

\section{PP-05}

\section{Medical undergraduates' perception of their role and willingness to assist in the health sector response for COVID-19}

\author{
Nuwan Wickramasinghe ${ }^{1^{*}}$, Wasana Jayarathne ${ }^{2}$, Senaka Pilapitiya ${ }^{3}$ \\ ${ }^{1}$ Department of Community Medicine, Rajarata University of Sri Lanka; ${ }^{2}$ Medical Education Unit, Rajarata University of Sri \\ Lanka; ${ }^{3}$ Department of Medicine, Rajarata University of Sri Lanka \\ *nuwick74@yahoo.com
}

Background: Global evidence suggests that there is no universal consensus on the appropriate roles for medical undergraduates in the health sector response (HSR) during the COVID-19 pandemic, hence, their involvement in HSR in countries across the world is diverse.

Objective: To assess the medical undergraduates' perception of their role and willingness to assist in COVID-19 HSR among the medical undergraduates in Faculty of Medicine and Allied Sciences (FMAS), Rajarata University of Sri Lanka (RUSL)

Methods: A cross-sectional online survey was conducted among all medical undergraduates studying in six batches of the FMAS, RUSL. A Google form prepared in English with statements about individual perception of medical undergraduates' role and their willingness to assist in the COVID-19 HSR was used to collect data. Data was analysed using SPSS version 25.0.

Results: Out of 782 medical undergraduates who completed the questionnaire (response rate=72.5\%), the majority were females $(70.1 \%, n=548)$. The numbers of participants in each year (from first to final year) were 154 (19.7\%), 145 (18.5\%), 68 (8.7\%), 138 (17.6\%), 167 (21.3\%) and 110 (14.1\%). The majority $(94.4 \%, n=738)$ reported that they have a responsibility to contribute to the COVID-19 HSR in the country, while $248(31.7 \%)$ believed that the government and/or the health sector is effectively utilizing medical undergraduates' potential in the HSR. According to $45.4 \%(n=355)$, they possess adequate medical knowledge to contribute to the COVID-19 HSR, while only $22.9 \%(n=179)$ believed they have adequate clinical skills. Regarding the potential ways of contribution, the majority reported they could help in developing health education messages $(89.6 \%, n=701)$, in disseminating health messages $(86.3 \%, n=675)$ and in field contact tracing activities of the COVID-19 patients $(75.6 \%, n=591)$. Some participants reported they could assist the curative health sector in COVID-19 patient management (43.9\%, $\mathrm{n}=344)$ and other non-COVID-19 patient management $(53.6 \%, \mathrm{n}=419)$. However, only 88 participants (11.3\%) reported they were involved in any such activities.

Conclusions \& Recommendations: Medical undergraduates are willing to assist mainly the preventive and also the curative health sector activities during the COVID-19 outbreak. However, the medical faculties need to facilitate and guide medical undergraduates to involve in the COVID-19 HSR.

Key words: COVID-19, medical undergraduates, health sector response 
Changes in admissions, deaths and disease patterns during COVID-19 outbreak in teaching hospital Karapitiya

\author{
Nishani Ubeysekara $^{1^{*}}$, Sampath Ranaweera ${ }^{2}$ \\ ${ }^{12}$ Teaching Hospital, Karapitiya; \\ *nishaniubaysekara@yahoo.com
}

Background: During COVID-19 outbreak, from the first reported case till reopening of the country from lockdown hospitals had to cater to different patient needs and conditions. Due to restrictions of mobility and associated social changes the morbidity and mortality patterns reported to the hospital could be expected to vary. It is important to know the changes in hospital morbidity and mortality for proper management of hospital resources during and after the locked down period.

Objective: To determine the changes in morbidity and mortality patterns during COVID-19 outbreak in teaching hospital Karapitiya

Methods: Cross sectional study was carried out for a period of 2 months from $11^{\text {th }}$ of March to $11^{\text {th }}$ of May at TH Karapitiya. Data was obtained from electronic data base and other registers of the hospital using a datasheet. Hospital admissions, deaths and midnight total were compared with the data reported from the 2 months period before the outbreak. Admissions due to Road Traffic Accidents (RTA), assaults and selected common infectious diseases i.e. dengue, leptospirosis, influenza and COVID-19 were collected and compared.

Results: There was a reduction of $48 \%, 33 \%, 64 \%$, and $40 \%$ per day for this period in admissions, deaths, transfers and midnight total respectively. There was $26 \%$ and $52 \%$ reduction in admissions due to Road traffic accidents and assaults. Number of influenza and dengue patients was decreased in March and April 2020 compared to 2019 same period but leptospirosis morbidity and mortality has been increased. Only 2 patients were positive for COVID-19 out of 342 suspected admissions.

Conclusions \& Recommendations: Decrease in admissions, deaths, transfers and morbidity due to RTAs and assaults can be due to changes in movements and decreased alcohol consumption of people during lockdown. Usage of personnel protective equipment and hand washing practices should be continued as they may be the reasons for decreased respiratory illnesses. Community awareness progammes may be needed to reduce leptospirosis and other morbidities.

Key words: morbidity, mortality, hospital, COVID19

\title{
PP-07
}

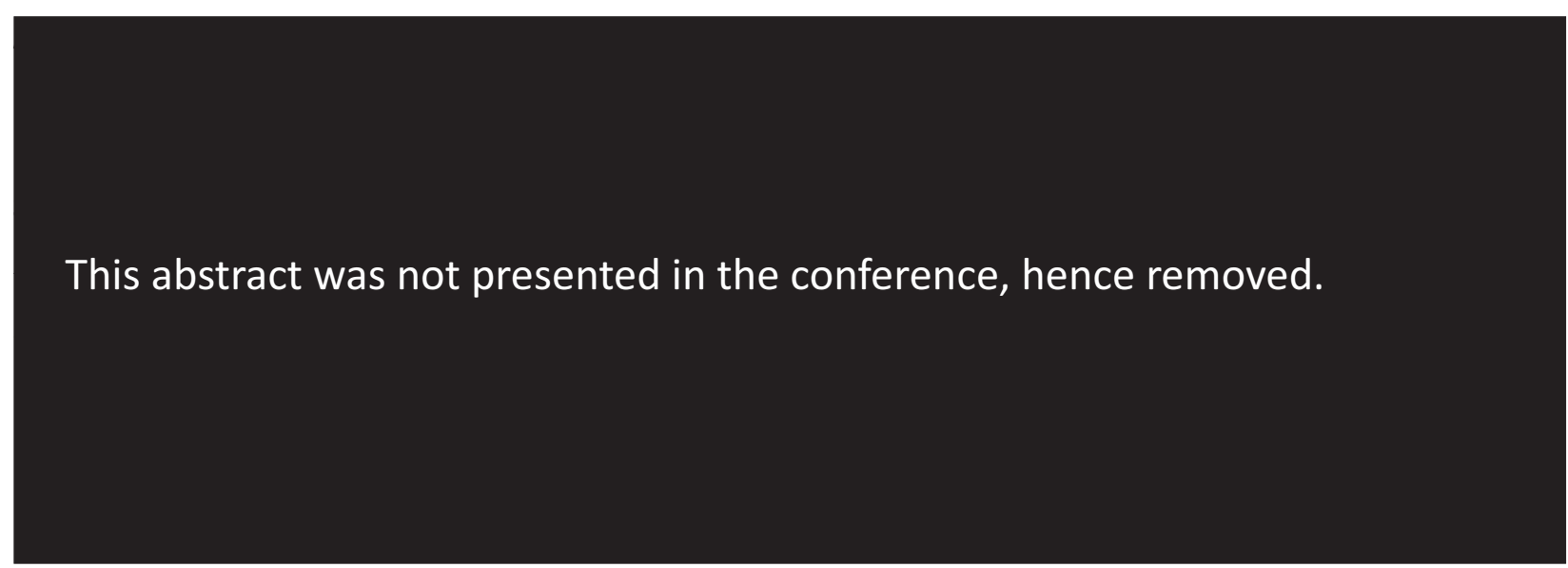


This abstract was not presented in the conference, hence removed.

PP-08

This was removed from the presentations.

PP-09

Survey on adequacy of hand hygiene facilities in field clinic centres of Badulla District in response to the preparedness of COVID-19

Kaushalya Kasturiaratchi ${ }^{1}$, Malith Kumarasinghe ${ }^{1^{*}}$, S G D de Silva ${ }^{2}$, S V W S Samarasinghe ${ }^{1}$, S D P S Senanayaka ${ }^{3}$, Ruvinda Jayawardena ${ }^{1}$ A M A Jayatilake ${ }^{3}$, S Irfaan ${ }^{3}$, F S Mubarak ${ }^{3}$, J J Hariyaram ${ }^{1}$

${ }^{1}$ Family Health Bureau; ${ }^{2}$ Regional Director of Health Services, Badulla; ${ }^{3}$ Postgraduate Institute of Medicine, University of Colombo

"malith.kumarasinghe@yahoo.com

Background: COVID 19 pandemic is a major cause for morbidity and mortality worldwide. One of the major preventive strategies accepted by World Health Organization and other health governing bodies around the world is hand hygiene.

Objectives: Objective of the survey was to assess the adequacy of hand hygiene facilities in field clinics in Badulla District in response to preparedness for new normal following lockdown. 
Methods: Survey was carried out in all field clinics under Family Health programme in Badulla District using a pretested survey form which was converted to a Google form. All field clinic centres physically located in Badulla District were selected for the survey.

Results: All clinic centres completed the survey $(\mathrm{N}=248)$. Out of all clinics $89.9 \%$ were poly clinics. Only $66.5 \%$ were having adequate water supply to satisfy all uses and $58.5 \%$ had uninterrupted water supply throughout the year. Majority does not have adequate hand washing facilities at the entrance of the clinic (54.4\%). More than seventy per cent $(71.8 \%)$ of clinic centres were equipped with washing facilities within the examination room. More than two third of the clinic centres did not have washing facilities within the latrines or within $5 \mathrm{~m}(36.7 \%)$. Though 99.2\% were equipped with adequate soap for hand washing, most did not have paper towel or any other method for drying (91.5\%). Average attendance of the respective clinics was significantly associated with the adequacy of water to satisfy all uses $\left(x^{2}=11.432, \mathrm{df} 2, \mathrm{p}=0.003\right) .42 .8 \%$ of clinic centres with average attendance less than 50 per session reported inadequate water supply.

Conclusions \& Recommendations: Close to two third of field clinics were equipped with adequate water supply. However significant gaps in availability of facilities for hand washing was observed. Therefore, it is important to prioritize the provision of facilities to the clinic centres especially during this pandemic situation as they are attended by pregnant mothers and children.

Key words: field clinics, hand hygiene, COVID-19 preparedness, facilities 


\section{POSTER SESSION 3 - WOMEN AND CHILDREN \\ 17.09.2020 \\ 12.00 NOON TO 1.00 PM}

\section{PP-10}

Acceptability, relevance and simplicity of new HPV/DNA screening implementation among $\mathbf{3 5}$ year old ever-married women in Kalutara district

\section{KCM Perera ${ }^{1 *}$, Chrishantha Abeysena², N Mapitigama ${ }^{3}$}

${ }^{1}$ Non-Communicable Diseases Unit, Ministry of Health \& Indigenous Medical Services; ${ }^{2}$ Department of Community Medicine, Faculty of Medicine, University of Kelaniya, ${ }^{3}$ Family Health Bureau

*chithranganieperera@yahoo.com

Background: Cervical cancer is the $2^{\text {nd }}$ leading cause of female cancer in Sri Lanka. All cervical cancers are virtually associated with human papillomavirus infection. HPV/DNA screening test is highly sensitive for high risk types of HPV (sensitivity 82\%-100\%). Therefore it's important to find acceptability, relevance and simplicity of new HPV/DNA test among the target age cohort ever married women of cervical cancer screening in Sri Lanka.

Objective:To explore acceptability, relevance and simplicity of new HPV/DNA screening implementation among 35 year age cohort ever married women in Kalutara district

Methods: Three focus group discussion sessions (FGDs) were carried out among 35 year old ever married women in $\mathrm{MOH}$ areas of Kalutara district, who had undergone HPV/DNA screening, representing urban, rural and estate sectors (each with 8 participants) of women. Convenient sampling technique was used to select participants. Results were tabulated and identified descriptive codes. Descriptive codes were modified to identify common themes and categories. Finally, an amalgamated list of codes was developed with FGDs. At last summary results were prepared.

Results: Some were aware of the lengthy screening intervals of HPV/DNA screening test (29.2\%, $n=7)$. Simplicity of the HPV/DNA screening test was expressed by participants as a convenient test $(83.3 \%, n=20)$, while (75\%, $n=18)$ and $(41.7 \%, n=10)$ of them stated respectively, that it was a neutral and quick test. Some mentioned environmental friendliness $(29.2 \%, n=7)$ and quick results $(20.8 \%, n=5)$ of the test. Majority were aware of repeated clinic visits for pap test $(75 \%, n=18)$ and colposcopy $(62.5 \%, n=15)$. Although it was an advanced technique $(33.3 \%, n=8)$, some were reluctant due to the fear of hurting oneself $(50 \%, n=12)$ and administering the test correctly $(33.3 \%, n=8)$. There was a marked acceptability among participants $(95.8 \%, n=23)$ for HPV/DNA screening test.

Conclusions and Recommendations: HPV/DNA test as a primary cervical cancer screening method is widely acceptable and its relevance and simplicity was well expressed by clients. HPV/DNA screening as a primary cervical cancer screening method should be considered in Sri Lanka as the suitability has been well proven.

Key words: cervical cancer screening, HPV/DNA screening test, acceptability, relevance, simplicity 


\title{
PP-11
}

\section{Health seeking patterns of adolescents with upper limb fractures}

\author{
Hemali Jayasekera ${ }^{1 *}$, Samitha Siritunga ${ }^{2}$, Upul Senarath $^{3}$ \\ ${ }^{1}$ Family Health Bureau, Ministry of Health, ${ }^{2}$ Non Communicable Disease unit, Ministry of Health, ${ }^{3}$ Department of Community \\ Medicine, Faculty of Medicine, University of Colombo \\ *hemalisenatilleke@gmail.com
}

Background: It is important to assess adolescent's health seeking patterns in Sri Lanka in relation to fractures, as a substantial proportion of patients tend to seek traditional treatments or native treatment, due to interplay between factors such as cost, accessibility and faith. This is amply supported by the evidence in other developing countries too. Findings of the study on health seeking pattern of an affected individual show what corrective and preventive measures have been taken by the person in order to rectify prevailing ill health.

Objective: To describe the health seeking patterns of adolescents with upper limb fractures following initial treatment from selected government hospitals in the Colombo district

Methods: A follow up study was carried out on a random sample of 400 adolescents with upper limb fractures treated at secondary and tertiary care hospitals in the district of Colombo. They were followed up at six weeks from the time of initial treatment at orthopaedic clinics or at their residences. Health seeking patterns of the study sample was described using frequency distributions. A cut off value was obtained using the median (SD) score of $2.0(0.38)$ by considering the responses given to items describing the health seeking patterns of adolescents. The participants who had not continued the treatment in the same hospital as advised by clinicians were categorized as changed health seeking patterns. Functional outcomes of adolescents with upper limb fractures were assessed at six weeks from the time of initial treatment by using a newly validated instrument. Poor functional outcomes following initial treatment was decided using a cut-off value using percentile values and based on expert opinion.

Results: In the majority, both parents were found to be the decision maker to seek health care services in the family for adolescent illness ( $n=239,59.8 \%)$. Most of the adolescent victims ( $n=282,70.5 \%)$ attended the same hospital for follow up care. Majority of them ( $n=113,40.0 \%$ ) attended the current hospital due to faith on hospital and service providers. The most common reason to attend any other hospital $(n=51,43.2 \%)$ was easy travelling or closeness to their residence. Majority of the participants ( $n=336,84 \%)$ stated that health facilities, services and accessibility to the current hospital $(n=346,86.5 \%)$ was very important for the child's illness. Out of the adolescent victims, two third of them $(n=302,75.5 \%)$ had to seek further treatment at follow up clinics. However, few of them ( $n=65,16.2 \%)$ were not followed up at clinics as advised. Out of them, majority ( $n=46,69.2 \%)$ went to seek treatment from eastern medicine (Ayurveda treatment) and few of them $(n=14,3.5 \%)$ sought treatment from a specialist or from a general practitioner. A higher proportion of adolescent victims who did not seek treatment at respective clinics had poor functional outcomes ( $n=52,34.0 \%$; 95\% Cl: 26.4-41.5\%). However, there was no statistically significant association between health seeking patterns of the adolescents and their functional outcomes after initial treatment $(p=0.68)$.

Conclusions \& Recommendations: Development of a new strategy in hospitals to continue treatment of upper limb fracture victims without changing the health seeking patterns is essential in order to improve follow up care.

Key words: adolescents, upper limb fractures, health seeking pattern 


\section{PP-12}

Prevalence and associated psychosocial factors of abuse and violence among pregnant women in Anuradhapura district

Ayesh Hettiarachchi ${ }^{{ }^{*}}$, Gayani Amarasinghe ${ }^{1}$, Imasha Jayasinghe ${ }^{1}$, Iresha Koralagedara ${ }^{2}$, Nuwan Wickramasinghe ${ }^{1}$, Thilini Agampodi ${ }^{1}$

${ }^{1}$ Department of Community Medicine, Faculty of Medicine and Allied Sciences, Rajarata University of Sri Lanka; ${ }^{2}$ Department of Anatomy, Faculty of Medicine and Allied Sciences, Rajarata University of Sri Lanka

*ayeshhettiarachchi@yahoo.com

Background: Globally one in three women experience physical or sexual abuse and violence during their lifetime. The prevalence estimates of violence against women range from 4-40\% in Low and Middle Income Countries (LMICS). Although studies have been conducted in specific populations, community-based studies on prevalence of abuse and violence (AV) among pregnant women are scarce in Sri Lanka.

Objective: To determine the prevalence and associated psychosocial factors of $\mathrm{AV}$ among first trimester pregnant women in Anuradhapura district

Methods: All pregnant women, who are less than 12 weeks into their pregnancy, registered at field antenatal clinics in Anuradhapura district from July to September 2019 were included in this study, as part of the Rajarata Pregnancy Cohort (RaPCo). Self-reported AV was assessed using selected items of validated Sinhala and Tamil versions of Abuse Assessment Screen (AAS). Mental health status was assessed using the validated Sinhala and Tamil versions of Edinburgh Postpartum Depression Scale (EPDS). Statistical significance of associations between different forms of $\mathrm{A} \vee$ with other variables was assessed using Chi-squared test.

Results: The sample included 3,233 pregnant women. Missing data for different items of the AAS ranged from $12.3 \%$ to $26.6 \%$. The percentage of women who have ever experienced emotional, physical or sexual abuse was $3.4 \%(n=111)$. Experience of physical and sexual abuse during the last twelve months was $1.9 \%(n=64)$ and $1.3 \%$ $(n=43)$ respectively. Eighty-three pregnant women $(2.6 \%)$ claimed that they live with fear of the perpetrator of abuse. Only $0.9 \%(n=30)$ reported experience of physical AV during the first trimester of the current pregnancy. All forms of abuse and fear of the perpetrator showed statistically significant association with high EPDS scores ( $p$ $<0.001$ ) while all forms of AV had statistically significant positive associations with the educational level of the pregnant mother and her husband $(p<0.05)$. None of the other socio-demographic factors tested were not associated with $\mathrm{AV}$ in this study sample.

Conclusions \& Recommendations: The prevalence of AV in pregnancy was lower than the previously reported values. AV was significantly associated with low educational status and high EPDS scores in the first trimester; thus, healthcare service providers need to identify vulnerable individuals' families and communities to prevent possible incidents of AV.

Key words: abuse, violence, mental health, pregnancy

\section{PP-13}

Competencies in detecting child mental health issues among government primary school teachers of Sammanthurai Educational Division of Sri Lanka

Ramzee Ahamed ${ }^{1 *}$, Oshan Disanayake ${ }^{1}$, Wasith Mohamed $^{1}$, Lenin Andagala ${ }^{1}$, Jamuna Gajmer ${ }^{1}$, Dilshan Wijesinghe ${ }^{1}$, Manuja Perera ${ }^{1}$ 
*ramzeeahamed94@gmail.com

Background: Teachers play an important role in promoting child mental health. However, related competencies among government primary school teachers aren't explored adequately in rural settings. Sammanthurai is located $350 \mathrm{~km}$ away from the capital and the majority are Muslims speaking Tamil.

Objective: To describe the competencies in detecting child mental health issues among government primary school teachers of Sammanthurai Educational Division of Sri Lanka

Methods: A descriptive cross-sectional study was conducted in Government Primary Schools of Sammanthurai Educational division. All teachers in primary classes $(N=134)$ were invited for the study. A self-administered questionnaire developed in Tamil language was used to collect data on their knowledge on symptoms and management of mental health issues, related attitudes and perceived challenges in identifying and intervening for mental health issues among their students.

Results: A total of 130 (97.0\%; Female=86.0\%, Male=14.0\%) responded. Majority (88.4\%, $n=114)$ were Muslims and the rest were Tamil. The majority $(98.4 \%, n=126)$ showed positive attitudes towards child mental health and all agreed that related knowledge is important. The majority $(82.8 \%, n=106)$ believed that they have the ability to recognize a child with mental health issues. Eighteen behaviors reflecting mental disorders (of 21) were correctly identified by a majority $(71.1 \%, n=90)$. Restlessness, excessive arguing with teachers and often questioning rules were identified by fewer participants $(35 \%, n=44)$. Majority $(65.1 \%, n=84)$ didn't know how to manage a child if they suspect a mental health issue and only 35 (28\%) stated that they will refer to a counselling teacher or a doctor. The commonest perceived challenges for identification and intervention in child mental health issues were: inadequacy of training; non-co-operative parents and overcrowded classrooms.

Conclusions \& Recommendations: Even though primary school teachers of Sammanthurai had positive attitudes on child mental health, the knowledge on management of related issues was unsatisfactory. The commonest perceived reason for the knowledge gap was inadequacy of training. Enhanced capacity building on child mental health with special attention to improving knowledge on management may improve the situation.

Key words: child mental health, competency, primary school teachers, Sammanthurai

\section{PP-14}

Parent reported mealtime eating problems in 3- 6 years olds with autism spectrum disorder: pilot study

\section{Prasadini Weerasekara $^{{ }^{*}}$, Shamini Hettiarachchi ${ }^{1}$, Samadhi Gunathilake $^{1}$}

${ }^{1}$ Faculty of Medicine, University of Kelaniya

*prasa.wee95@gmail.com

Background: "Selective" or "picky eating" is a frequent problem in children with Autism Spectrum Disorder (ASD). Most parents reported that food refusal, failure to eat the usual family diet, inappropriate rate of eating, failure to accept new foods, and inappropriate mealtime routine are the most challenging problems.

Objective: To determine mealtime behaviors, food preferences, and behaviors of children outside of mealtime and to describe the strategies and the challenges come across by parents in trying to change their child's mealtime behaviors

Methods: A mixed methods research design was conducted. Data were collected through a self- administered questionnaire, semi-structured interview and included 74 parents who have children between 3- 6 years with ASD 
attending the Multi-Disciplinary Team or the Speech and Language Therapy clinics of the Faculty of Medicine, University of Kelaniya. The sample was selected using a convenience sampling method. Descriptive statistical analysis and thematic analysis were used for data analysis

Results: A notewortry number of participants presented with coughing $(24 \%, n=18)$, vomiting $(26 \%, n=20)$, and drooling $(63.5 \%, n=47)$. Based on the parents' perception, their children had difficulty remaining seated during the mealtime $(68.9 \%, n=51)$, didn't tolerate foods that they don't like $(79.7 \%, n=59)$. A child's eating depends on the person who feeds $(55.4 \%, n=41)$. Most children preferred to eat spicy foods $(35.1 \%, n=26)$ and crunchy foods $(32.4 \%, n=24)$ were the most favorable food textures. Most parents used positive reinforcement $(58.1 \%, N=43)$, food modification $(21.6 \%, \mathrm{~N}=16)$ and showed cartoons during mealtime $(28.3 \%, \mathrm{~N}=21)$ as strategies. The majority of the parents reported they were feeling stressed $(50 \%, \mathrm{~N}=37)$, angry $(50 \%, \mathrm{~N}=37)$ and worried $(24.3 \%$, $N=18)$. Furthermore, parents reported the following as challenges: limited activities $(5.4 \%, N=4)$, participation restriction $(43.2 \%, \mathrm{~N}=32)$ and breakdown of their relationship $(22.9 \%, \mathrm{~N}=17)$.

Conclusions \& Recommendations: Food selectivity, food refusal based on texture or the taste were the most commonly reported problems. Most parents used positive reinforcements, food modifications, and showed cartoons on Tv or Tab during mealtime as strategies and reported that they feel stressed, angry, and worried. This study conveys the importance of screening mealtime difficulties in children with ASD.

Keywords: Autism spectrum disorder, mealtime behaviors, food selectivity 


\section{POSTER SESSIONS 04 - COMMUNICABLE DISEASES}

17.09.2020

12.00 NOON TO 1.00 PM

\section{PP-15}

\section{Distribution of leptospirosis in a high endemic district of Sri Lanka - an analysis of surveillance data}

Wenura Singarachchi ${ }^{1}{ }^{*}$, Pubudu Chulasiri ${ }^{2}$, Asiri Hemalage ${ }^{3}$

${ }^{1}$ Regional Epidemiologist, RDHS, Galle, ${ }^{2}$ Consultant Community Physician, Anti Malaria Campaign, ${ }^{3}$ Consultant Community Physician, Family Health Bureau

*wsingarachchi1967@gmail.com

Background: Leptospirosis is the most prevalent zoonotic disease in tropics of the world. It can vary from mild fever to a severe disease with multisystem involvement. Sri Lanka is a high endemic country with an estimated cumulative annual incidence of $52.1(95 \% \mathrm{Cl} 51.7-52.6)$ per 100,000 population. It is reported throughout the year with two peaks at the time of the monsoons. Despite the preventive measures in place, in certain districts such as Galle and Matara, leptospirosis is still on the rise. Galle district is a sentinel surveillance site with active surveillance of leptospirosis.

Objective: To evaluate the distribution of leptospirosis in a high endemic district of Sri Lanka

Methods: The surveillance data from Galle district from 2018 and 2019 were analyzed using descriptive statistics. The data were taken from IMMR (986 cases) and H 544 (412) in 2018 and 953 and 519 in 2019 respectively.

Results: Majority of the cases confirmed in 2018 and 2019 in Galle district were males ( $n=363,88.5 \%$ ) and mean age of the patients were 41.5 years $(n=407)$. Many were labourers $(23.2 \%)$ and only $10.7 \%(n=44)$ were farmers. Only 3.4\% $(n=14)$ have had prophylaxis at the time of onset. While $71.2 \%(n=291)$ were cured, $4.1 \%(n=17)$ died. There is a statistically significant difference between the gender $(p=0.09)$, duration of hospital stay $(p=0.026)$, age $(p=0.001)$, having chemoprophylaxis ( $p=0.02)$ with the deaths. Out of 410 patients, the confirmatory test (MAT) has been done only on 06 patients and 03 of them were positive. Most of the patients (47.8\%) were contaminated from paddy fields.

Conclusions and Recommendations: Even though the preventive prophylaxis is in place, majority had not taken it before contacting with the contamination sites. The major reason could be that prophylaxis was promoted among farmers although majority were not farmers in their occupation. It is recommended to promote chemoprophylaxis for leptospirosis for anyone who will be having a probable contact with paddy fields or other farming lands. Further research is needed to identify the other ways of contamination except farming lands.

Key words- leptospirosis, chemoprophylaxis, occupation, confirmatory test 
This abstract was not presented in the conference, hence removed.

\section{PP-17}

Surge capacity of the public sector preventive healthcare institutions for the management of dengue in Kurunegala district

Nayani Rajapaksha ${ }^{1}{ }$, Chrishantha Abeysena $^{2}$, Aindralal Balasuriya ${ }^{3}$

${ }^{1}$ Postgraduate Institute of Medicine, University of Colombo, Sri Lanka; ${ }^{2}$ Senior Professor, Department of Public Health, Faculty of Medicine, Ragama; ${ }^{3}$ Senior Lecturer, Kothalawala Defense University, Rathmalana

*rmnur2014@gmail.com 
Introduction: The surge capacity is defined as the ability to obtain adequate staff, supplies, structures and systems to provide sufficient care to meet immediate needs of an influx of patients following a large-scale incident or outbreak. Kurunegala district was reported a drastic spike in the dengue cases and management capacity of the healthcare institutions was exceeded due to the recent epidemic.

Objective: Aim of the study was to describe the surge capacity of the public sector preventive healthcare institutions for the management of dengue in Kurunegala district

Methods: A descriptive cross sectional study was conducted among all Medical Officers of Health areas $(n=28)$ in the district on May to September 2019. A pre-tested, validated, interviewer-administered tool was used to collect data which was formulated according to the "Science of Surge Theory" and "CO-S-TR Model". Adequate staff capacity was taken as $\geq 75 \%$ of the required cadre for the institutions. There was basic level ( 26 to $50 \%$ ), moderate level (51 to $75 \%$ ) and high level ( $>75 \%$ ) surge capacities for 10 broad areas of the assessment and the overall "adequate surge capacity" was considered as $\geq 50 \%$ for all the components of the tool.

Results: Response rate was $92.9 \%(n=26)$. The majority of the preventive healthcare institutions $(69.2 \% ; n=18)$ had inadequate staff capacity. The higher proportion ( $n=19 ; 73.1 \%$ ) of them had focal points for dengue management, three fourth $(76.0 \% ; n=19)$ did not have written plan for disaster preparedness, $8 \%(n=2)$ had included medical disaster preparedness, Personal Protective Equipment (PPE) (65.4\%; $n=17)$, chemical for mosquito control $(92.3 \% ; n=24)$ and fogging instrument $(88.5 \%, n=23)$ for dengue management activities. Larval survey instruments were not available in a higher proportion of the institutions $(80.8 \% ; n=21)$. The basic level capacity existed in a majority of institutions in the areas of staff mobilization $(53.8 \% ; n=14)$, management of the stuff $(76.9 \% ; n=20)$, triage of case $(76.9 \% ; n=20)$, and transportation $(46.2 \% ; n=12)$. The moderate level capacity existed in a majority in the areas of commanding system ( $42.3 \% ; n=11)$, control the incidence $(38.5 \% ; n=10)$, coordination of activities (61.5\%; $n=16)$, supplying of special needs $(50.0 \% ; n=13)$ and tracking of the cases $(76.9 \% ; n=20)$. There was no high level of capacity in place. The higher proportion $(84.6 \% ; n=22)$ had inadequate overall surge capacity for the management of dengue.

Conclusion and Recommendations: There is a need for improvement of surge capacity of the preventive healthcare institutions in the district and capacity development programmes should be initiated along with the results of the study.

Key words: Surge capacity, dengue, preventive sector, capacity development

\title{
PP-18
}

\section{Risk stratification index for distributing personal protective equipment for curative care institutions}

\author{
Dineshan Ranasinghe ${ }^{*^{1,3}}$, Dulanjali Rathnayake ${ }^{2}$, Eranga Pathirana ${ }^{1,3}$, Nayani Umesha Rajapaksha $^{4}$ \\ ${ }^{1}$ Society for Health Research and Innovations; ${ }^{2}$ Medical officer BH Horana; ${ }^{3}$ Medical officer BH Panadura; ${ }^{4}$ Post Graduate \\ Institute of Medicine, Colombo \\ *dineshanrana2000@yahoo.com
}

Background: The current global stockpile of Personal Protective Equipment (PPE) are insufficient to face current global pandemic. Surging global demand is driven not only by the number of COVID-19 cases but also by misinformation, panic buying, and stockpiling. Therefore, PPE should be used based on the risk of exposure and the transmission dynamics of the pathogen. There are recommendations from World Health Organization for rational use of PPE. The distribution of PPE is performed by the Medical Supplies Division (MSD) in Sri Lanka. Base hospitals had to deal with very limited number of stocks at the start of the epidemic due to maldistribution. As a result, BH Panadura received very limited number of PPEs and as a result needed to prioritize the distribution according to the risk stratification. 
Objective: To develop a mechanism to distribute the PPE according to the absolute risk for the units in Base Hospital, Panadura

Methods: The assessment was conducted using qualitative techniques. A risk stratification index for COVID-19 was developed by a team after a thorough literature review. The list of generated items was circulated among a panel of experts adopting a Modified-Delphi technique through emails. After taking the percentage agreement for the items, the scores for each risk factor were obtained.

Results: In the first round, each person agreed to stratify risk according to five main factors including contact time per patient, environment (open/ closed), initial contact, whether aerosol generating or not and exposure of duration for patients. According to the percentage agreements, aerosol generating procedure, close contact, the closed environment and exposure duration more than 15 minutes were scored an average of $80 \%$ each. Contact time of 5 - 15 minutes was scored $50 \%$ and less than 5 minutes was scored $20 \%$. For the item of contact, $80 \%, 50 \%$ and $30 \%$ were given for index case, for the first line contacts and for the second line contacts respectively. For the exposure time, if the unit staff has to work more than 12 hours per day, it was considered as high risk. The score given when working more than 12 hours, for $8-12$ hours, for $4-8$ hours and for less than 4 hours per day were $80 \%$, $60 \%, 40 \%$ and $20 \%$ respectively. The total risk for the unit was taken by multiplying each five risk factors for each unit and the risk of each unit was categorized. The items were distributed among the units according to that risk stratification. There was acceptance of this stratification among all units. This method was replicated in other hospitals in distributing PPE.

Conclusions \& Recommendations: The risk stratification index was effectively adopted in Base Hospital Panadura for rationally distributing of PPE to their utilisation and patient management

Key words: Personal Protective Equipment, pandemic, risk stratification 


\title{
POSTER SESSION 5 - HEALTHY LIFE STYLES
}

18.09.2020

10.00 AM TO 10.30 AM

\section{PP-19}

Validating a regression model to predict cardio-respiratory fitness $\left(\mathrm{VO}_{2} \mathrm{max}\right)$ of professional sportsmen in Sri Lanka

\author{
Madhawa Perera $^{{ }^{*}}$, Anoja Ariyasinghe ${ }^{1}$, Anula Kariyawasam ${ }^{1}$ \\ ${ }^{1}$ Department of Physiology, University of Peradeniya \\ *madhawadrck@gmail.com
}

Background: Cardio-respiratory fitness is a health related physical fitness component. Astrand-Rhyming CycleErgometer test is a standard test to assess cardio-respiratory fitness $\left(\mathrm{VO}_{2} \mathrm{max}\right)$. Yet, it is not always practical to perform for risk assessment in epidemiological studies. Thus, validating available non-exercise $\mathrm{VO}_{2}$ max prediction equation is a current requirement.

Objective: To validate an available $\mathrm{VO}_{2}$ max prediction equation based on age, weight, and resting pulse rate among professional sportsmen in Sri Lanka

Methods: A cross-sectional validation study was conducted on a cohort of sportsmen belonging to Sri Lanka Army and convenience sampling method was used to recruit 81 sportsmen aged $20-40$ years. Weight was measured using a balance beam scale to the nearest $0.1 \mathrm{~kg}$ and height by the stadiometer to the nearest $0.1 \mathrm{~cm}$. Radial pulse was assessed using palpation method and used to assess heart rate. Available regression equation developed by Rexhepi and Brestovci (2014) was used to predict $\mathrm{VO}_{2}$ max, while $\mathrm{VO}_{2}$ max was measured by the Astrand-Rhyming Cycle-Ergometer test using the Monark-Ergomedic 828E cycle-ergometer. Strength of association between the two methods was tested via Pearson's correlation. Paired-sample t-test was used to determine the significance of mean difference.

Results: Mean age of the participants (SD) was 26.27 (3.77) years. Mean weight and height (SD) were 70.98 $(10.52) \mathrm{kg}$ and $173.65(8.38) \mathrm{cm}$ respectively. Resting heart rate (SD) was 65.38 (11.33) bpm. Average $\mathrm{VO}_{2}$ max predicted by the equation (SD) was $3.52(0.17) \mathrm{l} / \mathrm{min}$, while it was $2.96(0.40) \mathrm{l} / \mathrm{min}$ by the Astrand-Rhyming CycleErgometer test. The mean difference was statistically significant $(p<0.01)$ and regression model over predicted the $\mathrm{VO}_{2}$ max. Correlation between $\mathrm{VO}_{2}$ max predicted through the equation and Astrand-Rhyming CycleErgometer test was relatively weak and significant $(r=0.36$ and $p<0.05)$.

Conclusions \& Recommendations: $\mathrm{VO}_{2}$ max prediction model based on age, weight, and resting pulse rate cannot be substituted for the Astrand-Rhyming Cycle-Ergometer test to assess cardiorespiratory fitness of professional sportsmen in Sri Lanka.

Key words: cardiorespiratory fitness, Astrand-Rhyming Test, $\mathrm{VO}_{2}$ max regression model 


\section{PP-20}

Breakfast patterns, factors associated and satisfaction on canteen breakfasts of medical undergraduates in a university of Sri Lanka

Lalith Nawarathna ${ }^{1}$, Akna Samarasekera ${ }^{1}$, Savinda Senanayake ${ }^{1 *}$, Lahiru Wijesooriya ${ }^{1}$, Thirani Wijewardana ${ }^{1}$, Manuja Perera ${ }^{2}$

${ }^{1}$ Faculty of Medicine, University of Kelaniya; ${ }^{2}$ Department of Public Health, Faculty of Medicine University of Kelaniya

"savinda101@gmail.com

Background: Poor breakfast habits have deleterious effects on human health. It is common among students and in a study conducted in Ghana among medical students, breakfast skipping at least once a week was $72 \%$. Breakfast patterns amongst Sri Lankan medical undergraduates are not adequately described.

Objectives: To describe the breakfast patterns, its associated factors and satisfaction level on food served in the faculty premises among first and third-year medical undergraduates of the University of Kelaniya

Methods: A Cross-Sectional Study was conducted using a self-administered, semi-structured questionnaire during three randomly selected days within December 2019 to January 2020 among eligible Medical Undergraduates ( $\mathrm{N}=340$ ). Descriptive and chi-square statistics were used to analyse data.

Results: The majority of participants responded $(94.7 \%, n=322)$. Of the participants, $61 \%$ of first-years $(n=98)$ and $36 \%$ of third-years $(n=58)$ consumed breakfast daily. First-years were more likely to have breakfast daily than third-years $(p=0.022)$. Rice and curry were the commonest $(30.7 \%, n=49)$ breakfast type amongst the first-years and milk-rice and milk-packets amongst the third-years $(14.0 \%, n=22)$. The year of study is significantly associated with the type of breakfast consumed ( $p=0.048$ ). Amongst first-years, sex was significantly associated with the type of breakfast $(p=0.006)$. However, no such association was observed in third-years $(p=0.69)$. The Body Mass Index (BMI) was not associated with the breakfast type they consumed in both batches (first years$p=0.060$; third years $-p=0.069$ ). A satisfaction rating of $5-6$ (of a maximum of 10 ) was the highest in both first $(70 \%$, $\mathrm{n}=112$ ) and third-years $(69 \%, \mathrm{n}=111)$. The commonest perceived factor for poor breakfast habits was savourless food among both first years $(32 \%, n=51)$ and third-years $(31 \%, n=50)$.

Conclusion and Recommendation: Prevalence of breakfast skipping was higher in third-years. Improvement of the canteen services will improve students' breakfast habits.

Key words: breakfast habits, medical undergraduates, Sri Lanka

\section{PP-21}

\section{Effects of black pepper on weight management: A systematic review}

Bhumini Karunarathna ${ }^{{ }^{*}}$, Tharushi Muthumala ${ }^{1}$, Buddhika Mahesh $^{2}$, Mahendra Arnold $^{1}$, Ruwan Ferdinando ${ }^{3}$, Wasantha Gunathunga ${ }^{4}$

${ }^{1}$ Ministry of Health and Indigenous Medical Services, Sri Lanka; ${ }^{2}$ University of Melbourne, Australia; ${ }^{3}$ National Institute of Health Sciences, Sri Lanka; ${ }^{4}$ Department of Community Medicine, Faculty of Medicine, University of Colombo, Sri Lanka

*bhumini_janani@yahoo.com

Background: Black pepper (Piper nigrum) is a commonly used spice in Sri Lankan food culture. Though it has traditionally been recognized for its medicinal properties, there is a scarcity of scientific evidence on its effects. Overweight and obesity are on the rise worldwide and remain major risk factors for non-communicable diseases. 
Objective: To systematically review the effects of black pepper on weight-management

Methods: The review was registered in the PROSPERO (International-Prospective-Register-of-SystematicReviews) with Registration ID: CRD42020182986. EMBASE, CINAHL, Cochrane-Library, AGRICOLA and PubMed databases were searched. Studies were screened independently by two reviewers with four screening questions. Discrepancies were intervened by a third reviewer. Risk-of-bias assessments were done with Grading-ofRecommendations-Assessment-Development-and-Evaluation (GRADE) criteria. Assessments of heterogeneity were done. Synthesis was done referring to "Preferred-Reporting-Items-for-Systematic-Reviews-and-MetaAnalysis" (PRISMA) guidelines.

Results: As clinically and methodologically heterogeneous, findings of selected eight studies were narratively described without meta-analysis. Study populations included: healthy individuals (in 3 studies), overweight/ obese individuals (in 4 studies) and those with hypercholesterolemia (in 1study). Pure black pepper was taken as the intervention in one study, as the control in another and as a component of a combination of spices in others. Two studies have assessed the appetite-modulatory-effect of black pepper where one of them had revealed a significant reduction of 'hunger' $(p=0.0007)$, 'desire to eat' $(p=0.0012)$, 'prospective consumption' $(p=0.0011)$ and significant increment in 'satiety' $(p=0.0044)$ and 'fullness' $(p=0.0009)$. One study has revealed the clinicalpotential of black pepper containing the formula for the maintenance of weight after intentional-weight-loss at one month $(p<0.05)$ and at 6 months $(p<0.05)$. Two studies have analysed the weight-change following consumption of black pepper where they have observed $6.7 \%$ of global weight-reduction and weight-change of $-1.0 \mathrm{~kg}(95 \% \mathrm{Cl}, 2.5$ to +0.5$)$ respectively. Three studies have observed the effect on the fat mass where one study had revealed more than $9 \%$ of fat-mass-reduction, a significantly greater reduction in total-fat-mass in comparison to the control group $(2.4 \pm 1.0 \mathrm{~kg}$ vs. $1.0 \pm 0.7 \mathrm{~kg} ; \mathrm{p}<0.05)$ where the remaining study did not reveal any significant reduction.

Conclusions \& Recommendations: Black pepper has an effect on both weight reduction and the maintenance of weight following intentional weight loss. Further studies are recommended to strengthen the existing evidence.

Key words: black pepper, weight management, fat mass reduction

\section{PP-22}

\section{Effects of beetroot preparations on exercise endurance: A systematic review}

Aruni Gallage ${ }^{1^{*}}$, PTS. Prasanga ${ }^{2}$, Gayani De Silva ${ }^{2}$, Sameera Senanayake ${ }^{3}$, Nalinda Wellappuli ${ }^{4}$ PK Buddhika Mahesh $^{5}$, SM Arnold ${ }^{4}$, Ruwan Ferdinando ${ }^{6}$, Wasantha Gunathunga ${ }^{1}$

${ }^{1}$ Department of Community Medicine, Faculty of Medicine, University of Colombo; ${ }^{2}$ Postgraduate Institute of Medicine, University of Colombo, Sri Lanka; ${ }^{3}$ Queensland University of Technology, Australia; ${ }^{4}$ Ministry of Health, Sri Lanka; ${ }^{5}$ University of Melbourne, Australia; ${ }^{6}$ National Institute of Health Sciences, Sri Lanka

*aruni@commed.cmb.ac.lk

Background: Physical activity including exercises is mandatory for healthy living. Products containing beetroot (Beta vulgaris), a commonly found food item have been used as popular exercise-supplements in the modern world. Beetroot contains high levels of nitrate and Betalain which have ergogenic properties. Time trial performances and oxygen consumption capacity $\left(\mathrm{VO}_{2} \mathrm{max}\right)$ are used for exploring the exercise-endurance.

Objective: To systematically review the effects of beetroot juice on exercise-endurance by reviewing the time trial performances and $\mathrm{VO}_{2}$ max

Methods: Registration from International-Prospective-Register-of-Systematic-Reviews (ID: CRD42020182853) was obtained prior to commencement. Studies were searched using subject headings and keywords in Cochrane- 
library, EMBASE, Agricola, PubMed and CINAHL databases. Articles were screened in 3 rounds for: being a human study on beetroot, having related outcomes and for the availability of quantifiable outcomes. Two reviewers independently did the screening of studies and a third reviewer intervened in resolving conflicts of selections. Risk-of-bias assessments were done with Grading-of-Recommendations-Assessment-Development-andEvaluation (GRADE) and Risk-Of-Bias-In-Non-randomized-Studies-of-Interventions (ROBINS-I) guidelines. The findings were narratively described. Preferred-Reporting-Items-for-Systematic-Reviews (PRISMA) guidelines were followed in reporting.

Results: Altogether 1314 articles were reviewed after de-duplication. During selection, 686, 479 and 130 articles were excluded in three rounds respectively and 19 were selected. All selected studies were interventional studies. Out of these, nine studies were conducted among trained athletes and nine studies were conducted among healthy individuals while one study was on both athletes and recreationally active healthy individuals. Most of the evidence were from studies with moderate risk of bias. The commonest intervention was supplementation of beetroot juice $(84.3 \%, n=16)$ as a drink while only three studies used tablets or capsules before the prescribed exercises. Two and eight studies evaluated only the effect of beetroot on time trial performance and $\mathrm{VO}_{2}$ max capacity respectively whereas both outcomes were explored in nine studies. Three (out of 11) studies found that beetroot has a significant effect on the time trial performance and four (out of 17) reported a significant effect on $\mathrm{VO}_{2} \max (p<.05)$.

Conclusions \& Recommendations: There are eye-opening evidence on potential effects of Beetroot on exercise endurance. Further scientific evidence is warranted for robust conclusions.

Key words: beetroot, exercise endurance, time trail performance, $\mathrm{VO}_{2}$ 
POSTER SESSIONS 6 - NON COMMUNICABLE DISEASES

18.09.2020

12.00 NOON TO 2.00 PM

\section{PP-23}

Web-based mechanism for door-step delivery of medicines to patients with Non-Communicable Diseases (NCDs) using the state and private pharmacy network during the COVID-19 outbreak in Sri Lanka

Champika Wickramasinghe ${ }^{1}$, Vindya Kumarapeli ${ }^{1{ }^{*}}$, Aravinda Wickramasinghe ${ }^{1}$, Nisal Fernando ${ }^{1}$, Udara Perera ${ }^{1}$, Arundika Senaratne ${ }^{2}$, Yasara Samarakoon ${ }^{2}$, Ishanka Talagala', Shanthi Gunawardena ${ }^{2}$, Samitha Sirithunga ${ }^{2}$, Chithramali Hasanthika Rodrigo ${ }^{2}$, Chithranganie Perera ${ }^{2}$, Dhanushka Abeygunathilaka ${ }^{2}$, Lakshima Nilaweera ${ }^{2}$, Thushari Kanchana Galagedara ${ }^{2}$, Tasneem Naina Marikkar ${ }^{2}$, Prabha Kumari ${ }^{1}$, Sumudu Rajasinghe ${ }^{1}$, Casthuri Kandasamy ${ }^{2}$, Sulfica Mohideen ${ }^{1}$

${ }^{1}$ Non-Communicable Disease Bureau; ${ }^{2}$ Directorate of Non-Communicable Diseases

*vindyalk@yahoo.com

Background: Discontinuation of medicines may lead to serious complications of NCD putting the patients in danger and causing an additional burden for the health system. Ministry of Health (MoH) introduced a mechanism to deliver medicines to the doorstep of people with NCDs who could afford to buy medicines from the state (Osusala) and private pharmacies during the COVID-19 outbreak.

Objectives: To provide an insight into the novel system developed to send a continuous supply of medicine to patients suffering from NCDs by establishing an online mechanism minimizing unnecessary exposure for COVID19

Methods: State (Osusala) and private pharmacies approved by the National Medicine Regulatory Authority (NMRA) were published through an easily searchable web-based application (https://pharmacy.health.gov.lk) on the $\mathrm{MoH}$ website. The public was educated about this initiative through media statements and posters and videos through mass and social media. The public could search their nearest pharmacy through the application "Locate nearest pharmacy delivery service" in the website, which provided a direct link to open-up WhatsApp/Viber to submit a picture of their recent prescription to the selected pharmacy. A tri-lingual helpline was established to provide guidance to the public on locating the nearest pharmacies and respond to public complaints.

Results : Over 1800 pharmacies initiated drug delivery services. This covered all districts and 342 (96.3\%) Medical Officer of Health areas while the highest coverage (18.8\%) was from Gampaha district.According to the Pharmacy Owners Association, 275,000 on-line orders were successfully delivered during the first two weeks. There were 165,787 web-page views during the first three weeks. Of the 68,167 web-page users, $80.0 \%(n=64,805)$ were new users; $94.9 \%(n=47,489)$ were local clients; $78.8 \%(n=53.716)$ accessed through a mobile application; rest through a desktop computer; $72.64 \%$ ( $n=68.167)$ accessed the web-page through the link given in the MoH Website, rest accessed through the links shared in Facebook mobile.

Conclusions and Recommendations: The web-based mechanism was a useful tool to facilitate doorstep delivery during the COVID-19 outbreak. This could be further developed into a mobile application with more functions such as order tracking and cost estimation with payment methods. This system can be used in the long run for the pharmacies who are willing and can cater to people who could afford and prefer this system.

Key words: Doorstep delivery of Medicines, NCDs, COVID-19 


\section{PP-24}

\section{Guava and its glycaemic control properties: a systematic review}

\section{Nimani de Lanerolle ${ }^{1 *}$, Samantha Ananda ${ }^{1}$, PK Buddhika Mahesh ${ }^{2}$, S.M Arnold ${ }^{1}$, Ruwan Ferdinando ${ }^{3}$, Wasantha $^{2}$ Gunathunga $^{4}$}

${ }^{1}$ Ministry of Health and Indigenous Medical Services, Sri Lanka; ${ }^{2}$ University of Melbourne,

${ }^{3}$ National Institute of Health Science; ${ }^{4}$ University of Colombo

*nimani.del.b@gmail.com

Background: Guava (Psidium guajava) plant is found in all regions of Sri Lanka. Though its glycemic-control properties are traditionally appreciated, there is paucity of documented scientific evidence on this. If this fact could be ascertained, fruits or other extracts of this abundant fruit can be utilized to complement blood glucose control

Objective: To systematically review the scientific evidence on the effect of Guava on glycaemic-control.

Methods: Review was registered in PROSPERO (International-Prospective-Register-of-Systematic-Reviews) registry (CRD42020183251). Five databases were searched: Cochrane-library, Agricola, EMBASE, PubMed and CINAHL. Study selection was carried out in three rounds with four screening questions by two investigators and any discrepancies were discussed with a third. Risk-of-bias assessments were done with Grading-ofRecommendations-Assessment-Development-and-Evaluation (GRADE) and Risk-Of-Bias-In-Non-randomizedStudies-of-Interventions (ROBINS-I) criteria. Narrative-synthesis was done following heterogeneity assessments. "Preferred-Reporting-Items-for-Systematic-Reviews-and-Meta-Analysis" (PRISMA) Guidelines were adhered.

Results: Six articles were selected having rejected 246,4 and 11 studies in the $1^{\text {st }}, 2^{\text {nd }}$ and $3^{\text {rd }}$ rounds respectively. The study populations included: healthy individuals ( 3 studies), diabetic patients ( 2 studies) and populations inclusive of diabetic patients (1 study). In five studies guava fruit-based product was used whilst guava bud was considered in one. Except in one study, guava-based-products were seen to bring about lowering of blood glucose levels. One study showed a lower rise of postprandial-blood-glucose level in the intervention group (mean differences: $1.96+/-0.96 \mathrm{mmol} / \mathrm{L}$ versus $2.6+/-1.09 \mathrm{mmol} / \mathrm{L}$ ). In another a lower fasting-blood-sugar level in intervention group was seen (24.8+/-3.6 \% in males and $18.9+/-3.2 \%$ in females). In the third, incremental area under the blood glucose curve was less, following consumption of guava as opposed to a glucose beverage. In another study the mean fasting-blood-glucose levels and prevalence of diabetes of two villages were studied, one in which guava buds were regularly consumed and another in which they were not; the former had lower prevalence of type 2 diabetes mellitus (Kale(M)=3.3\%; Wangiela $(M)=13.3 \%)$. In the sixth study the glycaemic indices and peak incremental indices of 6 fruits were studied and it was seen that there was no significant difference between healthy individuals and patients with diabetes.

Conclusions \& Recommendations: It is seemingly evident that guava has blood glucose lowering properties. To establish this fact further studies must be carried out, following which guava can be recommended for the above effect in appropriate diet plans.

Key words: guava, Psidium guajava, blood glucose, diabetes mellitus 
PP-25

\section{Systematic review of the effects of Phyllanthus emblica in glycaemic control}

UG Karawita ${ }^{1}$, WDS Lakshima ${ }^{1}$, MTQF Shanaz ${ }^{1}$, WDJK Amarasena ${ }^{1}$, PK Buddhika Mahesh ${ }^{2}$, SM Arnold ${ }^{3}$, Ruwan Ferdinando ${ }^{4}$, Wasantha Gunathunga ${ }^{5}$

${ }^{1}$ Post Graduate Institute of Medicine Colombo Sri Lanka; ${ }^{2}$ University of Melbourne, Australia; ${ }^{3}$ Ministry of Health Sri Lanka; ${ }^{4}$ National Institute of Health Sciences, Sri Lanka; ${ }^{5}$ University of Colombo, Sri Lanka

*upeksha.karawita@gmail.com

Background: Diabetes mellitus, characterized by chronic hyper glycaemia, accounts for an annual 1.6 million deaths globally. In Sri Lanka 7.4\% adults are with raised fasting blood glucose. "Nelli" (i.e. Phyllanthus emblica) has traditionally known to be helpful in controlling hyperglycemia.

Objective: To systematically-review the effect of Phyllanthus emblica on glycemic-control

Methods: PubMed, EMBASE, Cochrane Library, CINAHL and AGRICOLA databases were searched to select relevant studies. Human studies which include Phyllanthus emblica as a fruit or an ingredient in the intervention or exposure were selected in the first round. In second and third rounds, articles were screened for relevant clinical outcomes and for quantitative measurements. Two reviewers independently screened articles for eligibility criteria with the third intervening in resolving the conflicts. GRADE (Grading-of-RecommendationsAssessment-Development-and-Evaluation) and ROBINS-I (Risk-Of-Bias-In-Non-randomized-Studies-ofInterventions guidelines were used for risk-of-bias assessments. Meta-analysis was not performed following the heterogeneity assessments and narrative review of the findings was done. Registration (CRD42020180902) of "The-International-Prospective-Register-of-Systematic-Reviews" (PROSPERO) was obtained. Abstract was written following PRISMA (Preferred-Reporting-Items-for-Systematic-Reviews-and-Meta-Analysis) guidelines.

Results: Eighteen studies were selected, having respectively excluded 81, 106 and 22 studies in the three selection rounds. Six were done either among healthy individuals and 12 among patients with diabetes. Fifteen studies were conducted among age groups 18 to 75 years. Sample sizes ranged from 10 to 150 participants, with over 820 participants in total. In three studies Phyllanthus emblica was a single entity and in 15 , it was one component of a combined product. Fifteen selected studies had the mean Fasting-Blood-Sugar levels and 13 of them had highly significant results that Phyllanthus emblica or products containing it has an effect on glycemic control compared to non-intakes ( $p<0.001$ ). Out of those 13 studies with significant glycemic-control, 10 studies were done in hyperglycemic patients. In eight studies a significant reduction in HbA1c results $(p<0.05)$ were observed and 9 studies had significant reduction in Post-Prandial-Blood-Sugar levels $(p<0.05)$. None of the selected studies showed any negative impact on blood glucose level in both healthy and diabetic individuals.

Conclusions and Recommendations: Phyllanthus emblica probably has glycemic control properties warranting more research on the potential applications of this.

Key words: Phyllanthus emblica, Emblica officinalis, Amla, glycemic control

\section{PP-26}

Effects of bitter gourd (Momordica charantia) on blood sugar control: a systematic review

TD Bandara ${ }^{{ }^{*}}$, SA Wasala ${ }^{2}$, WIU Jayawickrama ${ }^{3}$, PK Buddhika Mahesh ${ }^{4}$, SM Arnold ${ }^{5}$, Ruwan Ferdinando ${ }^{6}$, Wasantha Gunathunga ${ }^{7}$ 
${ }^{1}$ National Dengue Control Unit-Ministry of Health, ${ }^{2}$ Office of the Regional Director of Health Services-Kandy, ${ }^{3}$ University of Lincoln-United Kingdom, ${ }^{4}$ University of Melbourne-Australia, ${ }^{5}$ Ministry of Health, ${ }^{6}$ National Institute of Health SciencesKalutara, ${ }^{7}$ Faculty of Medicine-University of Colombo

*thilankaattidiya@gmail.com

Background: Proper glycaemic control has become essential in addressing the rising chronic non-communicable disease burden. Bitter gourd (Momordica charantia) is a vegetable traditionally known to exert control on blood sugar levels.

Objectives: To systematically review the effects of Momordica charantia on blood sugar control among healthy adults and those with specific medical conditions

Methods: "Preferred-Reporting-Items-for-Systematic-Reviews-and-Meta-Analysis" (PRISMA) Guidelines were referred. Review was registered in the "International-Prospective-Register-of-Systematic-Reviews" (PROSPERO) with registration ID: CRD42020182831. The five electronic databases EMBASE, CINAHL, COCHRANE LIBRARY, AGRICOLA, PUBMED were searched. Human studies on use of Momordica charantia with quantifiable glycaemic control related outcomes were selected with four screening questions, by two reviewers independently with a third intervening when necessary. Risk of bias assessments were done with Grading-of-RecommendationsAssessment-Development-and-Evaluation (GRADE) and Risk-Of-Bias-In-Non-randomized-Studies-ofInterventions (ROBINS-I) guidelines. Narrative description of findings was done without meta-analysis due to heterogeneity of selected studies.

Results: Out of the 887 articles reviewed, after deduplication, 656, 138 and 82 were excluded in first, second and third rounds respectively. Eleven articles were selected for systematic-review. The study populations included patients with pre-diabetes and those with Type 2 diabetes, between 18 to 70 years-of-age. The interventions included bitter gourd (BG) extract in juice, tablet or capsule form. The comparators used were as follows: placebos, oral-hypoglycaemic drugs such as Metformin, Glibenclamide and Rosiglitazone and cucumber juice. The main outcomes measured were: change in the fasting-blood-sugar (FBS) levels (in all studies), HbA1c levels (in 9/11 studies) and PPBS/OGTT/2hPPS levels (in 8/11 studies). Out of 11 studies on FBS, six showed reduction in fasting plasma-glucose levels with $\mathrm{p}<0.05$ between the experimental group given $B G$ versus the control group (given placebo or oral hypoglycaemic drugs). Out of nine studies on $\mathrm{HbA1C}$, three studies showed a significant reduction of $\mathrm{HbA} 1 \mathrm{C}$ levels ( $\mathrm{p}<0.05$ ); between $\mathrm{BG}$ group versus control groups (one study), post-BG values compared to pre-BG (two studies). Out of eight studies on PPBS/OGTT/2hPPS, five studies showed significant reduction of OGTT/PPBS/2hPPS ( $p<0.05$ ); between BG group versus control group (two studies), post-BG values compared to pre-BG (three studies).

Conclusions and Recommendations: Bitter gourd (Momordica charantia) appears to have favorable effects on glycaemic control. Further research must be encouraged to gain more robust evidence.

Key words: bitter gourd, bitter melon, Momordica charantia, glycaemic control, blood sugar control

\section{PP-27}

Validity of using anthropometry over bioelectrical impedance analysis to predict overweight in Sri Lankan athletes

Madhawa Perera $^{{ }^{*}}$, Anoja Ariyasinghe ${ }^{1}$, Anula Kariyawasam $^{1}$

${ }^{1}$ Department of Physiology, University of Peradeniya

*madhawadrck@gmail.com

Background: Monitoring body composition and controlling adiposity is essential in improving athletic 
performance. Although bioelectrical-impedance analysis is a valid method of assessing body composition, it is not commonly available in middle-income counties like Sri Lanka. Thus, low-cost alternatives are required.

Objective: To explore the validity of using standard anthropometry (skinfold thickness, hip and waist circumference) to predict overweight in athletes as an alternative to bioelectrical-impedance analysis

Methods: Convenience sampling was used to select 60 male athletes in the age range of 20-35 years. All the athletes were professional sportsmen. Height, weight, hip and waist circumference were measured using standard techniques. Slim-Guide Skinfold Calliper was used to measure abdominal skinfold thickness. Tanita UM051 bioelectrical impedance analyser was used to quantify the body fat percentage. Overweight (adiposity) was defined as $\geq 20 \%$ of body fat. Body fat percentage was predicted using the equation proposed by Oliver et al. (2011). Pearson Correlation was used to test the association between measured and predicted body fat percentage. Ability of the equation to determine adiposity was tested by the receiver operator characteristics (ROC) analysis as expressed by area under the curve (AUC).

Results: Mean height (SD) and weight (SD) of the athletes were $176.8(8.6) \mathrm{cm}$ and $73(1.0) \mathrm{kg}$ respectively. Average measured (SD) and predicted body fat (SD) were 17.8 (6.9) \% and $12.2(5.8) \%$ respectively. There was a strong significant correlation between predicted and measured body fat percentage $(r=0.78 ; p<0.001)$. According to ROC analysis, the diagnostic ability of the prediction equation for overweight (excessive adiposity) was excellent ( $A \cup C=0.896,95 \% \mathrm{Cl}: 0.820-0.972, p<0.001$ ) and the optimal cut-off for classifying overweight is $>12$ $\%$ of body fat ( $90 \%$ of sensitivity and $75 \%$ of specificity).

Conclusions \& Recommendations: The body fat prediction equation proposed by Oliver et al., (2011) using skinfold thickness, hip and waist circumference showed an excellent ability to predict overweight among male athletes in Sri Lanka when bioelectrical-impedance analysis was used as the reference method. The best diagnostic criterion to determine overweight is $>12 \%$ of body fat.

Key words: body fat, overweight, athletes in Sri Lanka 


\section{POSTER SESSIONS 7 - HEALTH SYSTEMS}

18.09.2020

12.00 PM TO 2.00 PM

\section{PP-28}

The quality of causes of deaths data in Sri Lanka: an evaluation of completeness, timeliness and garbage coded deaths.

\section{HMNS Kumari $^{1^{*}}$, SD Dharmaratne ${ }^{2}$}

${ }^{1}$ Department of Mathematics, Faculty of Science, University of Peradeniya, Peradeniya, Sri Lanka; ${ }^{2}$ Department of Community Medicine, Faculty of Medicine, University of Peradeniya, Peradeniya, Sri Lanka and Department of Health Metrics Sciences, School of Medicine, University of Washington, United States of America.

*nadeeshaku@sci.pdn.ac.lk

Background: All countries need accurate and timely mortality statistics to inform health and social policy. The quality of causes of death data is critical as this directly affects the decisions regarding the public health of any country.

Objective: To assess the quality of causes of death data in Sri Lanka

Methods: We analysed the causes of death data available at the Department of Census and Statistics, Sri Lanka by age and sex from 1997 to 2014, but the data in 2008 was unavailable at the time of analysis. We evaluated the quality based on three factors: completeness, timeliness and garbage coded deaths. Completeness is the proportion of registered deaths in Sri Lanka while the timeliness is whether or not all the causes of deaths data from 1997 to 2019 have published before January 31 ${ }^{\text {st }}, 2020$. The deaths classified into "Symptoms, signs and abnormal clinical and laboratory findings, not elsewhere classified R00-R99" according to the International Classification of Diseases $-10^{\text {th }}$ revision was considered as the garbage coded deaths and the average of garbage coded death proportions were calculated. The average of completeness, timeliness, garbage coded death proportions was considered as the quality of causes of death data in this study.

Results: In Sri Lanka, the completeness of causes of death data is 1 as almost every death is registered. When considering the timeliness, still the causes of death data in 2008 and after 2014 are not publicly available. A higher percentage of garbage coded deaths have been recorded each year and it has exceeded $30 \%$ in some years. The garbage coded death percentage in 1997 and 2014 was $31 \%$ and $16 \%$ respectively and the average of the garbage coded death proportions is 0.2 . However, completeness and garbage coded deaths were high while the timeliness of causes of death data was unsatisfactory.

Conclusions \& Recommendations: Finally, it can be concluded that the quality of causes of death in Sri Lanka is low. Moreover, it is necessary to take immediate action by policymakers to enhance the quality of causes of death data.

Key words: Completeness, Garbage coded, Mortality data, Quality, Timeliness 
Availability of facilities at Medical Officer of Health $(\mathrm{MOH})$ offices and the training needs of $\mathrm{MOH}$ team in Sri Lanka

\author{
Indumini Gunatilake ${ }^{1 *}$, Janitha Hettiarachchi ${ }^{2}$, Ranil Ranathunga ${ }^{3}$, Nethmini Thenuwara ${ }^{3}$ Ruwan Silva $^{3}$ \\ ${ }^{1}$ Post Graduate Institute of Medicine, University of Colombo; ${ }^{2}$ Base Hospital, Homagama; ${ }^{3}$ Family Health Bureau, Ministry of \\ Health \\ *indumini12@gmail.com
}

Background: With the technical guidance of the Family Health Bureau, the Family Health Programme is implemented by the $\mathrm{MOH}$ teams island wide. Identification of the background information of $\mathrm{MOH}$ offices such as data on population, staff positions, facilities and of the capacity building programmes received is essential for future programme planning and management of resources.

Objective: To assess the human, physical and other facilities available at MOH offices in Sri Lanka

Method: Cross-sectional descriptive study was conducted in $\mathrm{MOH}$ offices in Sri Lanka using a postal questionnaire. All Medical Officers of Health $(\mathrm{MOOH})$ and Additional Medical Officers of Health $(\mathrm{AMOOH})$ were interviewed. Details of the $\mathrm{MOH}$ area, facilities available at $\mathrm{MOH}$ office and training needs of staff were assessed and data analysis was done using SPSS.

Results: Response rate was comparatively low (50.2\%) as this was a postal questionnaire. In most of the $\mathrm{MOH}$ areas (66.4\%) the population was more than 50,000 and around eleven per cent had population more than 100,000 . AMOOH were available only in $66 \%$ while Supervising Public Health Inspectors were available in $77 \%$ and Public Health Nursing Sisters in $69 \%$ MOHs. Public Health Inspector and Public Health Mid Wife cadres were filled only in $41 \%$ and $35 \%$ of $\mathrm{MOH}$ offices respectively. Most of the medical officers had work experience of more than ten years (68.3\%) while one third (34.9\%) have worked as a $\mathrm{MOH}$ for more than five years. Around two thirds of the $\mathrm{MOOH}$ have received ' $\mathrm{MOH}$ training'. Most of the Maternal and child health trainings conducted were received by less than half the staff. Almost all $\mathrm{MOH}$ offices were having basic facilities such as electricity, water supply, computers and vehicles while one third of the $\mathrm{MOH}$ offices didn't have some essential facilities such as adequate waiting area and proper garbage disposal. Most of the $\mathrm{MOH}$ were satisfied with available facilities (80.1\%) while half of them were satisfied with working as a $\mathrm{MOH}(54.1 \%)$.

Conclusion and Recommendations: Although almost all $\mathrm{MOH}$ offices are having basic facilities, lack of staff in all categories and inadequate training remain as common problems. Vacancies need to be filled the earliest and training needs should be addressed by relevant authorities.

Key words: Medical Officer of Health, Facilities, training needs

PP-30

Cervical cancer screening: Comparison of screening results between cervical and vaginal methods of HPV/DNA specimen collection among 35 year old ever married women in Kalutara District

KCM Perera ${ }^{1 *}$, Chrishantha Abeysena ${ }^{2}$, $\mathrm{N} \mathrm{Mapitigama}^{3}$

${ }^{1}$ Non-Communicable Diseases, Unit Ministry of Health \& Indigenous Medical Services; ${ }^{2}$ Department of Community Medicine, Faculty of Medicine, University of Kelaniya;

${ }^{3}$ Family Health Bureau

*chithranganieperera@yahoo.com

114

The College of Community Physicians of Sri Lanka - $25^{\text {th }}$ Annual Academic Sessions 
Background: Even after 20 years of cervical cancer screening with pap smears, there is no marked reduction in incidence, morbidity and mortality of cervical cancer in Sri Lanka. Two major drawbacks of the present programme are the suboptimal sensitivity (53\%) of the pap smear to detect Cervical Intraepithelial Neoplasia (CIN) and the low coverage. All cervical cancers are virtually associated with human papillomavirus infection. HPV/DNA test has a very high sensitivity (>90\%) to detect CIN II. HPV/DNA specimens can be collected from vagina or cervix.

Objective: To compare screening results between cervical versus vaginal methods of HPV/DNA specimen collection among 35 year old ever married women in Kalutara District

Methods: It was a descriptive cross-sectional study. Two subjects from each of 413 Public Health Midwife areas in Kalutara district were selected for the study by random sampling technique from the list of 35 year old ever married women population prepared from the relevant area eligible family register/s according to the ascending order of register number/s. After applying exclusion criteria at field and clinic setting, a number of 621 women were first subjected to vaginal HPV/DNA specimen collection by Public Health Midwives (PHMM) followed by cervical HPV/DNA specimen collection under the Cusco's speculum by Medical Officers of Health (MOOH) or Public Health Nursing Sisters (PHNSS) at same clinic session of community Well Woman Clinics. Sensitivity and specificity of cobas $4800 \mathrm{HPV} / \mathrm{DNA}$ cervical specimen to detect $\geq \mathrm{CIN}$ II were $92.9 \%$ and $72.1 \%$ respectively. Sensitivity, specificity, false positive and false negative rates of PHMM collected vaginal HPV/DNA specimen versus MOOH/PHNSS collected cervical HPV/DNA specimen for cobas 4800 test (gold standard) were calculated.

Results: Sensitivity, specificity, positive predictive value (PPV) and negative predictive value (NPV) of the vaginal versus cervical HPV/DNA specimen screening method were 100\%, 98.9\%, 86.4\% and 100\% respectively. Kappa coefficient between vaginal versus cervical HPV/DNA specimen screening method was 0.92 .

Conclusions and Recommendations: There was a good concordance between cervical versus vaginal HPV/DNA specimen screening methods for cobas 4800 Polymerase Chain Reaction (PCR) based HPV/DNA screening test. Vaginal specimen collection method can be considered to improve quality \& coverage of cervical cancer screening programme, as it can be collected by PHMM, while during their home visits or clinic setting.

Key words: Cervical cancer screening, HPV/DNA test, HPV/DNA cervical specimen, HPV/DNA vaginal specimen

\section{PP-31}

Streamlining undergraduate research to generate evidence for health planning: a collaboration between health and higher education sectors

Amila Chandrasiri $i^{1}$, Sujeewa Amarasena ${ }^{2}$, Chandima Sirithunga ${ }^{3}$, Imendra Kotapola ${ }^{2}$, Pubudu Chulasiri ${ }^{3^{*}}$, Eranthi Weerathunga ${ }^{2}$

${ }^{1}$ Post Graduate Institute of Medicine, University of Colombo; ${ }^{2}$ Faculty of Allied Health Sciences, University of Ruhuna; ${ }^{3}$ Regional Director of Health Services Office, Galle

*amilachan@yahoo.com

Background: As the health care planning process at the district level is predominantly based on requests forwarded by health institutes, the use of research evidence looks inadequate. On the other hand, a large number of undergraduates in-state universities conduct research projects each year and there is a potential of directing these projects to generate vital evidence for health care planning at the district level.

Objective: To plan and conduct a collaborative program between Regional Director of Health Office (RDHS), Galle and Faculty of Allied Health Sciences (FAHS), the University of Ruhuna to involve a group of BSc Nursing students to do their undergraduates researches to provide evidence for district-level planning 
Methods: Firstly, advocacy was done to obtain the support from the Dean of FAHS. A batch of BSc nursing undergraduates was allocated for the project. An orientation program was done for the batch and key thematic areas were introduced. Students were requested to select topics under those areas. Primary care, maternal and child health, human resource management, customer satisfaction, alcohol and drug use, suicide prevention were given as the thematic areas considering the priority health issues in the district. Fourteen students enrolled for the program. A Consultant Community Physician was appointed from RDHS to co-supervise each research project and guidance was given to develop research proposals. RDHS office provided every possible facilitation for carrying out those researches including transport and access to institutes. Funds were also given through Provincial Ministry of Health.

Results: All 14 research projects were completed successfully and findings were handed over to the Planning Unit of RDHS. This evidence was used for the annual planning process in the following year and in the on-going primary care development project.

Conclusions and Recommendations: At the end of the program, a symposium was held to allow students to present their findings for a larger gathering. Top-level policymakers in the province including Governor, Chief Secretary, Provincial Director of Health and top officials from other sectors participated and it was strategically used as an advocating opportunity. This initiative provided a role model to other RDHS and PDHS offices to develop similar collaborations.

Key words: research, evidence, health planning 


\section{POSTER SESSIONS 8 - NUTRITION}

18.09.2020

12.00 NOONTO 2.00 PM

PP-32

\section{Effects of pineapple on wound healing: systematic review}

PHMGM Priyadarshani $i^{1 *}$, OPD Niroshana ${ }^{1}$, DJ Galappaththi ${ }^{1}$, KL Premachandra ${ }^{1}$, Dimuth Peiris ${ }^{2}$, PK Buddhika Mahesh $^{3}$, SM Arnold ${ }^{4}$, Ruwan Ferdinando ${ }^{5}$, Wasantha Gunathunga ${ }^{6}$

${ }^{1}$ Post Graduate Institute of Medicine, University of Colombo, Sri Lanka; ${ }^{2}$ Keele University, United Kingdom; ${ }^{3}$ University of Melbourne ; ${ }^{4}$ Ministry of Health and Indigenous Medical Services., Sri Lanka; ${ }^{5}$ National Institute of Health Sciences, Sri Lanka; ${ }^{6}$ University of Colombo, Sri Lanka

*mayuripalihakkara@gmail.com

Background: Optimum wound healing is essential in preventing wound related complications. Pineapple fruit (Ananas comosus) and its constituents like bromelain had shown therapeutic benefits including antiinflammatory, antibacterial, antifungal, analgesic, free-radical-scavenging and proteolytic activity which potentially facilitate wound healing processes.

Objective: To systematically-review scientific evidence on effectiveness of using pineapple or its constituents for optimum wound-healing

Methods: Review was registered in the PROSPERO (International-Prospective-Register-of-Systematic-Reviews) with registration ID: CRD42020180993. Relevant studies in five scientific databases: PubMed, EMBASE, Cochrane Library, CINAHL and Agricola were searched. Study selection was done with three screening questions: being a human study on pineapple, having wound-healing related outcomes and availability of quantitative measurements. Risk-of-bias assessments were done with Grading-of-Recommendations-AssessmentDevelopment-and-Evaluation (GRADE) criteria. Due to the observed heterogeneity narrative synthesis was done. "Preferred-Reporting-Items-for-Systematic-Reviews-and-Meta-Analysis" (PRISMA) guidelines were adhered in reporting.

Results: Out of 162 articles, 66,73 and 9 articles were excluded by first, second and third screening questions and fourteen were selected. Adult patients of 18-65 years with episiotomy, burns and surgical wounds were among the study populations. Pineapple was administered as diet rich in pineapple, oral-tablets and local-applications in 1, 6 and 7 studies respectively. The health outcomes of pineapple explored were as follows: pain-reduction (3 studies), accelerated healing of episiotomy wounds (2), reduction of oedema (1), skin-irritation-reduction (2), wound-size-reduction (1) and quality of wound-debridement (5). Among three studies, two have shown significant reduction of pain compared to control group $(p<0.05)$. Accelerating wound healing following episiotomy was found to be significant $(p<0.05)$ according to REEDA (Redness-Edema-Ecchymosed-DischargeApproximation) scale in both studies. A double-blind RCT has shown 7.5\% reduction of linear measurement of swelling in the treatment group than in the control group. Among two clinical trials on the improvement of skinirritation, one revealed a significant decrease of Trans-Epidermal- Water-Loss (TEWL) and other showed better perception of product efficacy. All 5 studies regarding wound debridement showed favourable outcomes. There was one clinical trial showing significant mean reduction of the size of the wound.

Conclusions \& Recommendations: Usage of pineapple and its constituents as orally or as local applications have shown favourable outcomes on optimizing wound healing. Further research must be encouraged to determine 
the potential ways of utilizing these effects.

Key words: wound healing, pineapple, ananas comosus, bromelain

\section{PP-33}

\section{Effect of carrot on serum carotenoid level: A systematic review}

\section{Amila Herath ${ }^{1}$, Nilupul Janapriya ${ }^{2 *}$, Praveen Nagendran ${ }^{3}$, Vidura Jayasinghe ${ }^{4}$, PK Buddhika Mahesh ${ }^{5}$, SM Arnold ${ }^{6}$, Ruwan Ferdinando ${ }^{7}$, Wasantha Gunathunga ${ }^{8}$.}

${ }^{1,2,3}$ Postgraduate Institute of Medicine, University of Colombo; ${ }^{4,6}$ Ministry of Health, Sri Lanka; ${ }^{5}$ University of Melbourne; ${ }^{7}$ National Institute of Health Sciences, Sri Lanka; ${ }^{8}$ University of Colombo, Sri Lanka.

*janaps2@hotmail.com

Background: Vitamin A deficiency, associated with negative health consequences is a common nutritional problem worldwide. Natural food items like carrots (Daucus carota) are enriched with carotenoids which can potentially be converted to vitamin A following consumption.

Objectives: To systematically review the effects of carrot on serum carotenoid levels.

Method: EMBASE, CINAHL, Cochrane Library, AGRICOLA, and PubMed databases were searched. Studies were screened with three rounds by two independent individuals with four screening questions. Discrepancies were intervened by a third reviewer. Risk-of-bias assessments were done with Grading-of-RecommendationsAssessment-Development-and-Evaluation (GRADE) and Risk-Of-Bias-In-Non-Randomized-Studies-ofInterventions (ROBINS-I) criteria. Clinical, methodological, and statistical heterogeneity were assessed, and narrative synthesis of results was done without meta-analysis due to observed heterogeneity. Review was registered in the PROSPERO (International-Prospective-Register-of-Systematic-Reviews) with registration ID: CRD42020181353. Reporting was done with Preferred-Reporting-Items-for-Systematic-Reviews-and-MetaAnalysis (PRISMA) guidelines.

Results: Out of the 1834 studies, 1287, 292 and 221 were excluded in first, second and third rounds with deduplication. Thirty-four articles including 10 randomized control trials were analyzed. All studies consisted of healthy adults between 18 and 74 years. Serum-alpha (in 6 studies), beta-carotene (in 21 studies), and lutein level (in 1 study) were the main outcomes. Serum-alpha and beta-carotene levels were higher $(p<0.05)$ among people who consumed a diet with carrot than without, in two studies. One study showed $687 \%$ and $227 \%$ increase of alpha and beta-carotene levels respectively following carrot consumption. Different types of carrots were compared, and two articles showed organic-carrot providing more alpha and beta-carotene than the conventional-carrot $(p<0.05)$. One study showed that yellow-carrot increases serum lutein than white-carrot [Mean differences (SD) being $0.19(0.08)$ and $-0.04(0.004)$ respectively]. Three studies showed that processed carrots provide more alpha and beta-carotene than raw carrot $(p<0.05)$. In six studies, serum-carotenoid levels were compared with carrot consumption with other vegetables like spinach and tomatoes. Another four studies showed that carotenoid absorption increases when carrot is consumed along with avocado, fermented-milk, mayonnaise, or oily-foods respectively $(p<0.05)$.

Conclusion and recommendation: Consumption of carrot seemingly increases serum carotenoid levels and processed carrot seems to provide more carotene than raw carrot. Further research should be carried out.

Key words: Vitamin A deficiency, Serum Alpha Carotene, Serum Beta Carotene, Serum Lutein, Serum Carotenoid, Carrot. 


\section{PP-34}

Knowledge of iron deficiency, dietary iron intake and associated factors among advanced level students in an urban community in Western Province

\section{Dinandi Nadeesha ${ }^{1^{*}}, \mathrm{CJ}$ Wijesinghe ${ }^{2}$}

Department of Nursing, Faculty of Allied Health Sciences, University of Ruhuna; ${ }^{2}$ Department of Community Medicine, Faculty of Medicine, University of Ruhuna

dinandi92@gmail.com

Background: Iron deficiency is a common health problem among school children. Lack of knowledge concerning nutrition is one of the most significant reasons for nutritional problems such as iron deficiency.

Objective: To assess the knowledge of iron deficiency, dietary iron intake and associated factors among advanced level students in schools of Sri Jayawardhanapura educational zone

Method: The study sample consisted of 400 advanced level students in Sri Jayawardhanapura educational zone. A multistage random sampling technique was used to recruit students for the study. Data was collected using a selfadministered questionnaire, which included a short Food Frequency Questionnaire to assess dietary intake of iron rich food. Level of knowledge and dietary intake was categorized according to a scoring system. Data analysis was done using MS Excel and Statistical Package for Social Sciences (SPSS), version 20. Ethical clearance was obtained from the Ethical Review Committee of the Faculty of Allied Health Sciences, University of Ruhuna.

Results: Majority were in the age group of 17-18 years, in Rs. 40,000-60,000 income category and had only one sibling. $86.3 \%(n=345)$ were living in nuclear families. Only $(85 \%, n=340)$ of the students were aware about iron deficiency and only $(6 \%, n=4)$ knew about all iron rich foods mentioned in the questionnaire. A very small proportion $(1.5 \%, n=6)$ knew about food that reduce iron absorption and only few students knew the foods that could increase iron absorption. Weakness $(65.8 \%, n=263)$ and fatigue $(59.5 \%, n=238)$ were the commonly identified symptoms of iron deficiency anaemia. $19 \%$ ( $n=76)$ of students had a good overall knowledge regarding iron deficiency which was associated with consumption of spinach, vegetables, egg and fish $(p<0.05)$. Only $(4 \%$, $\mathrm{n}=16$ ) of the participants thought that they are likely to be iron deficient. Eighty-three students (20.8\%) perceived that preparing meals with iron rich food or consuming iron rich food is difficult. Over half of the sample $(54.5 \%$, $\mathrm{n}=218$ ) believed that they consume adequate amounts of iron rich food.

Conclusion and recommendations: Although awareness of iron deficiency among adolescent school children in Sri Jayawardhanapura educational zone was high (85\%), the knowledge about specific aspects appears to be inadequate. In view of the magnitude of the problem of iron deficiency and the number of risk factors involved, systematic measures need to be taken to prevent and treat iron deficiency anemia among students.

Key words: Iron deficiency anaemia, dietary iron intake, Nutritional knowledge, Advanced level students

PP-35

\section{Effect of Moringa oleifera on haematological parameters: A systematic review}

Chiara Perera ${ }^{1}$, Dakshila Galappatti ${ }^{1}$, A Thrimavithana ${ }^{1}$, Buddhika Mahesh ${ }^{2}$, Iresha Jayawickrama ${ }^{3}$, SM Arnold ${ }^{4}$, Ruwan Ferdinando ${ }^{5}$, Wasantha Gunathunga ${ }^{6}$

${ }^{1}$ Post Graduate Institute of Medicine, University of Colombo, Sri Lanka; ${ }^{2}$ University of Melbourne; ${ }^{3}$ University of Lincoln, United Kingdom; ${ }^{4}$ Ministry of Health, Sri Lanka; ${ }^{5}$ National Institute of Health Sciences, Sri Lanka; ${ }^{6}$ University of Colombo

*chiara.himshi@gmail.com 
Background: Moringa (Moringa oleifera) is a plant found in many regions. Its extracts, especially of leaves, are a rich source of fibre, proteins and micronutrients including iron. Some research has assessed its benefit in improving haematological parameters and conditions including iron-deficiency-anaemia which affect approximately one-third of the global population. However, up to now the evidence in past research is not conclusive.

Objective: To systematically-review the effect of moringa on haematological-parameters

Methods: Preferred-Reporting-Items-for-Systematic-Reviews (PRISMA) guidelines were followed. PubMed, Cochrane-library, Agricola, CINAHL and EMBASE databases were searched. The selection of articles was done in three rounds by two independent reviewers intervened by a third in resolving conflicts. Human studies on Moringa with relevant outcomes and quantitative measurements were included. Risk-of-bias assessments were done with Grading-of-Recommendations-Assessment-Development-and-Evaluation (GRADE) and Risk-Of-BiasIn-Non-randomized-Studies-of-Interventions (ROBINS-I) guidelines. Clinical, methodological and statistical heterogeneity were assessed and results were narratively-synthesized without meta-analysis. Registration from International-Prospective-Register-of-Systematic-Reviews (ID: CRD42020181432) was obtained.

Results: Following de-duplication there were 213 articles. Respectively 139, 55, 13 articles were excluded at first, second and third rounds. Six studies on Moringa-leaf extracts, covering nine outcomes were included. Four studies included children below 2 years as the study population and two included reproductive and postmenopausal women. Among children under 2 years, mean improvement in heamoglobin-level ranged between 0.31-2.6 and there was a reduction of the prevalence of anaemia by $53 \%(95 \% \mathrm{Cl}: 35.1,72.0 ; \mathrm{p}<0.001)$ in the interventional group. Haemoglobin level among anaemic women in reproductive-ages showed an improvement with a mean difference (MD) of $-0.794(S D 0.81)(p<0.05)$ in the interventional group, whereas in the control group the MD was -0.644 (SD 0.83). Post-menopausal-women who were supplemented showed a significant improvement of $17.5 \%$ in haemoglobin compared to the baseline values $(p \leq 0.01)$. Two studies showed improvements in ferritin levels with a MD of 29.378 (SD 42.48) (p-0.012) among anaemic women and 31.9 (SD 23.8) MD among children under 2 years. One study showed an improvement [MD (SD)] in erythrocyte count 0.482 (2.26), hematocrit 0.947 (4.56), MCV 0.635 (11.22), MCH 1.312 (4.94), MCHC 2.459 (2.86), and RDW 1.400 (2.07) compared to the control group.

Conclusions and Recommendations: Moringa-leaf extracts as a natural supplement, is seemingly a useful remedy for improving haematological parameters, especially in improving the haemoglobin level among children and female adults.

Key words: Moringa, Moringa oleifera, anaemia, haemoglobin, hematological parameters 
